OPEN ACCESS

Edited by:

Jacqueline Jonklaas, Georgetown University,

United States

Reviewed by:

Salvatore Benvenga,

University of Messina, Italy

Tania M. Ortiga-Carvalho,

Federal University of

Rio de Janeiro, Brazil

*Correspondence: Apostolos Chatzitomaris apostolos.chatzitomaris@

ruhr-uni-bochum.de

Specialty section: This article was submitted to

Thyroid Endocrinology,

a section of the journal

Frontiers in Endocrinology

Received: 13 April 2017 Accepted: 27 June 2017

Published: 20 July 2017

Citation:

Chatzitomaris A, Hoermann R, Midgley JE, Hering S, Urban A, Dietrich B, Abood A, Klein HH and

Dietrich JW (2017) Thyroid Allostasis-Adaptive Responses of Thyrotropic Feedback Control to Conditions of Strain, Stress, and

Developmental Programming. Front. Endocrinol. 8:163. doi: 10.3389/fendo.2017.00163

\section{Thyroid Allostasis-Adaptive} Responses of Thyrotropic Feedback Control to Conditions of Strain, Stress, and Developmental Programming

\author{
Apostolos Chatzitomaris ${ }^{1 *}$, Rudolf Hoermann ${ }^{2}$, John E. Midgley ${ }^{3}$, Steffen Hering ${ }^{4}$, \\ Aline Urban ${ }^{5}$, Barbara Dietrich ${ }^{6}$, Assjana Abood ${ }^{1}$, Harald H. Klein ${ }^{1,7}$ and \\ Johannes W. Dietrich ${ }^{1,7}$
}

'Medical Department I, Endocrinology and Diabetology, Bergmannsheil University Hospitals, Ruhr University of Bochum, Bochum, Germany, ${ }^{2}$ Private Consultancy, Research and Development, Yandina, QLD, Australia, ${ }^{3}$ North Lakes Clinical, Ilkley, United Kingdom, ${ }^{4}$ Department for Internal Medicine, Cardiology, Endocrinology, Diabetes and Medical Intensive Care Medicine, Krankenhaus Bietigheim-Vaihingen, Bietigheim-Bissingen, Germany, ${ }^{5}$ Department for Anesthesiology, Intensive Care and Palliative Medicine, Eastern Allgäu-Kaufbeuren Hospitals, Kaufbeuren, Germany, ${ }^{6}$ kbo-Isar-Amper-Klinikum, Klinikum München-Ost, Haar, Germany, ${ }^{7}$ Ruhr Center for Rare Diseases (CeSER), Ruhr University of Bochum and Witten/ Herdecke University, Bochum, Germany

The hypothalamus-pituitary-thyroid feedback control is a dynamic, adaptive system. In situations of illness and deprivation of energy representing type 1 allostasis, the stress response operates to alter both its set point and peripheral transfer parameters. In contrast, type 2 allostatic load, typically effective in psychosocial stress, pregnancy, metabolic syndrome, and adaptation to cold, produces a nearly opposite phenotype of predictive plasticity. The non-thyroidal illness syndrome (NTIS) or thyroid allostasis in critical illness, tumors, uremia, and starvation (TACITUS), commonly observed in hospitalized patients, displays a historically well-studied pattern of allostatic thyroid response. This is characterized by decreased total and free thyroid hormone concentrations and varying levels of thyroid-stimulating hormone (TSH) ranging from decreased (in severe cases) to normal or even elevated (mainly in the recovery phase) TSH concentrations. An acute versus chronic stage (wasting syndrome) of TACITUS can be discerned. The two types differ in molecular mechanisms and prognosis. The acute adaptation of thyroid hormone metabolism to critical illness may prove beneficial to the organism, whereas the far more complex molecular alterations associated with chronic illness frequently lead to allostatic overload. The latter is associated with poor outcome, independently of the underlying disease. Adaptive responses of thyroid homeostasis extend to alterations in thyroid hormone concentrations during fetal life, periods of weight gain or loss, thermoregulation, physical exercise, and psychiatric diseases. The various forms of thyroid allostasis pose serious problems in differential diagnosis of thyroid disease. This review article provides an overview of physiological mechanisms as well as major diagnostic and therapeutic implications of thyroid allostasis under a variety of developmental and straining conditions.

Keywords: thyroid allostasis, non-thyroidal illness syndrome, thyroid hormone metabolism, hypothalamuspituitary-thyroid feedback control, TACITUS syndrome 


\section{INTRODUCTION}

Contemporary diagnosis of thyroid disorders relies predominantly on point measurements of thyrotropin [thyroid-stimulating hormone (TSH)] concentration (1). While some guidelines recommend combining TSH measurements with free thyroxine (FT4) determination $(2,3)$, others constrain diagnostic workup on TSH measurements as a first-line diagnostic test and only recommend determining peripheral thyroid hormones, if TSH concentrations fall outside of their respective reference ranges (4-6). This strategy rests upon the assumptions of a log-linear relationship between TSH and FT4 (7-10), a long plasma half-life of thyroid hormones $(11,12)$ and tight coupling of all involved control elements of the feedback loop $(13,14)$. While TSH-based diagnostic interpretation may be inexpensive (at least at the beginning of the decision-making process) it is over-simplifying and involves considerable risks of both false positive and false negative results. Restrictions of TSH-based protocols include circadian and ultradian variation of TSH and thyroid hormones (15-18), the plasticity of central components of the feedback loop under substitution therapy with levothyroxine (19-22) and, as we will subsequently outline, reactive adjustments of thyroid homeostasis in certain phases of development and conditions of strain and stress (23-29).

The hypothalamic-pituitary-thyroid (HPT) axis acts as an adaptive, dynamic system, functioning in two distinct operating modes. The system operates as a homeostatic regulator in unstrained resting conditions, aiming at constant value control (30-33) and maintaining serum concentrations of thyroid hormones in the vicinity of a fixed set point $(17,18,34-38)$. The stable situation in equilibrium permits the use of TSH measurement for diagnostic purposes in thyroid disease. However, concentrations of TSH and thyroid hormones may be altered in other physiological and pathological situations in the absence of any dysfunction of the thyrotropic control system or any of its elements (23-25,
39-42). The feedback control mechanism is able to modify its transfer parameters, if a need arises, to tune consumption to available supply with oxygen, energy, and glutathione. The operating mode then shifts to a system of tracking control, which features a dynamically changing set point (26, 43-45). Clinical patterns emerging from this kind of adaptation are well known to physicians. They typically include, but are not limited to, altered, either low or high, T3 concentrations, changes in binding of thyroid hormones to plasma proteins and adjustment of the central control input. In humans, allostatic operation of the HPT axis was initially described in exhausting exercise, starvation, and systemic illness (46-52). Similar patterns were later observed under such diverse conditions as fetal life, major depression (MD), and space flight. However, adding further to the complexity of the constellation, opposite changes have been described in other situations such as pregnancy, endurance exercise, and certain psychiatric diseases (Figure 1) (27-29).

The characteristic adaptive constellation of thyroid homeostasis to severe illness is referred to as low-T3 syndrome, nonthyroidal illness syndrome (NTIS), euthyroid sick syndrome (ESS) or thyroid allostasis in critical illness, tumors, uremia, and starvation (TACITUS). About $30 \%$ of hospitalized patients (54) and more than $60 \%$ of patients affected by critical illness $(55,56)$ experience transient changes in serum concentrations of TSH and thyroid hormones. Characteristic patterns are low levels of free and total 3,3',5-triiodothyronine (T3) $(39,40,56)$, impaired plasma protein binding of thyroid hormones $(57,58)$ and, in more severe cases, thyrotropic adaptation with a downward shift of the set point characterized by paradoxically low TSH levels in the presence of normal or even low concentrations of FT4 $(59,60)$. Conversely, serum concentrations of 3,5,5'-triiodothyronine (rT3) and 3,5-diiodothyronine (3,5-T2) are typically increased (39, 40, 61-63).

In severe illness, the presence of NTIS predicts poor prognosis $(54,60,64-66)$. It is still a matter of fierce debate if patients

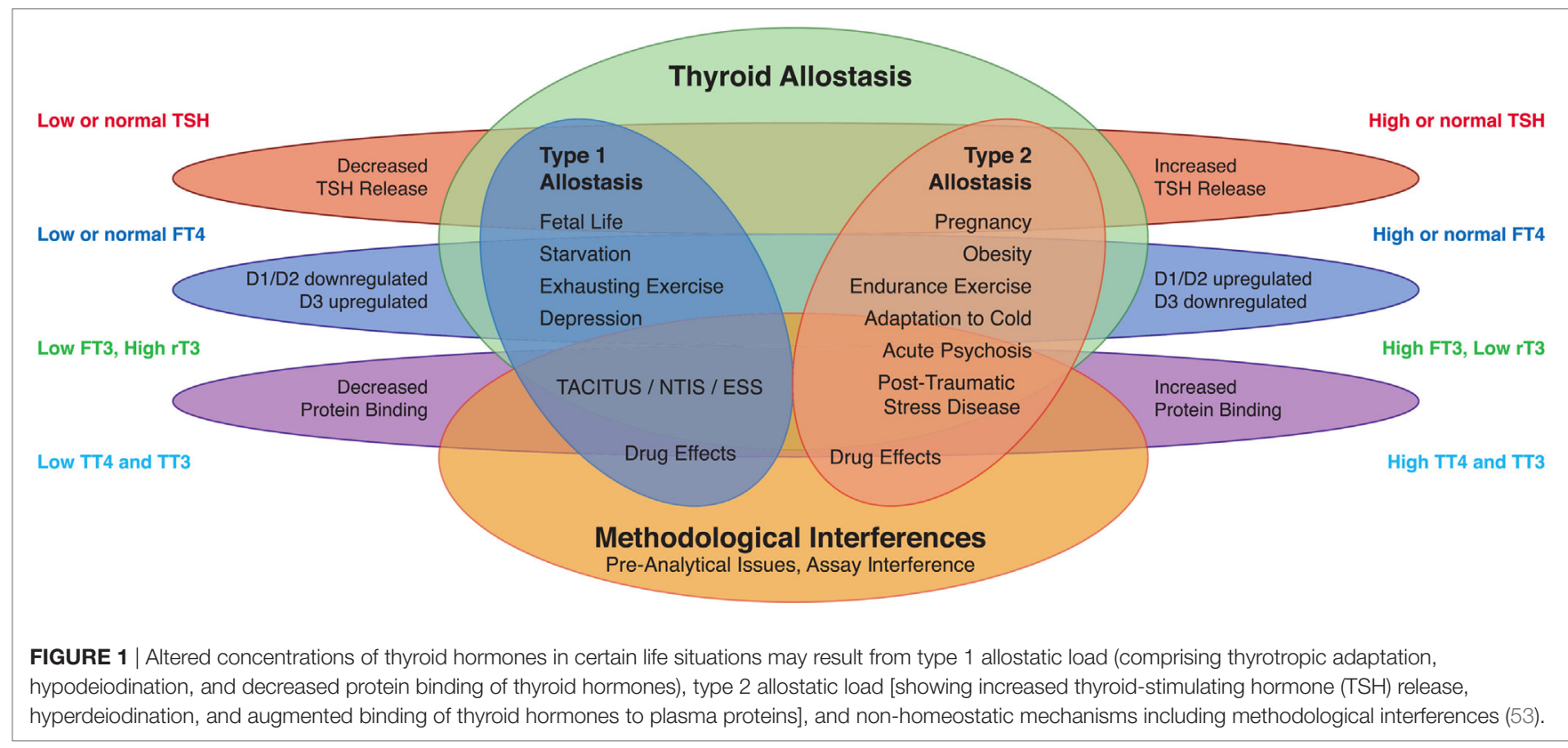


affected by the syndrome may benefit from substituting thyroid hormones (67-70). Importantly, significant problems in differential diagnosis may arise from both considerable overlap of hormone concentrations in NTIS with those in primary or secondary thyroid disorders and by methodological interference with thyroid hormone assays (71-73).

This review article provides an overview of adaptive responses of thyroid homeostasis in type 1 and type 2 allostatic situations. It is based on a broad literature search executed with the search formulas "non-thyroidal illness OR non-thyroidal illness OR NTI OR NTIS OR TACITUS OR euthyroid sick OR low T3 OR low triiodothyronine OR Euthyroid Sick Syndromes [MeSH]," "(thyroid OR thyroxine OR triiodothyronine) AND (allostasis OR allostatic)" and "amygdala AND TRH" in PubMed, the authors' own collections of literature and secondary publications referenced there. Where not otherwise specified information provided refers to the human organism. Data from animal research are reported, where information on the human metabolism is lacking.

\section{HISTORICAL OVERVIEW}

Perhaps the first description of NTIS dates back to the tenth century BC, when King David was on his deathbed: "Now King David was old, and advanced in years: and when he was covered with clothes he was not warm." [1 Kings 1:1]. Of note, David was not mentally impaired, since in the same time he had managed to defend Solomon, his designated successor, against a subtle conspiracy. Therefore, the situation described by the unknown author seems to represent an exclusively peripheral reduction of thyroid hormones, perhaps in the context of senescence and/or multi-morbidity.

In the human organism, transient alterations of thyroid hormone metabolism unrelated to pituitary or thyroid disease were first explicitly described in 1968, when Clifford Irvine reported reduced half-life of T4 in athletic training, which was reversible after three days' rest (74). The same author had made similar observations in horses, where thyroxine secretion rate increased in training and adaptation to cold, and half-life decreased in trained animals (75). Shortly later, Harland and Orr described a significantly decreased half-life of T4, when rats were exposed to a cold environment (76). Transiently changed concentrations of thyroid hormones were first described in 1971 by Terjung and Tipton, who reported increased concentrations of free and total T4 during bicycle ergometer training and reduced total T4 levels $24 \mathrm{~h}$ later (46).

In 1973, Rothenbuchner et al. reported decreased serum concentrations of T3 in the starving organism (47). Nearly simultaneously another group confirmed this observation in a different population (49). Shortly thereafter T3 concentrations were observed to be reduced in patients with critical illness requiring intensive care, in tumors and in uremia $(48,51,52,77)$.

The last four decades witnessed the discovery of many more pathologies that are associated with the low-T3 syndrome or other patterns of NTIS, including sepsis, circulatory arrest, stroke, myocardial infarction, pulmonary embolism, inflammatory bowel disease, renal failure, and gastrointestinal fistulae $(24,25,39,56,66)$.
A pattern typical of "NTIS" was also observed specifically in non-pathological conditions, such as the fetal period, torpor in poikilotherm animals, and hibernation in certain mammalian species $(78,79)$. These observations suggested that ESS is not a dysfunction of the feedback loop, rather an allostatic reaction and potentially useful adaptation of the pituitary-thyroid feedback control system to reduced supplies in energy, oxygen, and glutathione. We therefore recently coined a new term of TACITUS to provide a more neutral designation that encompasses several non-pathological conditions with adaptations of TSH and thyroid hormones $(18,35)$.

\section{MECHANISMS OF THYROID ALLOSTASIS}

In situations of current or anticipated strain central and peripheral mechanisms interact to ensure a coordinated adaptation of thyroid hormone signaling (43). This is associated with a variety of alterations at the molecular level in nearly all tissues.

\section{Cybernetic Principles of Integrative Thyroid Control}

Homeostatic control of thyroid function represents a classical example of a hypothalamic-pituitary-mediated endocrine feedback mechanism (Figure 2) (18, 35). Its principal mediators are hypothalamic thyrotropin-releasing hormone (TRH), pituitary thyrotropin (TSH), thyroxine (T4), and triiodothyronine (T3).

Thyroid-stimulating hormone is a glycoprotein hormone with a rather short half-life of 50-60 min, which stimulates synthesis and release of T4 and to a lesser degree T3 from the thyroid gland via binding to a specific TSH receptor (35). With respect to classical thyroid hormone actions (effects mediated via nuclear thyroid hormone receptors) $\mathrm{T} 4$ is a prohormone requiring activation to the highly agonistic hormones T3 and 3,5-T2 to be effective. However, other non-classical actions of T4, acting, e.g., via integrin receptors, do not require prior activation, rendering T4 an active hormone with respect to non-classical effects (80).

Plasma T3 is derived from several sources, including direct formation in the thyroid gland and release by proteolysis of thyroglobulin $(\mathrm{Tg})$, deiodination from $\mathrm{T} 4$ in the thyroid and deiodination in peripheral organs (12). T4 and T3 display prolonged plasma half-lives of 1 week and 1 day, respectively, resulting from intracellular accumulation and a high proportion of plasma protein binding $(17,35,81)$. T3 affects most tissues in a pleiotropic manner. It also closes the feedback loop by inhibiting both synthesis and release of TSH from the pituitary gland $(17,18,35)$.

This "short" feedback loop is augmented by additional control motifs, including an ultrashort feedback loop of TSH release $(17,82)$, a long feedback loop, where thyroid hormones inhibit TRH release in the hypothalamus $(83,84)$, and a direct stimulatory effect of TSH on T3 formation. A TSH-T3 shunt has been predicted in animal and cell culture experiments (85-90), and we recently demonstrated its existence in the human organism $(19,22,91-94)$. 


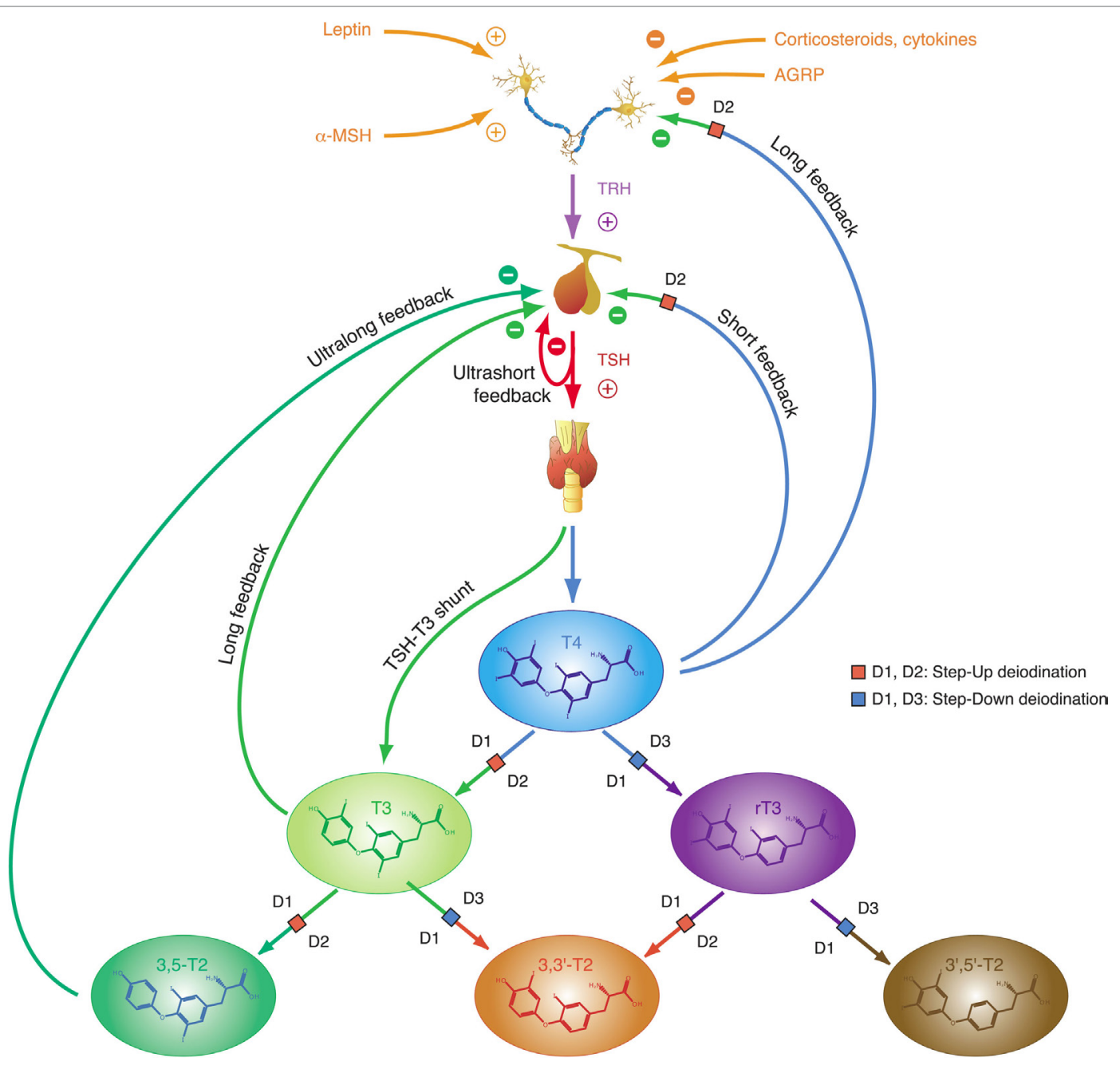

FIGURE 2 | Thyroid homeostasis comprises ultrashort, short, and long feedback mechanisms. In addition, conversion between iodothyronines is adaptively mediated by three distinct deiodinases $(18,35)$. Deiodination is controlled by multiple local and global mediators including thyroid-stimulating hormone (TSH).

The integrative control at the hypothalamic level is mediated by parvocellular hypophysiotropic paraventricular nucleus (PVN) TRH neurons. Their activity provides an interface between thyroid hormone feedback, nutritional status, and stimulatory or inhibitory influences of the circadian rhythms (Figure 3) (95). In this respect, tanycytes lining the third ventricle play a pivotal role in central homeostasis. They are able to fine-tune the sensitivity of PVN via provision of central T3 and to degrade TRH via pyroglutamyl peptidase II (PPII) at the level of the median eminence (Figure 3) $(95,96)$.

\section{Allostasis and Allostatic Load}

In 1988, Sterling and Eyer extended the classical paradigm of homeostasis with the theory of allostasis (100). Briefly, an allostatic response is defined as a dynamic stress reaction that maintains stability through change (101). This distinct operating mode of homeostatic systems becomes apparent in straining and occasionally life-threatening situations. Allostasis both contains and extends the homeostatic principles by adapting set points and other boundaries of control (Table 1) (101). The primary mediators of allostatic response include but are not limited to catecholamines, hormones of the hypothalamo-pituitary-adrenal (HPA) axis and cytokines (102). Of note, allostasis deals with a tradeoff situation. It ensures survival in extreme situations, where, e.g., the demand of energy exceeds supply, but this protective reaction occurs at the expenses of a stress reaction (referred to as allostatic state), which, in turn, may have adverse consequences of its own. The cumulative result of an allostatic state is referred to as allostatic load of the organism (Figure 4). If allostatic load remains excessive or persists over a period of time it may confer pathology and turn out to be life threatening by its own nature (allostatic overload).

Usually, two types of allostatic load are distinguished. Type 1 allostatic load occurs, if energy demands exceed the sum of energy intake and the amount of energy that can be mobilized from stores. Typical examples are breeding birds exposed to inclement weather conditions and the conflict of homeothermic animals resulting from reduced availability of food in cold 


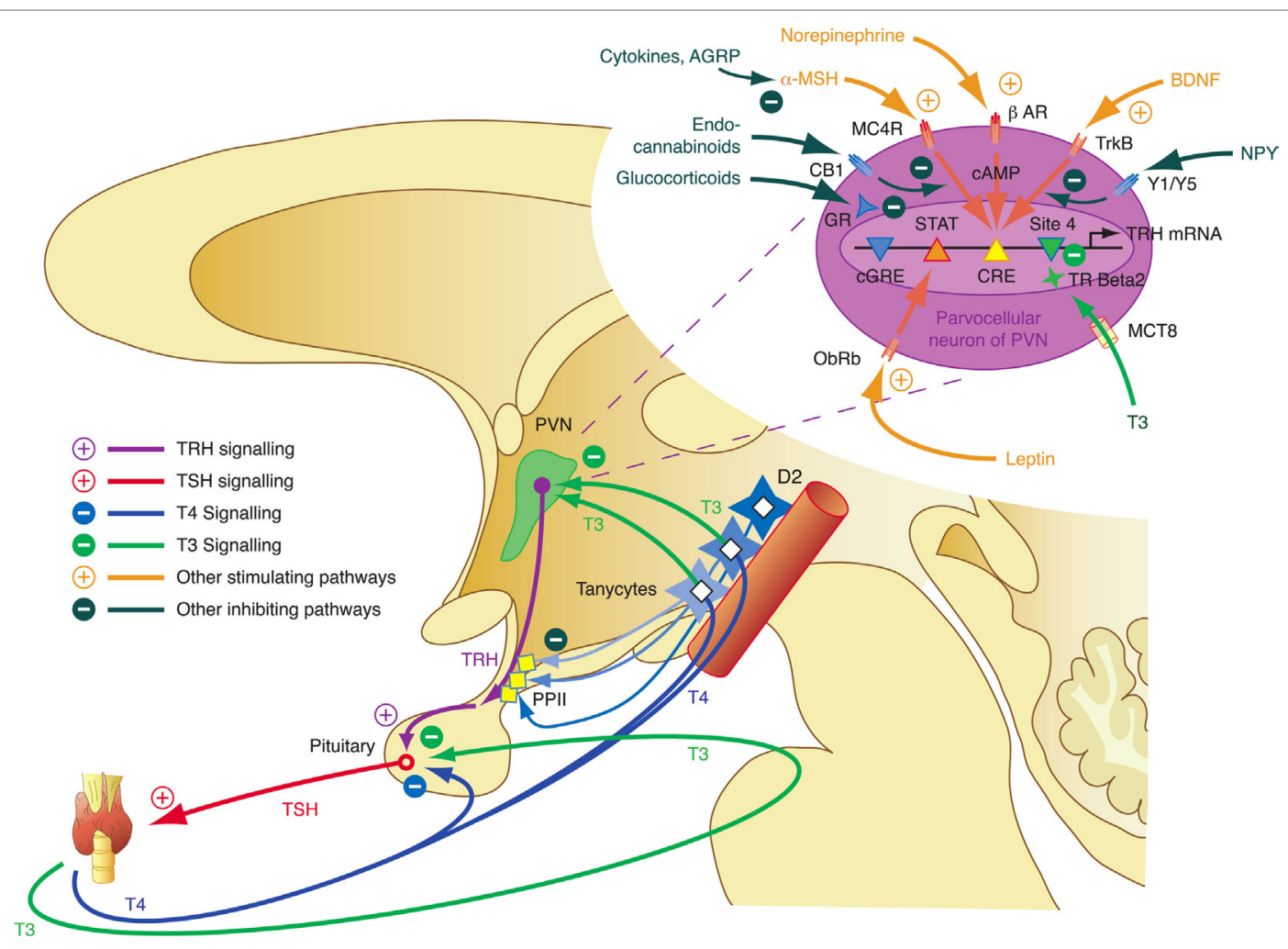

FIGURE 3 | Critical components of the central governor of thyroid homeostasis include parvocellular thyrotropin-releasing hormone (TRH) neurons, which integrate multiple afferent signals relaying information on nutrition and stress, and tanycytes lining the third ventricle at the blood-brain barrier, which are able to control both synthesis and degradation of thyrotropin-releasing hormone (TRH) via type 2 deiodinase (D2) and pyroglutamyl peptidase II (PPII) (95, 97-99).

TABLE 1 | Key concepts of homeostasis and allostasis (103, 104).

\begin{tabular}{ll}
\hline Homeostasis & Allostasis \\
\hline $\begin{array}{l}\text { Constant or oscillating set point } \\
\text { Physiologic equilibrium }\end{array}$ & Changing set point \\
No or little anticipation a of demand & Compensated equilibrium \\
No adjustment based on history & Adjustment based on history \\
Adjustment carries no price & Adjustment and accommodation carry \\
No pathology & a price (allostatic load) \\
\hline
\end{tabular}

${ }^{a}$ Anticipatory components of homeostatic control are usually restricted to small effects of, e.g., circadian rhythms, while allostasic anticipation results in profound adaptation in the awaiting of major strains of threats.

seasons, when they have both to save energy and to increase energy spending on maintaining body temperature (101). Type 2 allostatic load results from expected increase in energy demand, although the cumulative energy balance is still sufficient. This constellation is typical of psychosocial stress situations, e.g., in predominating competitive social structures within animal populations and, as applied to humans, conflicts arising from differences in socioeconomic status (101). Multiple components of an unhealthy lifestyle including overnutrition, poor sleep, and toxic chemicals are also able to contribute to the phenotype of allostasis (107). Long-term consequences of type 2 allostatic load include obesity, hypertension, type 2 diabetes mellitus, endothelial cell damage, and dyslipidemia, i.e., classical components of metabolic syndrome.

Our group has proposed to extend the concept of allostasis to the adaptive response of thyroid function in defined straining situations (35). This extension goes beyond the simple issue of energy balance, although thyroid hormones have an intricate relationship to energy homeostasis. While stimulating the mobilization of energy for metabolic usage thyroid hormones also increase its consumption. Their activation is coupled with a depletion of reduced glutathione stores involved in regeneration of NADH and NADPH acting as cofactors of deiodinases $(86,87,108-110)$. It may therefore be expected that when energy or glutathione availability does not meet their consumption, active thyroid hormones are selectively downregulated. By analogy to classical concepts we will subsequently refer to this situation as type 1 thyroid allostasis. Conversely, in situations, where energy stores have to be mobilized to meet anticipated demands (e.g., in pregnancy, endurance training and adaptation to cold weather conditions), upregulation of active thyroid hormones will be beneficial. Since these situations bear a resemblance to classical type 2 allostatic load, we will sum them up as type 2 thyroid allostasis. This is further justified because a high-T3 constellation in the absence of hyperthyroidism is also observed in obesity (111) and psychosocial stress (112), i.e., type 2 allostatic load according to the classic definition by McEwen and Wingfield. 

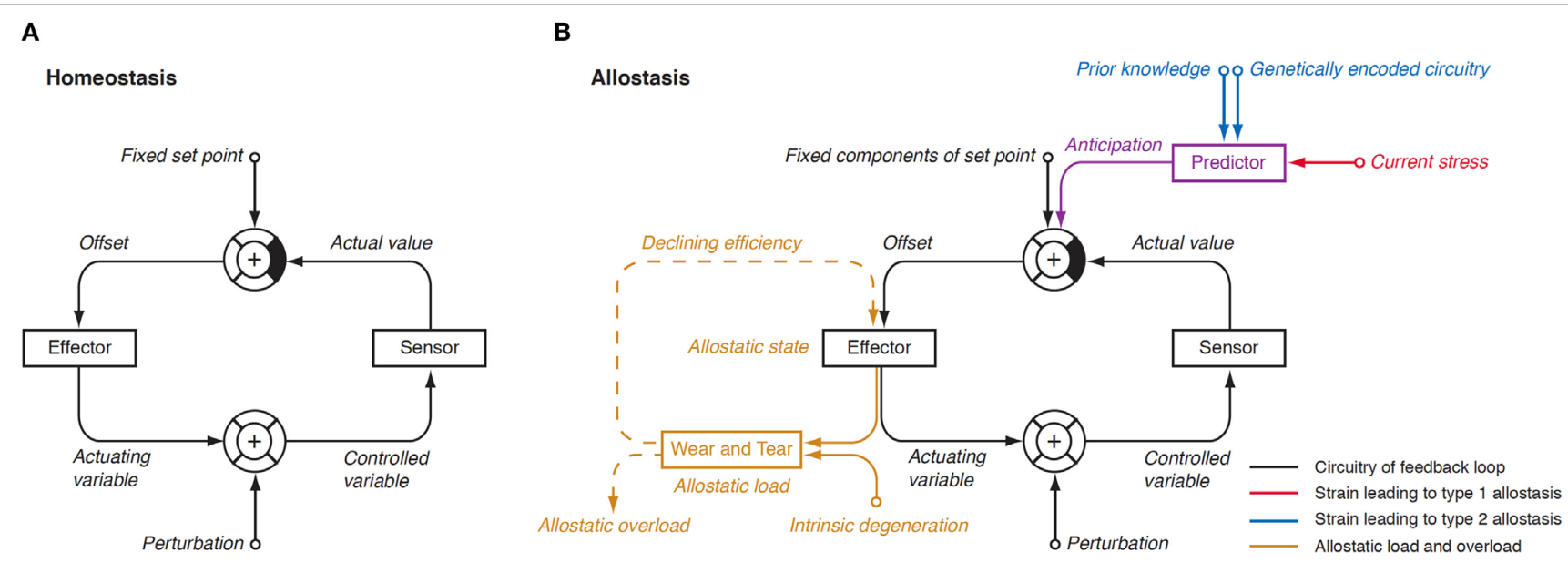

FIGURE 4 | (A) In a physiological homeostatic system, afferent information is compared with a fixed set point, and the sensed discrepancy leads to counterregulatory activity of the effector. Negative (degenerative) feedback ensures static stability of the system. (B) In situations of allostasis, stress signals are looped in at a central level, thus resulting in ongoing offset signaling. Due to saturation of receptors and enzymes, this discrepancy reduces the efficiency of the effector and, if ongoing, gives rise to "wear and tear" reactions. Both mechanisms combine as allostatic load, which may be a source of pathology on its own (105, 106).

In summary, unlike classical stress transduction systems the HPT axis produces two phenotypically distinct types of allostatic load if strained: in type 1 allostasis production of thyroid hormones, especially T3, is downregulated, while it is upregulated in type 2 allostasis. In that respect, the thyroid stress reaction differs sharply from that of the HPA axis, the prime example of an allostatically controlled system, as the latter responds invariantly with increased release of cortisol.

\section{Molecular Mechanisms of Thyroid Allostasis}

In situations of starvation, inflammation, and oxidative stress, a variety of mediators (including nitric oxide, hydrogen peroxide, proteolysis-inducing factor, angiotensin II, TNF- $\alpha$, and other cytokines) converge in the NF- $\mathrm{BB}$ pathway, a key regulatory system of immune response, cell proliferation, and apoptosis (113). Among multiple other effects the NF-KB/IL6 signaling pathway $(114,115)$ inhibits T3-induced expression of peripheral type 1 deiodinase. Downregulation of D1 and peripheral type 2 deiodinase (D2) results in reduced concentrations of free and total T3 $(41,116)$.

Recent research revealed a complex interaction of insulin and thyroid hormone signaling in skeletal muscle, which might also extend to lung and liver tissue $(117,118)$. Via the PI3KmTORC2-Akt pathway insulin and IGF-1 inactivate FOXO1 by phosphorylation at Ser256, which leads to increased D2 activity (117). T3 again inhibits Akt activity, thereby closing a negative feedback loop (118). This mechanisms might play a pivotal role in linking reduced concentrations of insulin in fasting state (119) as well as decreased IGF-1 levels in a subgroup of critically ill (120) to hypodeiodination and consecutive low-T3 syndrome.

In isolation, decreased peripheral step-up deiodination would lead to increased (disinhibited) TSH release, which would result in elevated serum thyrotropin concentration. This, in turn, would reset the concentrations of $\mathrm{T} 3$ to their previous levels, thus neutralizing the effect of hypodeiodination. However, concomitantly with reduced peripheral step-up deiodination, D1 and D2 located in hypothalamic tanycytes (95), and the anterior pituitary gland are upregulated. This change is mediated by bacterial lipopolysaccharide $(121,122)$, alterations in cytokines, e.g., IL-12 and IL-8 (43) and, possibly, increased concentrations of 3,5-diiodothyronine (61-63), triiodothyroacetate, and tetraiodothyroacetate $(123,124)$ during the acute phase response. The upregulation of central step-up deiodination results in increased central thyroid hormone signaling and, consequently, suppressed release of TRH and TSH. The seeming paradox that low-T3 syndrome may ensue from hyperdeiodination is resolved by the spatial diversity of deiodinase activity (Figure 5). This was investigated in silico by computer simulations (20) and confirmed by means of animal experiments in vivo $(83,84,121$, 122, 125-127).

A coordinated interaction of central and peripheral deiodinases in the lead-up to low-T3 syndrome is further supported by upregulation of type 3 deiodinase (D3) in TACITUS (129, 130), giving rise to elevated serum concentrations of rT3, a iodothyronine with inhibiting effects on thyroid hormone signaling. Increased D3 activity in starvation may be caused by decreased leptin concentrations as shown in mice experiments (23, 131). During prolonged critical illness, decreased food intake might be an important factor in regulating the activity of liver deiodinases (132). D3 in peripheral organs might also be upregulated by hypoxia due to decreased tissue perfusion during illness (133).

In addition, TSHb is decreased through IL- $1 \mathrm{~b}$ and TNF- $\alpha$ independently of T3 uptake and action in pituitary cells (134, 135). Moreover, supraphysiological concentrations of IL-1a and IL-1b suppress cAMP accumulation, thus inhibiting the TSHinduced Tg mRNA expression and Tg release in human cultured thyrocytes $(136,137)$. 


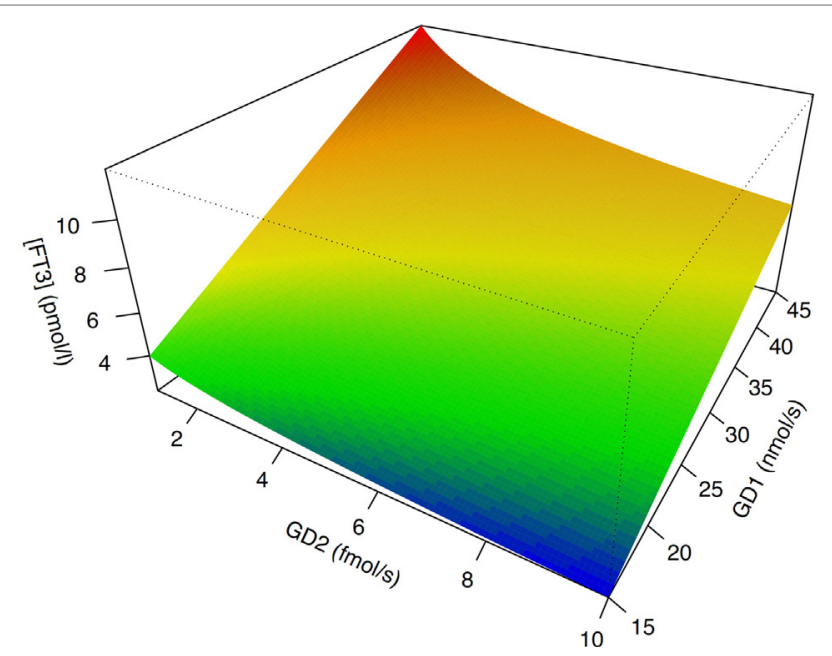

FIGURE 5 | The phenotype of low-T3 syndrome may result from both peripheral hypodeiodination and central hyperdeiodination. Although FT3 concentrations rise with increasing sum activity of peripheral type 1 deiodinase (GD1), they descend with increasing activity of central type 2 deiodinase (GD2). This seeming paradox is explained by feedback effects $(20,21)$. Despite research in humans being hindered by ethical and methodological barriers, results of computer simulations [shown is sensitivity analysis based on SimThyr 4.0 (128)] and animal experiments $(126,127)$ are consistent.

Thyrotropin-releasing hormone neurons originating from the hypothalamic PVN, the major autonomic output area of the hypothalamus $(95,138-140)$, play a key role in the central control of thyroid homeostasis by providing a set point for the short loop control (141). The release of TRH is inhibited by central T3, which is predominantly generated by D2 expressed in tanycytes lining the third ventricle (142-145) (Figure 3). This circuit forms an additional long feedback mechanism of thyroid homeostasis $(83,84)$. Apart from the so defined cascade control mechanism, TRH neurons contribute to the coordination of global energy metabolism by integrating multiple afferent signals (146) including catecholamines $(147,148)$, cocaine- and amphetamine-regulated transcript $(149,150)$, leptin (151), and alpha-MSH $(146,152)$ (all stimulating) as well as neuropeptide $Y$ (NPY) (153-155), agouti-related peptide (141, 146, 156), and glucocorticoids (146) (all inhibiting). Moreover, endocannabinoids have been shown to exert inhibitory effects on TRH neurons via the type 1 cannabinoid receptor (97). Animal experiments revealed that the integration of all afferent projections has profound effects on secretion of TRH and consecutively TSH in straining situations (95).

Depending on the origin of stress (physical or psychogenic), its duration and the animal's endocrine and energetic status TRH release may be upregulated or downregulated (157) subsequently affecting the set point of the overall homeostatic system. Downregulation with consecutive thyrotropic adaptation, i.e., low or normal TSH levels despite low concentrations of T4 and/or T3, may occur for instance in cases of systemic infection and sepsis, where lipopolysaccharides induce D2 activity in tanycytes (126). Moreover, low TRH expression in the PVN characterizes the NTIS (95). In addition to the effects of NPY as neurotransmitter, elevated fasting serum concentrations of NPY have a stimulatory effect on hepatic thyroid hormone degradation via increased glucuronoconjugation (facilitating biliary clearance) and sulfoconjugation (enabling step-down deiodination to rT3S) $(140,158)$.

A high proportion of the circulating iodothyronines is bound to thyroxine-binding globulin (TBG), transthyretine, and albumin. This mechanism contributes to the exceptionally long half-lives of thyroid hormones. In case of rapid onset of stress situations, e.g., severe illness, the time frame of the described control mechanisms would be too long to be effective, if plasma protein binding of thyroid hormones remained unchanged. However, in critical illness the extent of plasma protein binding is reduced owing to decreased concentrations of binding proteins and the existence of certain binding inhibitors $(57,58,159)$. This effect is putatively mediated via cytokines (160). Consequently, degradation of iodothyronines is considerably accelerated, which represents another underlying mechanism toward the adaptation of the feedback loop to conditions of type 1 allostatic load (161-163).

In an animal model for prolonged critical illness the iodothyronine membrane transporters MCT10 and OATP1C1 (but not MCT8) were increased, suggesting some adaptation at the level of transmembrane transport, however, with uncertain clinical relevance (164).

Finally, alternative metabolic pathways of thyroid hormones in peripheral tissues such as sulfation, conjugation to bile acids and glucuronide, and ether link cleavage may affect the concentrations of thyroid hormones in critical illness (165-169).

\section{THYROID ALLOSTASIS IN VARIOUS PHYSIOLOGICAL AND PATHOLOGICAL CONDITIONS}

A variety of scenarios associated with type 1 and type 2 allostatic load have been recognized to result in adaptive changes in thyroid homeostasis. Table 2 provides a short summary, and the associated conditions are subsequently described in more detail.

\section{Energy Restriction and Starvation}

Early reports that serum concentrations of T3 are reduced in states of low caloric intake $(47,49)$ gave rise to the concept of what we now call the Low-T3 syndrome. Reduced T3 concentrations have been described in various conditions associated with energy deprivation, including anorexia nervosa (183-185), calorie-free diet in obesity (47), military combat training with caloric restrictions $(186,187)$ and other energy-deficient situations (188). Even moderate weight loss may result in hypodeiodination with consecutive decreased T3 concentrations (189). Today, at least three mechanisms explaining this finding are known (Figure 6) (23). In the fed state, peripheral step-up deiodination is stimulated by insulin (119) and bile acids (190-192). In addition, increased leptin concentrations facilitate release of TRH and TSH via the hypothalamic melanocortin pathway $(23,83,146,193)$. Together, these different mechanisms enhance conversion of T4 to T3, thus mediating postprandial thermogenesis. Conversely, 
TABLE 2 | Characteristic phenotypical changes of thyroid-stimulating hormone (TSH) and various classical and non-classical thyroid hormones in certain allostatic situations show nearly opposing changes in type 1 and type 2 allostatic load $(61,63,111,123,170-182)$.

$\begin{array}{llllll}\text { TSH } & \text { FT4 } & \text { TT4 } & \text { FT3 } & \text { TT3 } & \text { rT3 }\end{array}$

Type 1 allostasis in fetal period, acute and chronic critical illness, and in deprivation of energy

\begin{tabular}{|c|c|c|c|c|c|c|}
\hline Fetal life & $\downarrow, \rightarrow$ or $\uparrow$ & $\downarrow$ & $\downarrow$ & $\downarrow$ & $\downarrow$ & $\uparrow$ \\
\hline Caloric deprivation & $\rightarrow$ or $\downarrow$ & $\rightarrow$ & $\downarrow$ & $\downarrow$ & $\downarrow$ & $\uparrow$ \\
\hline Exhausting exercise & $\rightarrow$ or $\downarrow$ & $\rightarrow$ & $\downarrow$ & $\downarrow$ & $\downarrow$ & $\uparrow$ \\
\hline Critical illness (general) & $\rightarrow$ or $\downarrow$ & $\rightarrow$ & $\rightarrow$ or $\downarrow$ & $\downarrow$ & $\downarrow$ & $\rightarrow$ or $\uparrow$ \\
\hline Chronic heart failure & $\rightarrow$ or $\downarrow$ & $\rightarrow$ & $\rightarrow$ or $\downarrow$ & $\downarrow$ & $\downarrow$ & \\
\hline Renal diseases & $\rightarrow$ & $\rightarrow$ or $\downarrow$ & $\rightarrow$ or $\downarrow$ & $\rightarrow$ & $\downarrow$ & $\rightarrow$ \\
\hline Liver diseases & $\rightarrow$ & $\rightarrow$ or $\downarrow$ & $\uparrow$ & $\downarrow$ & $\rightarrow$ or $\uparrow$ & $\rightarrow$ or $\uparrow$ \\
\hline Pulmonary diseases & $\rightarrow$ & $\rightarrow$ & $\rightarrow$ & $\downarrow$ & $\rightarrow$ & \\
\hline Diabetes mellitus & $\rightarrow$ or $\downarrow$ & $\rightarrow$ or $\uparrow$ & $\downarrow$ & $\downarrow$ & $\downarrow$ & $\rightarrow$ or $\uparrow$ \\
\hline Sepsis & $\downarrow$ & $\rightarrow$ & $\rightarrow$ or $\downarrow$ & $\downarrow$ & $\downarrow$ & $\rightarrow$ or \\
\hline HIV infection & $\rightarrow$ & $\rightarrow$ or $\downarrow$ & $\rightarrow$ & $\rightarrow$ or $\downarrow$ & $\rightarrow$ & $\rightarrow$ or \\
\hline Depression & $\rightarrow$ & $\rightarrow$ or $\uparrow$ & $\uparrow$ & $\downarrow$ & $\downarrow$ & $\rightarrow \mathrm{O}$ \\
\hline
\end{tabular}

Type 2 allostasis-related conditions

Pregnancy

Endurance training

Obesity

Adaptation to cold

Acute schizophrenia

Post-traumatic stress disorder

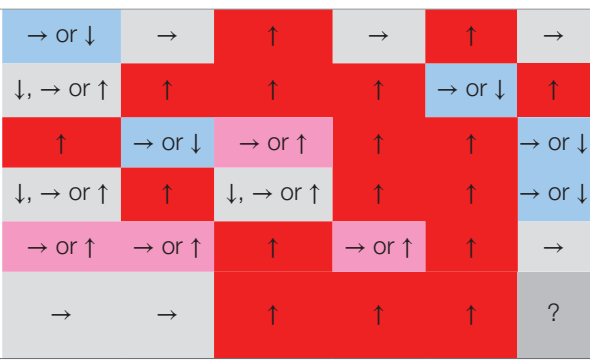

FT4 and FT3, free T4 and T3, respectively; TT4 and TT3, total (free + protein-bound) T4 and T3, respectively; rT3, reverse T3; TSH, thyroid-stimulating hormone. Hormone concentration unchanged $(\rightarrow)$, increased $(\uparrow)$, decreased $(\downarrow)$, or not reported (?). Small studies also reported increased concentrations of 3,5-diiodothyronine (3,5-T2) (61-63), triiodothyroacetate and tetraiodothyroacetate (123, 124), and decreased concentrations of 3-monothyronamine (63) in critical illness and chronic heart failure (not shown in table). See text for definition of type 1 and type 2 allostasis in the context of pituitary-thyroid function.

in fasting conditions concentrations of insulin, bile acids, and leptin are low, which results in decreased step-up deiodination and thyrotropic adaptation, and eventually in low-T3 syndrome. Additional mechanisms leading to impaired TSH release include increased expression of neuromedin B, a bombesin-related peptide, which is an inhibitor of TSH secretion, and upregulation of hypothalamic D2 expression during fasting (23), resulting in low TRH expression in the PVN $(25,95,98,194)$.

\section{Obesity}

Obesity is a classical consequence of type 2 allostatic load (101). It is linked to multiple metabolic and endocrine responses (111) including thyroid function. The interconnection between thyroid hormones and body weight is bidirectional, and both hypothyroidism and hyperthyroidism are known to result in changes of body mass. Conversely, obesity may result in adaptive responses of thyroid homeostasis: a variety of studies, as recently reviewed by Pacifico et al. (195) and Fontenelle et al. (111), described elevated TSH levels and increased total step-up deiodinase activity (although predominantly within the reference range) in patients with weight gain, while concentration of rT3 has been reported to be decreased. Reversibility of these alterations after weight loss indicates that they are consequence rather than cause of overweight (196). A recent study (42) described a significant rise in TSH in the absence of peripheral hypothyroidism in men with non-metastatic prostate cancer undergoing androgen deprivation therapy. The effect was mediated by body composition changes and by the fat-associated hormone leptin rather than androgen deficiency. Another study interrelated non-alcoholic fatty liver disease with higher fT3 concentrations in euthyroid subjects, probably consequent to central obesity (197). Both central and peripheral components of the feedback loop are apparently involved in the reactive adjustments to obesity (Figure 7). Increased concentrations of adipokines such as leptin have been proposed to be a key element of obesity-related thyroid allostasis, but mitochondrial dysfunction $(195,198)$, chronic inflammation, and insulin resistance (199) as well as both central and peripheral resistance to thyroid hormone may play additional roles (111).

Since thyroid hormones are potent stimulators of adaptive thermogenesis (202-204), upregulation of TSH release and deiodinase activity stimulates dissipation of energy and therefore may be part of autoregulatory mechanisms of body mass and fat storage. On the other hand, some of the obesity-related changes in thyroid function may contribute to the unfavorable metabolic phenotype of overweight (111). This and significant cardiovascular side effects of hyperthyroidism are the main reasons that intake of thyroid hormones is strongly discouraged as an adjunct in the treatment of obesity (205).

\section{Adaptive Thyroid Responses to Thermoregulatory Challenge}

In mammals, thyroid hormones are potent mediators of efficient thermoregulation. This ensues from a complex mechanism tightly integrating deiodinase activity with sympathetic signals (206), which leads to upregulation of the protein UCP1 in mitochondria of skeletal muscle and brown adipose tissue (207-209). This results in uncoupled oxidative phosphorylation and finally non-shivering thermogenesis (202-204, 210, 211). It is therefore not surprising that mammals, typical examples for homeotherm animals (endotherm thermoregulators), usually exhibit elevated serum concentrations of T4 and T3 in winter and during hypothermia as long as they are sufficiently fed $(212,213)$. Increased concentrations of TSH and/or thyroid hormones in cold seasons and during hypothermia have also been described in humans (214-217). Although the mechanism of thyroid hormonemediated expression of UCP1 plays a pivotal role in efficient thermoregulation of mammals $(202,218,219)$ it has not been described in non-mammal homeotherm vertebrates, e.g., in birds, and it is probably inexistent in homeotherm arthropods. Of note, although some insect species, e.g., bombus and apis, are homeotherm $(220,221)$, their temperature regulation is less potent and less energy efficient than that of mammals. This may be in part due to the fact that they probably lack endogenous production of thyroid hormones (222-224). 


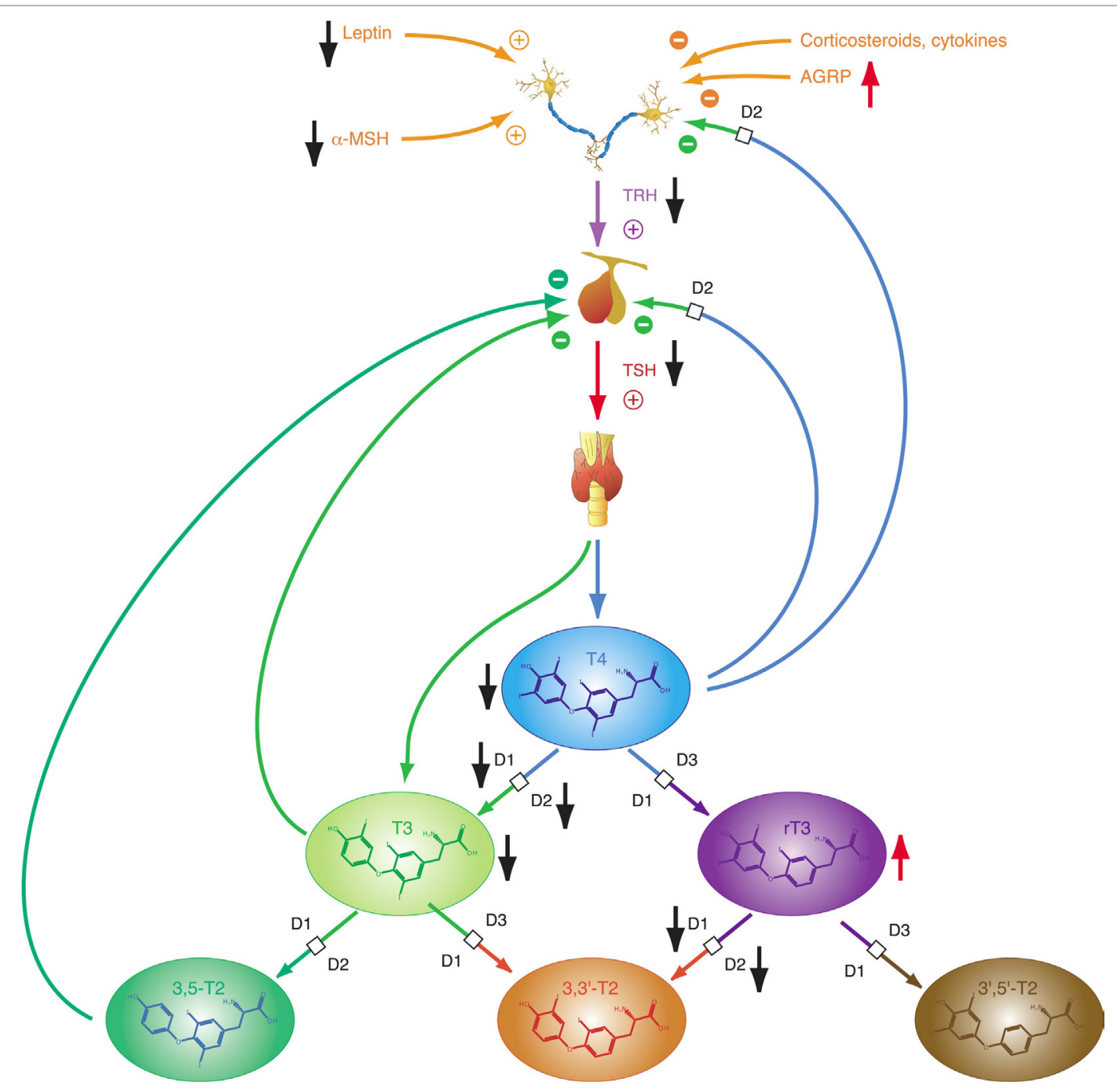

FIGURE 6 | In starvation, both step-up deiodination (via D1 and D2) and thyroid-stimulating hormone (TSH) release are reduced, leading to low-T4 and low-T3 constellations. rT3 concentrations may be increased. Black and red arrows indicate the direction of change from normal, homeostatic conditions in fed state.

In hibernating mammals, the situation is different to that of non-hibernating mammals, since here concentrations of $\mathrm{T} 4$ and T3 are downregulated during hibernation $(78,225-228)$. This also applies to the endocrine response to cold in starving mammals (229) and poikilotherm vertebrates during torpor (79).

In summary, during cold periods T3 and T4 are upregulated in fed non-hibernating homeotherm mammals, but in an NTISlike pattern downregulated in hibernating mammals, starving non-hibernating mammals and poikilotherm vertebrates. Both mechanisms support conservation of energy: the first one by making thermoregulation more efficient, and the second one by partly tuning down the metabolism in periods of lower demand and supply.

\section{Fetal Life}

Iodothyronines are critical for development in the embryonal and fetal periods. Both hypothyroidism (230) and oversupply with thyroid hormones (231) may result in fetal loss and severe developmental disorders. In humans, the fetal thyroid gland starts to secrete hormones in the beginning of the 12th week of gestation (29). However, the feedback loop begins to be functional in the 20th week, i.e., in mid-gestation (29). In the first half of pregnancy, the fetus is largely dependent on maternal supply with thyroid hormones, probably explaining, why production of iodothyronines is upregulated in the mother (230). Despite this anti-NTIS-like pattern in the maternal metabolism, which is mainly mediated via human chorionic gonadotropin (hCG) and estrogens (230), concentrations of free and total T3 are low in the fetus throughout gestation, and concentrations of TBG, free and total $\mathrm{T} 4$ are, although rising with increasing gestational age (230), lower in the fetal than in the maternal circulation (Figure 8) (232). TSH levels attain a maximum of about $15 \mathrm{mIU} / \mathrm{L}$ in the 20th week, when the feedback loop maturates, and then again at birth (29). Both in fetal serum and in amniotic fluid, concentrations of rT3 are markedly increased (230), which probably results from high activity of type 3 deiodinase in placental tissue and multiple fetal 

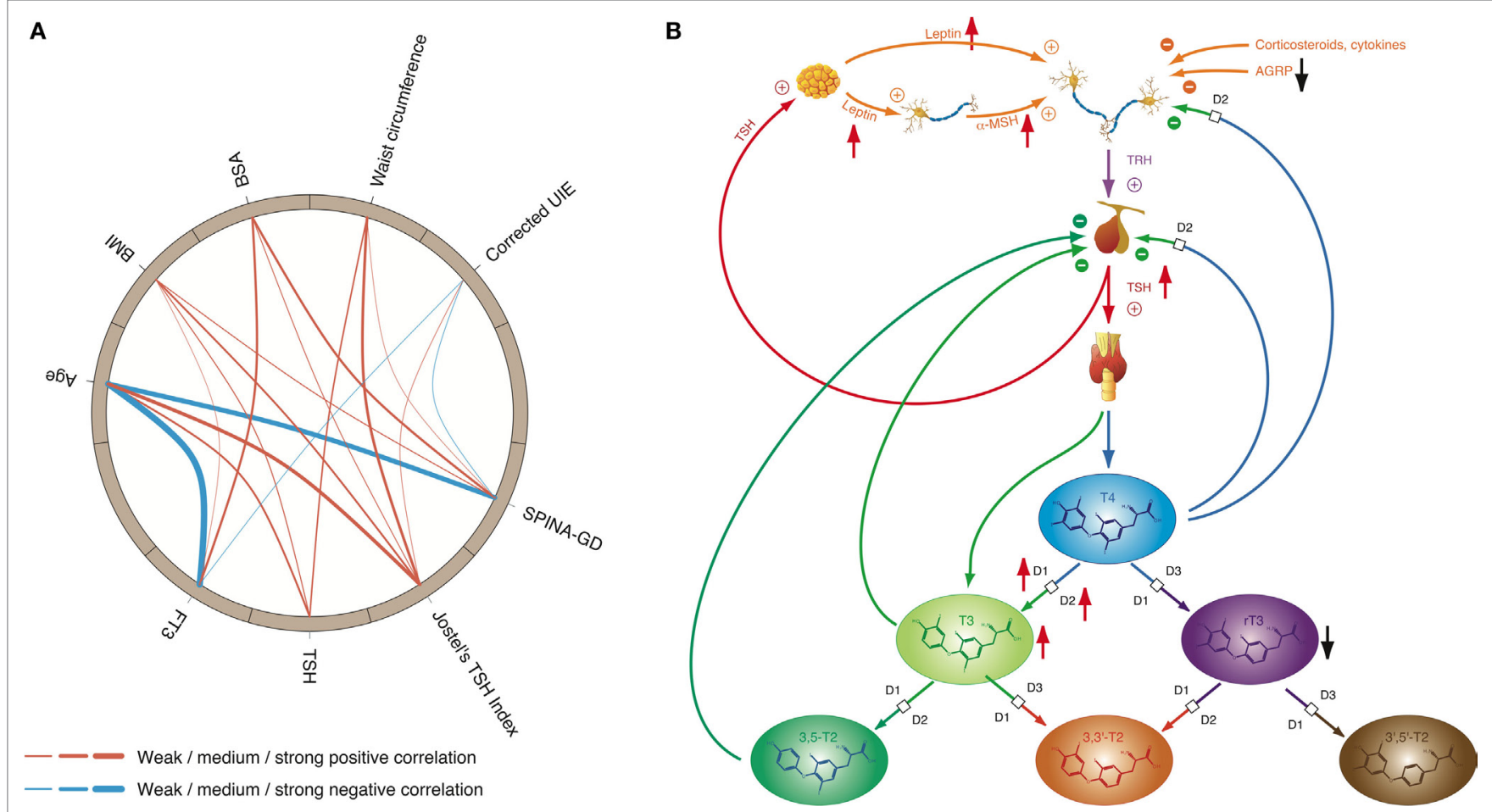

FIGURE 7 | High-T3 concentrations (although in most cases within the reference interval), reduced rT3 concentrations, increased activity of type 1 and type 2 deiodinase, and comparatively high thyroid-stimulating hormone (TSH) levels are the typical signature of obesity, a classical phenotypical sequela of type 2 allostatic load. (A) In healthy participants of the NHANES program (200), concentrations of TSH and FT3 as well as Jostel's TSH index (a measure for the set point of thyroid homeostasis) and SPINA-GD (an estimate for total deiodinase activity) show a significantly positive correlation to body mass index (BMI) and waist circumference, and with the exception of TSH also to body surface area (BSA). In addition, FT3 and SPINA-GD correlate negatively to age, and minor associations exist to creatinine-corrected urinary iodine excretion (UIE). In this circular map, positive correlations are marked in red and negative correlations in blue. The widths of the splines represent the correlation coefficient to denote the strengths of association (201). (B) Mechanisms of adaptive responses in obesity are mediated by elevated leptin concentrations and increased alpha-MSH signaling, while activity of AGRP terminals is reduced.

organs (230). Increased concentrations of sulfated metabolites of iodothyronines result from low type 1 deiodinase activity in fetal tissues and because T4 sulfate and T3 sulfate are not substrates for placental type 3 deiodinase (230). At birth, concentrations of TSH, T4, and T3 sharply spike to attain slightly elevated levels in the neonatal metabolism (29).

These patterns of thyroid hormones in the normal fetus closely resemble the constellation of NTIS. The conclusion that the normal fetal concentrations of thyroid hormones are beneficial despite being markedly different from that of both healthy adults and healthy newborns is supported by the observation that this constellation is actively defended in situations of thyroid disorders (233): in hypothyroid fetuses D2 activity increases and activities of D1 and D3 decrease, thus providing support for shunting of T4 to brain tissue (230), while, on the contrary, elevated concentrations of iodothyronines stimulate the activity of D3, which results in increased degradation of active thyroid hormones to rT3, 3,3' -T2 and $3^{\prime}, 5^{\prime}-\mathrm{T} 2$ (234-236).

\section{Pregnancy}

The adaptive endocrine response in pregnancy manages a tradeoff situation, where the maternal organism is faced with the dual challenge of optimizing conditions for the developing fetus and its own survival. Allostatic changes are mediated both by the central hypothalamic-pituitary unit and the fetal-placental unit. The latter secretes protein and steroid hormones that modify the function of endocrine organs in the mother's organism throughout pregnancy (237). Due to its high structural similarity with TSH, the glycoprotein hormone hCG stimulates the human TSH receptor, which enables the placenta to gain parallel control over the thyroid system in early gestation (238). In extreme situations, e.g., starvation, the adaptive gestational responses control type 1 allostasis. Mostly, however, resources are sufficient to permit an anticipatory endocrine response of type 2 allostasis. Typical responses of the pituitary-thyroid axis in pregnancy include enhanced secretion of thyroxine from the thyroid gland and increased step-up deiodination. Unlike in obesity or other states of type 2 allostasis, TSH concentrations are low-normal or slightly decreased (230) (Figure 8B). This is a consequence of both elevated concentrations of T4 and hCG (stimulating TSH receptors in the anterior pituitary gland). In addition, plasma protein binding of thyroid hormones is increased. The majority of these effects are mediated by hCG, which displays, in addition to its gonadotropic action, mild TSH-mimicking effects in its sialylated form and TSH-antagonistic effects in a desialylated variant (239). Thyroid overstimulation by hCG is possible in pregnant women in the first trimester resulting in a distinct entity of gestational hyperthyroidism or hyperthyroidism in trophoblastic diseases, 


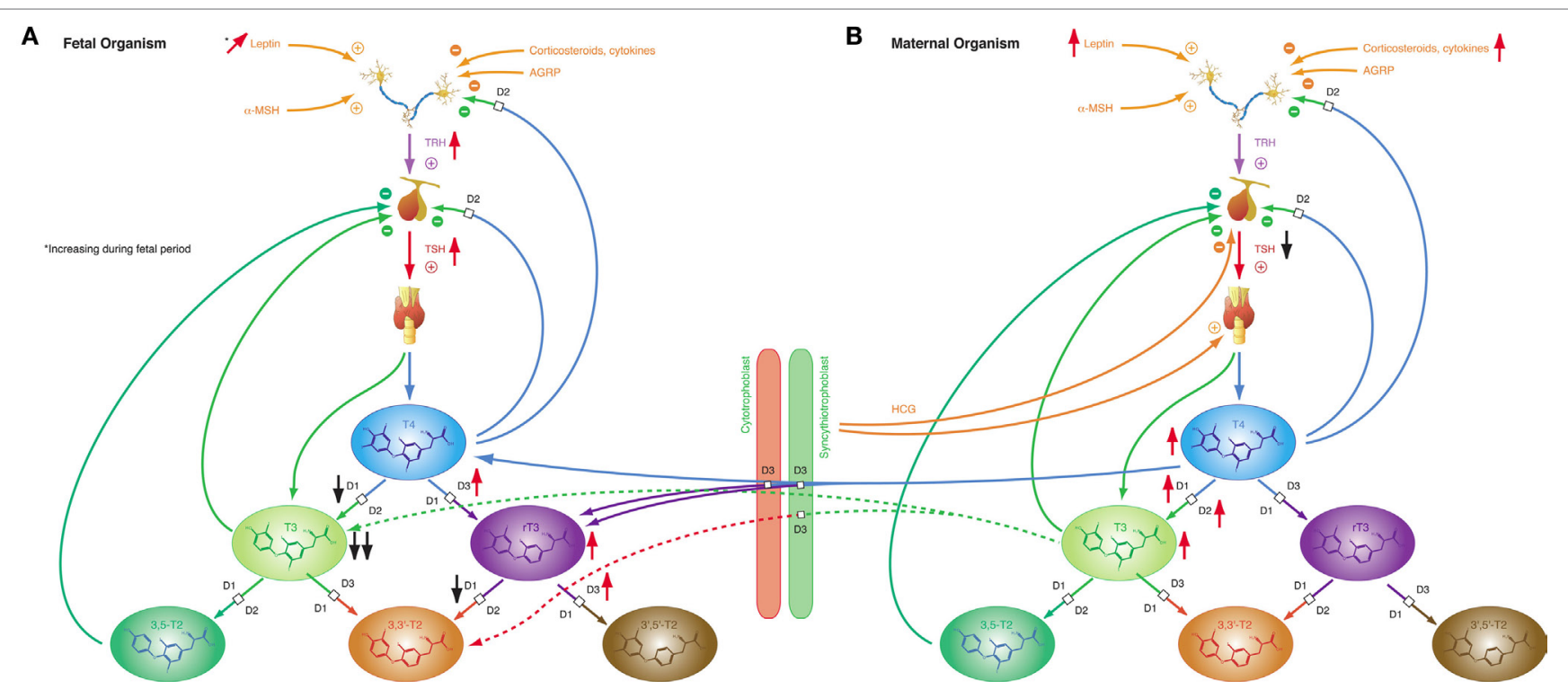

FIGURE 8 | Fetal and maternal thyroid homeostasis are dovetailed to optimize conditions for both organisms. (A) After maturation of the feedback loop in the 20th week of gestation, fetal thyroid-stimulating hormone (TSH) concentrations and step-down deiodination via D3 are temporarily increased, while step-up deiodination is decreased. This results in a pattern of markedly reduced T3 concentrations and elevated rT3 levels. Black and red arrows indicate the difference compared to normal, homeostatic conditions in healthy newborns and adults. (B) Pregnancy is accompanied by a characteristic "anti-NTIS"-like constellation of thyroid homeostasis including high concentrations of T3 and T4, step-up hyperdeiodination and increased binding of thyroid hormones to plasma proteins.

which may also affect men with testicular cancer $(238,240-247)$. This scenario exceeds physiological adaptation and translates into a specific disease entity. It demonstrates the strength of hCGmediated effects, which confer a not so rare risk of subclinical hyperthyroidism in otherwise normal pregnancies (238).

The "anti-NTIS"-like pattern of maternal thyroid homeostasis in pregnancy results in increased availability of thyroid hormones for the developing fetus, which is especially necessary in the early phases of gestation, when the fetal thyroid is still unable to produce sufficient amounts of thyroid hormones, the more as the transport capacity through the placental barrier is limited.

Pregnancy-related allostatic changes in thyroid function are frequently causing problems in the differential diagnosis of thyroid disease as described below in the Section "Methods of Assessment and Differential Diagnosis." Because a sufficient supply with levothyroxine is critical for the development of the fetus, thresholds for initiation of substitution in subclinical hypothyroidism and dosage adjustment in hypothyroid women taking L-T4 prior to pregnancy had been lowered by professional societies (248-251). Based on evidence the American Thyroid Association and the Endocrine Society had recommended to lower the upper range of the TSH reference range to 2.5, 3.0, and $3.5 \mathrm{mIU} / \mathrm{L}$ in the first, second, and third trimester of pregnancy, respectively. Although several observational studies reported adverse pregnancy outcome in even mild hypothyroidism (252-261), two recent interventional trials did not confirm a beneficial effect of substitution therapy in subclinical hypothyroidism and hypothyroxinemia with respect to children's IQ at age of 5 years and secondary outcome markers $(262,263)$. Consequently, the recommended upper limit of the TSH reference range has been raised back to $4 \mathrm{mIU} / \mathrm{L}$ in the most recent guideline issued by the American Thyroid Association (264). However, thyroid peroxidase antibodies should be measured in pregnant women with TSH concentration above $2.5 \mathrm{mIU} / \mathrm{L}$ and treatment be considered, if antibody titers are positive, even if TSH levels are between 2.5 and $4 \mathrm{mIU} / \mathrm{L}$ (264).

The reason for these discrepancies and the lack of success by interventional studies is unknown. Ethnic differences among study populations (265) and the inverted $\mathrm{U}$ shape of the relation between maternal FT4 concentration and child IQ (266-268) as well as the relatively late onset of substitution therapy after the 10 th week of gestation in the reported substitution trials $(262,263)$ may play a role. This uncertainty warrants further research.

\section{Exercise}

Intensive muscle activity in sports and training is associated with profound changes in endocrine control (27) and cytokine patterns $(269,270)$. This suggests modifications of thyroid homeostasis during or after exercise.

The response of thyroid hormones to exercise varies (Figure 9). With a few exceptions (271-273), most studies investigating thyroid hormones during or in a short-time interval after training found elevated concentrations of TSH, T4 and/or T3 (46,274-276). After resting or in prolonged training programs with repeated heavy strain, however, the majority of studies described reduced concentrations of TSH, T4, and T3 (186, 187, 277-281). This seeming contradiction was attributed to hemoconcentration in or after exercise leading to falsely elevated hormone concentrations in short-time exercise (27). This assumption is supported by trials, where thyroid hormones have been measured both on short and long timescales. Hormone concentrations, while elevated during physical strain or at exhaustion decreased at rest 

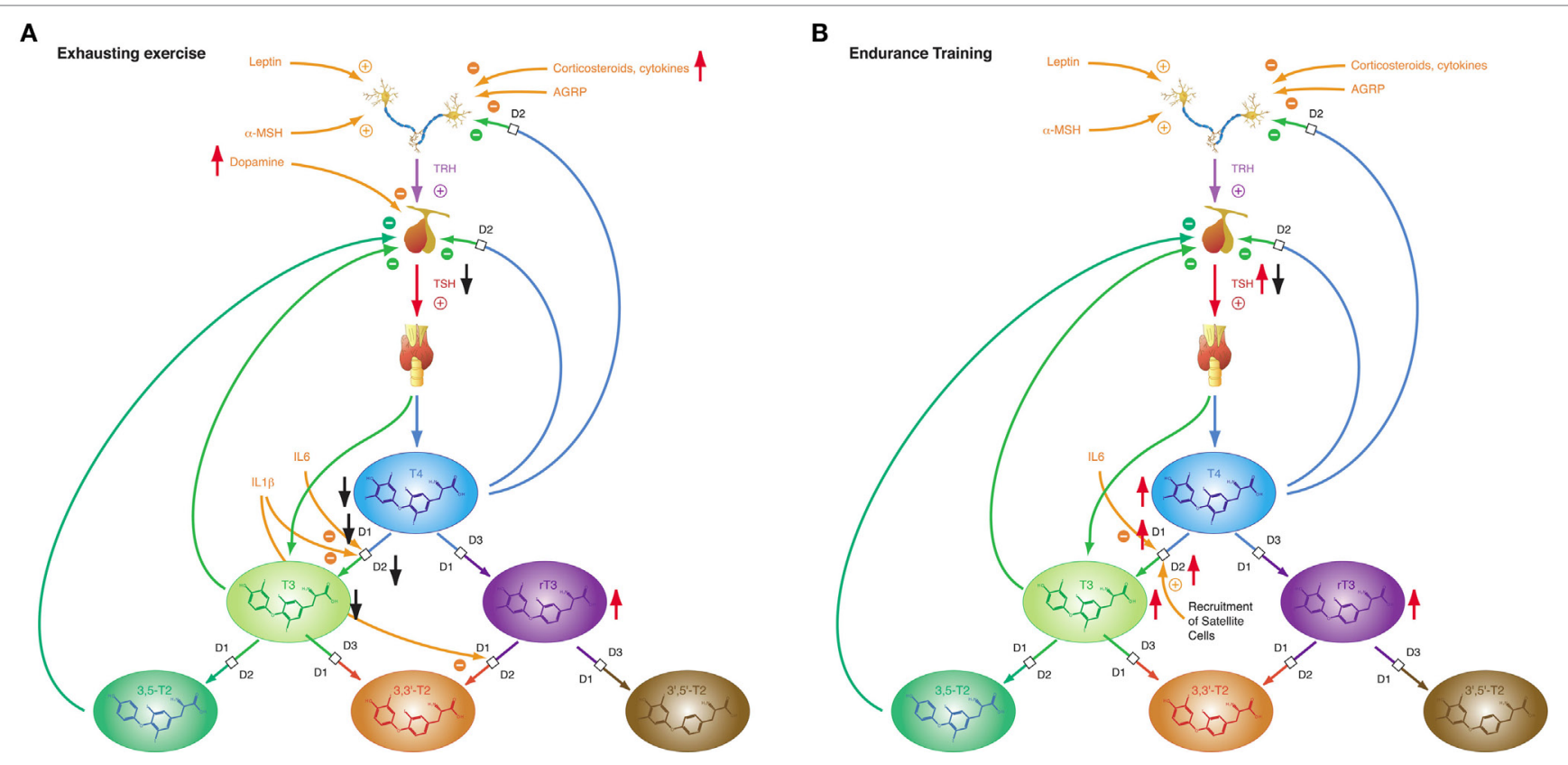

FIGURE 9 | The adaptive response of the hypothalamic-pituitary thyroid axis to exercise is heterogeneous, depending on duration and intensity of training and on the interval between exercise and laboratory investigations (27). This diversity may result from pre-analytical factors (e.g., hemoconcentration) and from an overlap of type 1 and type 2 allostatic load. (A) Exhausting exercise. (B) Endurance training.

after exercise (46, 186, 275-277). Resting allows for rehydration and represents a more realistic situation. As a consequence it has been recommended to allow for a 24 -h recovery period before participants report for laboratory testing (282).

Of note, TSH and thyroid hormone concentrations are elevated in endurance exercise and in the beginning of military combat training before exhaustion $(186,277,283)$, even if allowance was made for resting and rehydration before investigation (283). With the onset of exhaustion, the pattern changes and hormone concentrations decrease to subnormal values $(186,187,277)$. This suggests that the variable homeostatic response to exercise may possibly result from a second mechanism, where type 1 allostasis ensues from exhaustion and deprivation of energy, thereby leading to downregulation of TSH and peripheral thyroid hormones, whereas in endurance training and before exhaustion allostasis is shifted to type 2 and stimulated release of TSH, T4 and T3.

The NTIS-like pattern of thyroid hormones after exhausting training is confirmed by two studies showing increased rT3 concentrations $(187,283)$ in physical strain. The type 1 allostatic endocrine responses were more pronounced in military combat training programs, when participants were subject to additional deprivation of sleep and energy $(186,187,277)$.

\section{Acute and Chronic Critical IIIness}

Characteristic patterns of NTIS have been described in a multitude of acute and chronic somatic illnesses including states of shock (284), circulatory arrest $(285,286)$, respiratory failure (65), community-acquired pneumonia (287), sepsis (288), chronic respiratory $(289,290)$ and cardiovascular $(61,64,66,291,292)$ disease, renal failure (293-298), COPD (289), gastrointestinal diseases (299-301), autoimmune diseases (71, 302, 303), and cancer $(130,290,304)$. Phenotypes of NTIS with high and highnormal FT4 concentrations have been described in dementia and frailty in elderly persons (305).

While most forms of acute critical illness may be interpreted as a state of starvation, the chronic form of severe illness-a result of modern critical care-represents most commonly a state of adequate nutrition (306). Hence it is not surprising that acute and chronic critical illness elicit different phases of NTIS: the acute phase (Figure 10A) and the chronic or prolonged phase (Figure 10B), also referred to as wasting syndrome (307). The former seems to beneficially affect outcome, the latter to have an impairing effect (308).

Non-thyroidal illness syndrome is a disease-independent risk factor for survival, so it is important to understand the underlying mechanisms (60). Patients with low free T3 show a significantly higher mortality and a significantly longer duration of mandatory ventilation $(56,309)$. Furthermore, low free T3 is a strong prognostic predictor in B-cell lymphomas (310). The alterations of the acute phase of NTIS in critical illness occur within hours or days and are defined by increased release of anterior pituitary hormones, low levels of anabolic peripheral effector hormones, reduced thyroid hormone-binding protein concentration, reduced binding affinity, reduced expression of thyroid hormone transporters, decreased thyroid hormone uptake and altered expression of D1 and D3 activity and the thyroid hormone receptor alpha1 (TR $\alpha 1)$. The prolonged phase, on the other hand, is characterized by a suppression of the hypothalamic-anterior-pituitary-peripheral-hormone axis and low levels of anabolic peripheral effector hormones. Peripheral tissues respond by reactively increasing the expression of monocarboxylate transporters, upregulating D2 activity, reducing D1 

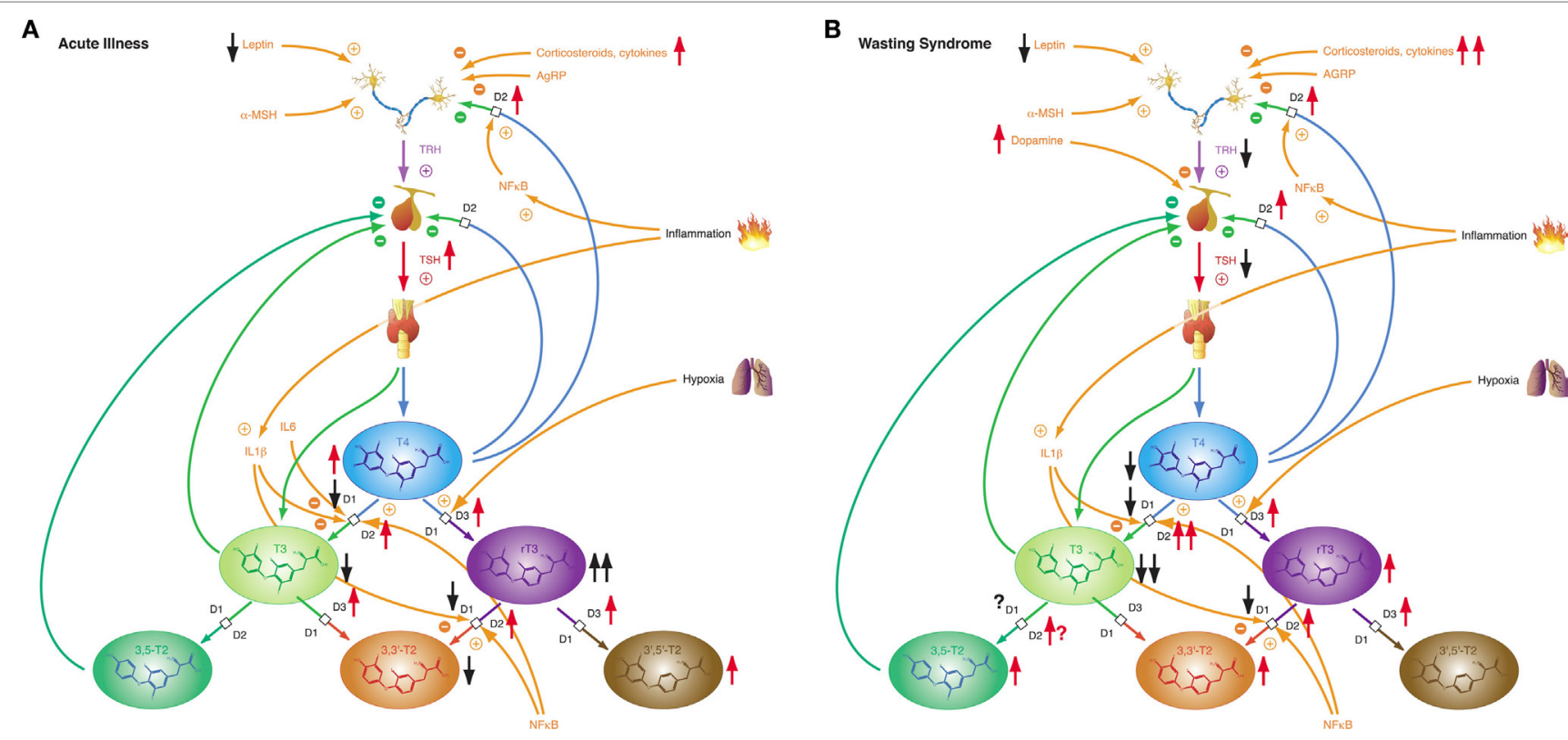

FIGURE 10 | Depending on severity and duration of disease, non-thyroidal illness syndrome presents with two related, but distinct phenotypes. (A) Allostatic reactions of the pituitary-thyroid feedback control system in acute illness lead to slightly decreased T3 and 3,3'-T2 concentrations, slightly elevated T4 and $3^{\prime}, 5^{\prime}$-T2 levels and markedly increased rT3 concentrations. (B) Medium-term and long-term adaptations in ongoing illness ("wasting syndrome") and chronic disease result in thyrotropic adaptation and slight increases of rT3, 3,3'-T2, and 3,5-T2 concentrations concomitant to low-T3 syndrome.

activity, and increasing sensitivity to thyroid hormone receptors. The chronic phase is characterized by a loss of pulsatility of TSH secretion, a reduced TRH-gene expression in the hypothalamic PVN, and suppressed hypothalamic stimulation. However, the pathogenesis is unclear. Altered D3 activity and MAPK and hedgehog pathway seem to play a pivotal role in the whole process (311). Despite our current knowledge, critical questions remain unanswered.

\section{Psychosocial Stress and Psychiatric Diseases}

The relationship between thyroid hormones and psychological phenomena is a paramount example of mutual and reciprocal influences of mind and body. It had been recognized for more than 150 years that diseases of the thyroid are frequently accompanied by psychiatric symptoms $(312,313)$. Although depression is a classical symptom of hypothyroidism, and psychosis may result from thyrotoxicosis, the linkage is clearly bidirectional (314). A great number of studies over the last decades showed that characteristic changes of thyroid hormone concentration may arise from mental or psychological disorders $(28,314)$ in the absence of thyroid disease. This assumption is confirmed by interventional studies that show normalization of formerly changed hormonal parameters after the underlying psychiatric disease has been successfully treated.

As early as in 1968 John Mason predicted thyroid hormone concentrations to rise in response to psychosocial stress (315). Subsequent research revealed that the interaction is complex and non-linear and that it is additionally dependent on the nature of the underlying psychiatric disease. A recent study demonstrated that stress could trigger the onset and the recurrence of hyperthyroidism in patients with Graves' disease (316). However, hyperthyroxinemia is indeed a nearly universal observation in different expressions of psychiatric disorders (317-322).

A large body of studies reported a characteristic pattern of thyroid hormones in MD $(314,323)$. Concentrations of T4 or FT4 are commonly increased during depression (324-329) and revert after recovery from $\mathrm{MD}$, irrespective of the modality of treatment (330-339). Despite the presence of elevated T4 concentrations TSH levels tend to be normal in depressive patients, but circadian variation of TSH concentration is impaired (339-342) and the response to TRH test is blunted (323). Both total and free T3 concentrations are reduced in $\operatorname{MD}(175,176,343)$, but elevated in bipolar I disorder $(237,344)$. Concomitantly, rT3 concentrations are temporarily increased in both $\mathrm{MD}$ and manic disorder; however, not in bipolar I disorder $(334,345,346)$.

Similar to the situation in bipolar I disorder, concentrations of free and total T3 are frequently elevated in post-traumatic stress disorder (PTSD) $(177-179,181,182,347)$, another classical example of a type 2 allostatic reaction (112). Except for concomitant borderline personality disorder (348), the common high-T3 syndrome in PTSD is at least partly due to increased step-up deiodination $(179,181,182)$. Two studies in combat veterans of World War II and the Vietnam war revealed levels of total T4 and both total and free T3 to significantly correlate to severity of PTSD $(181,349)$. This anti-NTIS-like pattern is complemented by elevated TBG concentrations and increased plasma protein binding in these patients compared to healthy controls (179). Despite an elevated set point of thyroid homeostasis the response to TRH stimulation is blunted in PTSD (350). 
A small number of studies reported elevated concentrations of FT4, TT3, and FT3 in schizophrenia spectrum disorders. This observation was, however, not reproducible in all studies and apparently dependent on severity of symptoms and the time after admission $(351,352)$.

In summary, MD is accompanied by a partly NTIS-like pattern, whereas bipolar I disorder and PTSD as well as severe and newly diagnosed schizophrenia involve a hormone constellation typical of type 2 allostasis. A relatively high set point for T4 is shared by all four disorders, as evidenced by unsuppressed TSH levels despite high T4 concentrations, whereas the response to the TRH test is mitigated.

Although our knowledge of the precise mechanisms mediating the endocrine response in this class of affective disorders is still limited, recent research revealed some elements that may play a key role in this scenario. For a long time, it was assumed that central TRH, which has in addition to its endocrine function widespread neurotransmitter and neuromodulatory effects, has a pivotal function in the link between depression and altered thyroid hormones. While TRH concentrations in CSF are increased in depressed patients $(353,354)$ and TRH levels are particularly high in subjects with violent suicidal behavior (353), the results after treatment and in recovery are inconsistent (323). A decisive influence possibly lies in the spatial distribution of neuromodulators and the complex interaction of positive and negative feedback loops between the limbic system and hypothalamus (Figure 11). $\mathrm{TRH}$ expression is upregulated in the amygdala in response to stress (355) and amygdala kindling (356), but downregulated in hippocampus (357). Via two pathways, such as the stria terminalis and the ventral amygdalofugal pathway, the amygdala stimulates the PVN, the origin of hypophysiotropic TRH neurons, with cholinergic and glutamatergic terminals (358). As a consequence, TSH release increases in situations of stress-induced type 2 allostasis (359). Of note, amygdala activity is inhibited again by means of feedback loops mediating the anxiolytic-like effect of TRH (360). In addition, the activity of the feedforward path is sensitive to context and circadian conditions, too (361). This complexity warrants further research.

From a teleological perspective, the type 1 allostatic pattern in depression makes sense. Depression and starvation represent sickness behavior, a common final path of the sickness syndrome, which may be beneficial by promoting social immunity (362).

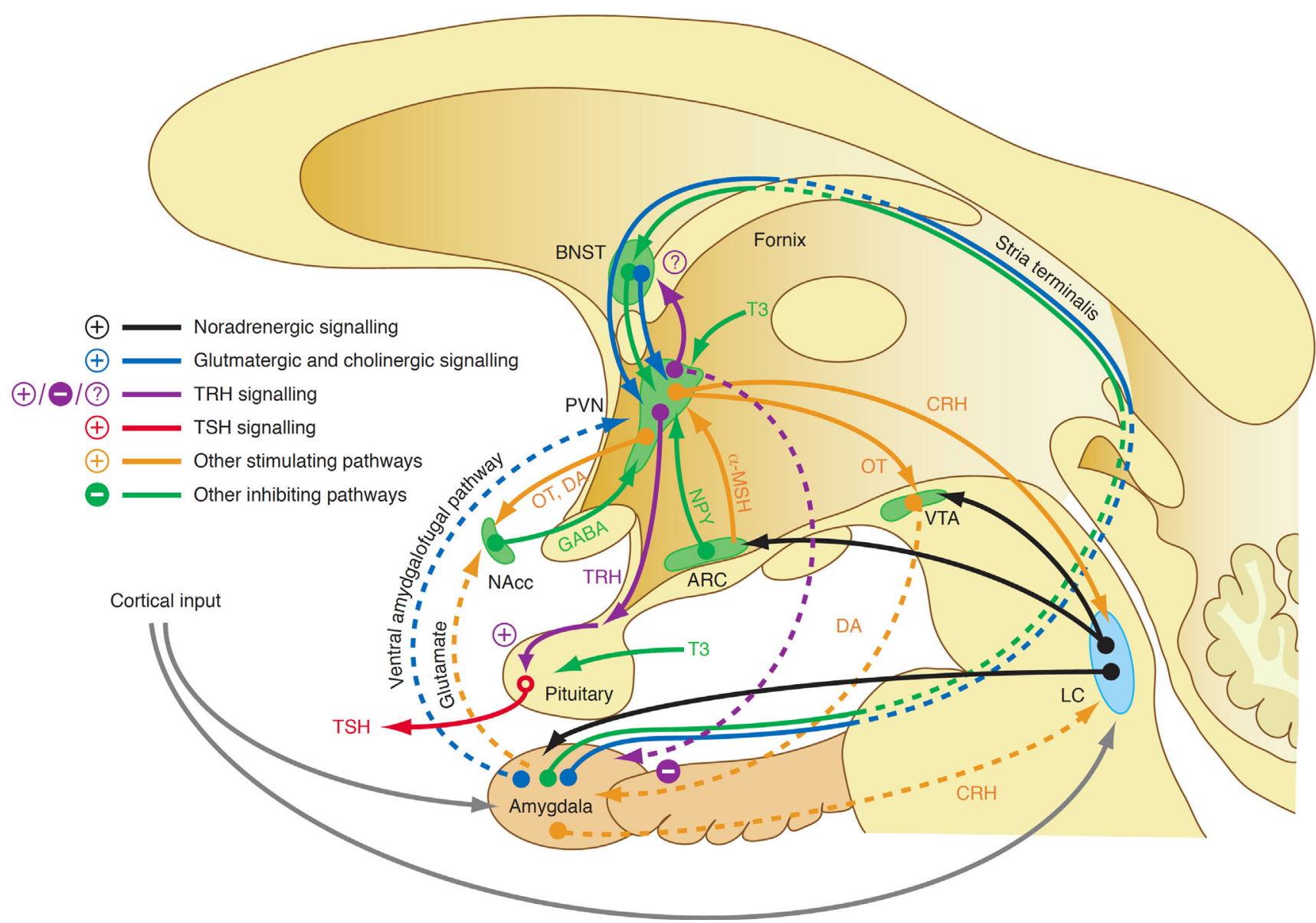

FIGURE 11 | A complex interaction of positive and negative feedback mechanisms linking centers of the limbic system to hypothalamic nuclei explains the adaptive response of the hypothalamic-pituitary thyroid loop in type 2 allostasis resulting from psychosocial stress situations (355, 356, 358, 359). ARC, arcuate nucleus of the hypothalamus; BNST, bed nucleus of the stria terminalis; $\mathrm{CRH}$, corticotrophin-releasing hormone; DA, dopamine; GABA, gamma-aminobutyric acid; LC, locus coeruleus; NAcc, nucleus accumbens; OT, oxytocin; VTA, ventral tegmental area. 
In this model, depression is the mediator between inflammation and NTIS.

\section{NON-HOMEOSTATIC MECHANISMS}

In illness, changes of measured hormone concentration may result from exogenous factors including pharmacological effects of drugs and assay interference. They have in common that they do not represent an adaptive homeostatic reaction of the organism. As these effects are common in TACITUS, overlap with the phenotype of NTIS and can be confused with allostatic reactions, the following section delivers a short overview over triggering scenarios and their consequences.

\section{Drug Effects}

A large number of drugs is known to influence thyroid function interfering with various mechanisms of thyroid hormone metabolism (363). Lithium and aminoglutethimide decrease thyroid hormone secretion. A high iodine load, as it ensues from amiodarone and/or radiocontrast dye application, decreases both central and peripheral deiodinases activity (364-368). In addition to causing hypodeiodination, amiodarone has antagonistic actions on T3 signaling, presumably due to its molecular similarity to thyroid hormones $(369,370)$. Dopamine, glucocorticoids, and somatostatin analogs suppress TSH release (371). Thyroxine absorption is altered by multiple substances including caffeine, bile acid sequestrants, sucralfate, ferrous sulfate, and aluminum hydroxide (372). This results in disruption of the enterohepatic circulation of thyroid hormones, thus contributing to reduced half-life. Moreover, many drugs alter thyroxine and triiodothyronine transport in serum such as estrogens, tamoxifen, heroin, methadone, mitotane, androgens, anabolic steroids, furosemide, NSAIDs, and salicylates by either increasing or decreasing TBG concentration or displacing them from protein-binding sites $(363,373)$. Antiepileptic drugs such as phenobarbital, phenytoin, and carbamazepine increase hepatic metabolism of thyroxine and triiodothyronine. In addition to amiodarone propylthiouracil, macrolides, and unselective beta-adrenergic blockers inhibit the activity of type 1 deiodinase (374), while sorafenib is able to increase D3 activity (375).

\section{Assay Interferences}

Significant problems in FT4 and FT3 assay interpretation can arise in the varying performance of tests from different manufacturing sources $(376,377)$. For example many tests are affected by residual interference from effects of albumin concentrations that are often considerably reduced in NTIS and thereby lead to artificially low estimates of FT3 or FT4. In addition, some tests are insufficiently robust to the lower concentrations of thyroid hormone-binding proteins overall found in these conditions. Some drugs used in severe illness can also distort the results directly by displacing bound thyroid hormones. FT3 tests appear to suffer more in this regard than FT4 tests, though both can be compromised (377).

This can significantly affect conclusions as to the exact magnitude of allostatic effects on thyroid function and may hinder comparison of any findings from studies using different methods of measurement. The most convincing results will therefore be found using assays with minimal interference and closest adherence to the Mass Action criteria governing the working of such assays.

\section{EFFECTS OF HETEROGENEOUS OR UNKNOWN ORIGIN}

The subsequently described influences originate from human civilization. They therefore fail to trigger a natural adaptive response of thyroid homeostasis. Since their action is complex, it is possible, however, that some of the associated mechanisms elicit an allostatic reaction by physiological mimicry of natural factors.

\section{Endocrine Disruptors}

Multiple industrial substances in the environment are able to profoundly modify thyroid function (378-380). The mechanisms are as heterogeneous as the substances, and there is some overlap to drug effects (see above). This applies, e.g., to perchlorate, which inhibits iodine uptake into the thyroid and may therefore cause primary hypothyroidism $(381,382)$. Primary hypothyroidism may also result from exposure to polyhalogenated aromatic hydrocarbons (383) and bisphenol A (384). The effects of polychlorinated biphenyls (PCBs) include increased hepatic degradation of thyroid hormones and inhibition of deiodinase activity, which applies predominantly to cerebral D3 (385-387). Typical high-T3 syndromes under PCB exposure are therefore probably caused by decreased D3 activity rather than by stimulated D1 or D2 activity. Some plant-derived substances have thyromimetic effects and lead to decreased concentrations of TSH, FT4, and FT3 (388). In reality, endocrine disruptors are rarely present in isolated forms. Interactions among different disruptors are complex and may be additive, sub-additive, and super-additive, depending on the individual combination of substances and their respective concentrations (389-391). This makes the effects difficult to predict in the individual situation. Endocrine disruptors may result in clinical thyroid disease whose etiology is hard to pinpoint.

\section{Space Flight}

Space journeys expose the human organism to multiple challenges. They include low or zero gravity, radiation, and impaired circadian rhythm. It is, therefore, not surprising, that manned space exploration is associated with multiple hormonal changes (392). Among them, alterations of the HPT axis seem to play a minor, but potentially significant role. Crewmembers of the Spacelab D-2 mission had slightly increased TSH concentration during flight, suggesting a form of subclinical hypothyroidism (393). These results are compatible to observations in rats and rhesus monkeys (394-397). The most plausible reason for slightly impaired thyroid function during spaceflight is the utilization of iodinated water (398). Iodine was used as a bactericidal agent in US spacecraft water systems until 1997, when a device was implemented in Space Shuttles (and later the International Space Station) to remove iodine from water before consumption. As a result post-flight TSH elevations are no longer observed in astronauts (399). However, regardless of iodine removal, in male astronauts TT4 concentrations and FT4 index continue to be 
higher after space flight and T3 concentrations are decreased after flight. Due to unknown reasons this NTIS-like pattern is observed in men only, but not in women (399).

\section{METHODS OF ASSESSMENT AND DIFFERENTIAL DIAGNOSIS}

Allostatic adaptations of the HPT axis frequently pose serious problems for diagnosis and differential diagnosis of thyroid disorders, because concentrations of both TSH and peripheral thyroid hormones may change considerably and fall widely outside their normal reference ranges. A diagnostic problem arises from the fact that reference ranges for thyroid parameters have been established for healthy non-pregnant adults under resting and fed conditions-a premise that is not invariably met, especially not in conditions accompanied by both severe thyroid dysfunction and systemic illness or pregnancy, where early diagnosis is essential. Moreover, even the uncompromised reference interval for TSH varies significantly by age, sex, hour of day, and ethnicity (400).

The endocrine features of TACITUS share overlapping elements with all of the following diseases, hypothyroidism (low-T3 concentration and, in chronic illness, reduced T4 concentration, and even elevated TSH in the recovery phase), hyperthyroidism (transiently increased FT4 levels and occasionally low TSH concentrations) and hypopituitarism (thyrotropic adaptation with low TSH levels despite low or normal FT4 concentrations) (73). This may present a huge challenge for differential diagnosis $(24,35)$. For instance, the combination of reduced TSH level and normal or even slightly increased FT4 concentration, which arises from markedly different half-lives of TSH and T4 in transitional periods of thyrotropic adaptation, may be confused with subclinical or overt hyperthyroidism (71). The situation is even more complex as the clinical spectrum of numerous severe diseases shares phenotypical features with hypothyroidism or thyrotoxicosis, respectively (72). As an example, sepsis is usually associated with fever and hyperdynamic circulation including tachycardia and peripheral vasodilatation, which are also characteristic for thyroid storm. Conversely, myxedema coma is marked by impaired vigilance, hypothermia, hypercapnia, and bradycardia, and it is therefore difficult to differentiate from critical non-thyroidal illnesses. Even subclinical hyperthyroidism may pose a risk to patients, especially to those, who are required to receive a high iodine load, e.g., in form of amiodarone or iodinated radiocontrast agents-procedures that are frequently necessary in the critically ill.

It is therefore both essential and difficult to distinguish TACITUS from diseases that are accompanied by decreased TSH levels, e.g., thyrotoxicosis and hypopituitarism. If FT3 and FT4 are both elevated or at least in the upper quintile of the respective reference ranges the diagnosis of thyrotoxicosis is straightforward. The differential diagnosis between TACITUS and subtle forms of subclinical hyperthyroidism or hypopituitarism may be more difficult, especially if an isolated thyrotropic dysfunction is present. A history of prior symptoms and signs of pituitary dysfunction may be helpful. It is also useful to evaluate the function of the corticotropic axis in patients with critical illness and possible
TACITUS. In case of dysfunction treatment with glucocorticoids should be commenced prior to thyroid hormone substitution.

Hypothyroidism associates mostly with elevated TSH levels. Positive antithyroid antibodies support the diagnosis of Hashimoto thyroiditis, however without proving the diagnosis of hypothyroidism and in most cases with significant delay.

Thyroid dysfunction induced by amiodarone therapy may lead to laboratory findings similar to TACITUS. Medical and drug history may help to approach the right diagnosis. Differential diagnosis is more complex, if typical amiodarone-induced changes of thyroid function are to be distinguished from amiodarone-induced thyrotoxicosis (e.g., in tachyarrhythmia), since in both cases FT4 concentrations may be elevated (by impaired deiodination under amiodarone or by hypersecretion of thyroxine, respectively).

Today, most intensive care units are equipped with ultrasound devices. Therefore, thyroid ultrasonography may be used as an inexpensive and non-invasive method to visualize size and internal structure of the thyroid gland. Thyroid enlargement, the presence of nodules (especially of TIRADS class 2 and colloid types 2 and 3 ) or diffuse hyperperfusion of the thyroid are indicative of hyperthyroidism.

Challenges in the assessment of thyroid function during pregnancy result from the normal gestational changes in thyroid activity and increased prevalence of conditions that cause hyperthyroidism in pregnancy (401). Additional uncertainty arises from an ongoing controversy, if levels of total (264) or free thyroid hormones $(401,402)$, measured either via immunoassays (403) or LC/tandem mass spectrometry (404), are the preferred targets for diagnostic interpretation $(248,405)$. There is no doubt, however, that laboratory investigations must always be accompanied by careful clinical evaluation of the patient's symptoms and history (401). Some professional guidelines suggested trimester-specific reference intervals for the concentrations of TSH and peripheral thyroid hormones $(248,264,406)$, while the recent guideline of the American Thyroid Association recommended elevating the upper limit of the reference range back to $4 \mathrm{mIU} / \mathrm{L}$ (264). Considering the significant differences among guidelines and the conflicting results of clinical trials critical questions still remain unanswered.

Calculating model-based structure parameters of thyroid homeostasis may be helpful in differential diagnosis (407). Recent studies have used mathematical models for diagnosis and prognosis of thyroid disorders, such as Hashimoto thyroiditis and Graves' disease $(408,409)$. Multiple studies showed total step-up deiodinase activity (SPINA-GD) to be significantly reduced in subjects affected by NTIS $(61,299-301)$. In patients with heart disease, SPINA-GD negatively correlated to age, atrial conduction time, and concentrations of B-type natriuretic peptide as well as 3,5-diiodothyronine (3,5-T2), and it predicted atrial fibrillation after cardiac surgery (61). In a study with 219 obese patients SPINA-GT, an estimate of thyroid's secretory capacity, assisted in identifying subjects with mild secretory insufficiency of the thyroid (410). In chronic renal failure, SPINA-GT correlated to creatinine clearance, suggesting toxic effects of azotemia on thyroid function (411). Calculating the ratios of total to free T4 (TT4/FT4) $(300,301)$ and of total to free T3 (TT3/FT3) (300) may be helpful to screen for impaired plasma protein binding of 
thyroid hormones in NTIS. Jostel's TSH index, a measure for thyrotropic anterior pituitary function (412), is decreased in patients with central adaptation in TACITUS syndrome (299). Despite accumulating evidence for the use of structure parameters in NTIS, their diagnostic utility is still insufficiently evaluated, and they have not been studied in other situations of thyroid allostasis including starvation, pregnancy, and psychiatric diseases. They have emerged, however, as valuable tools for clinical research $(19-22,24,92,94,407)$.

\section{TREATMENT OF LOW-T3 SYNDROME IN TACITUS-AN OPEN QUESTION}

As noted above, low-T3 syndrome and other components of NTIS correlate to severity of disease and independently predict the outcome of affected patients (54, 60, 64-66, 413-416). Guided by the idea that NTIS represents a form of illness-mediated hypothyroidism, it was suggested to treat the condition with levothyroxine (L-T4) or liothyronine (L-T3) with the expectation to improve the prognosis of critically ill patients $(39,70)$.

In fact certain surrogate markers, e.g., hemodynamic parameters and other markers of cardiovascular function, were demonstrated to improve after initiation of treatment with L-T3 $(417,418)$. With one exception of preterm infants (419) hard endpoints including survival could not be ameliorated by thyroid hormone administration $(25,170,420,421)$. In contrary, some studies observed even detrimental effects of therapy (25).

IL6-induced oxidative stress decreases the catalytic activity of D1 and D2. Selenium supplementation failed to demonstrate a beneficial effect on NTIS, although it improves critical intracellular antioxidant functions, particularly of selenoproteins (115). By providing bacteriotoxic iodine atoms, increased step-down deiodination due to stimulated D3 activity might be beneficial by defending against bacterial infections (55).

Several studies have demonstrated that treatment of the underlying disease can aid in the resolution of NTIS $(422,423)$.

In conclusion, universal substitution therapy cannot currently be recommended in TACITUS (424). Vastly insufficient diagnostic methods, as noted above, hinder the development of valid laboratory-based decision criteria that would help to safely identify critically ill patients with mild hypothyroidism. Diagnosis of myxedema coma therefore still relies on score systems, which either incorporate TSH and FT4 concentrations among other parameters $(425,426)$ or completely renounce the use of hormone measurements $(426,427)$.

\section{CONCLUSION}

The hypothalamus-pituitary-thyroid feedback control mechanism is a dynamic adaptive system. In resting equilibrium conditions of healthy adults the behavior of all elements involved is sufficiently stable to be diagnostically interpretable. This changes dramatically in straining situations such as starvation, exhaustion, or nonthyroidal illness. In the latter situations requirements of energy, oxygen or glutathione exceed supply, prompting the control loop to switch to a different operating mode that helps to adjust consumption to available resources. This type of allostatic response is termed type 1 and it is marked by low-T3 syndrome, reduced plasma protein binding of thyroid hormones, thyrotropic adaptation, and high concentrations of rT3. A similar constellation is observed during the fetal life. An inverted response pattern is seen in cases of predictive adaptation marked by type 2 allostatic load (including obesity, endurance training, adaptation to cold and post-traumatic stress disease). Here, concentrations of TSH, FT3, and TT3 are elevated, as is the plasma protein binding of thyroid hormones. A partly similar pattern to type 2 allostasis is seen in pregnancy.

Is thyroid allostasis beneficial or harmful? Perhaps an answer can be found in the very extremes of thyroid function, thyroid storm and myxedema coma. Although both diseases are located in opposing edges of the functional spectrum, they share a special kind of interaction between dysregulation of thyroid homeostasis and increased sensitivity of the organism to altered thyroid hormone signaling. They also have a pathophysiological pattern in common: the preexisting thyroid dysfunction may remain oligosymptomatic and undiscovered for years, yet an unspecific trigger (e.g., infection, apoplexy, or myocardial infarction) may ignite a complex causal network that results in a life-threatening crisis $(72,426)$. Thyroid storm is a form of insufficient adaptation, since thyrotoxicosis prevents the development of TACITUS in cases of critical illness. On the other hand, myxedema coma represents a form of overcompensation, which is marked by a massive amplification of hypothyroidism by the development of NTIS in severe disease. Both forms of thyroid crisis are life threatening: thyroid storm by insufficient allostasis and myxedema coma by allostatic overload. These examples illustrate the Janus-faced character of allostasis: although lifesaving in many cases it may occasionally threaten survival through the burden of allostatic load.

Differential diagnosis of type 1 and type 2 allostasis from peripheral or central thyroid dysfunction may be difficult, the more as physiological reactions of the feedback loop overlap with non-homeostatic mechanisms including drug effects, preanalytical factors and assay flaws in critical illness (Figure 1).

In an allostatic context correct interpretation of thyroid function cannot be based on simple diagnostic rules or laboratory tests. Rather it requires a deep understanding of physiology and a comprehensive diagnostic strategy that integrates the patient's history, clinical parameters, and laboratory findings. Developing and validating reliable algorithms that support the required level of integration is a fundamental task for future thyroid research.

\section{AUTHOR CONTRIBUTIONS}

AC, AA, JD, RH, and JM made the literature research and wrote the manuscript. BD wrote the part of the manuscript thyroid in psychiatric diseases. AU wrote the part of manuscript concerning thyroid and amiodarone. $\mathrm{HK}$ and $\mathrm{SH}$ critically read and revised the manuscript. All the authors have read and approved the manuscript.

\section{FUNDING}

Writing of this review article did not receive any specific grant from any funding agency in the public, commercial, or not-forprofit sector. We acknowledge support by the DFG Open Access Publication Funds of the Ruhr-Universität Bochum. 


\section{REFERENCES}

1. Garber JR, Cobin RH, Gharib H, Hennessey JV, Klein I, Mechanick JI, et al. Clinical practice guidelines for hypothyroidism in adults: cosponsored by the American Association of Clinical Endocrinologists and the American Thyroid Association. Endocr Pract (2012) 18(6):988-1028. doi:10.4158/EP12280.GL

2. Brenta G, Vaisman M, Sgarbi JA, Bergoglio LM, Andrada NC, Bravo PP, et al. Clinical practice guidelines for the management of hypothyroidism. Arq Bras Endocrinol Metabol (2013) 57(4):265-91. doi:10.1590/S000427302013000400003

3. 日本甲状腺学会 [Japan Thyroid Association]. Guidelines | Japan Thyroid Association Tokyo: JTA. (2010). Available from: http://www.japanthyroid.jp/en/guidelines.html or archived from https://web.archive.org/ web/20170328073456

4. Biondi B, Bartalena L, Cooper DS, Hegedus L, Laurberg P, Kahaly GJ. The 2015 European Thyroid Association guidelines on diagnosis and treatment of endogenous subclinical hyperthyroidism. Eur Thyroid J (2015) 4(3):149-63. doi:10.1159/000438750

5. Chaker L, Bianco AC, Jonklaas J, Peeters RP. Hypothyroidism. Lancet (2017). doi:10.1016/S0140-6736(17)30703-1

6. Ross DS, Burch HB, Cooper DS, Greenlee MC, Laurberg P, Maia AL, et al. 2016 American Thyroid Association guidelines for diagnosis and management of hyperthyroidism and other causes of thyrotoxicosis. Thyroid (2016) 26(10):1343-421. doi:10.1089/thy.2016.0229

7. Baloch Z, Carayon P, Conte-Devolx B, Demers LM, Feldt-Rasmussen U, Henry JF, et al. Laboratory medicine practice guidelines. Laboratory support for the diagnosis and monitoring of thyroid disease. Thyroid (2003) 13(1):3-126. doi:10.1089/105072503321086962

8. Cohen JL. Thyroid-stimulation hormone and its disorders. In: Becker KL, editor. Principles and Practice of Endocrinology and Metabolism. Philadelphia, PA: J. B. Lippincott Company (1990). p. 144-52.

9. Jonklaas J, Soldin SJ. Tandem mass spectrometry as a novel tool for elucidating pituitary-thyroid relationships. Thyroid (2008) 18(12):1303-11. doi:10.1089/ thy. 2008.0155

10. Reichlin S, Utiger RD. Regulation of the pituitary-thyroid axis in man: relationship of TSH concentration to concentration of free and total thyroxine in plasma. J Clin Endocrinol Metab (1967) 27(2):251-5. doi:10.1210/ jcem-27-2-251

11. Geigy D. Wissenschaftliche Tabellen. Basel: J. R. Geigy AG (1968).

12. Pilo A, Iervasi G, Vitek F, Ferdeghini M, Cazzuola F, Bianchi R. Thyroidal and peripheral production of 3,5,3'-triiodothyronine in humans by multicompartmental analysis. Am J Physiol (1990) 258(4 Pt 1):E715-26.

13. DiStefano JJ III. A model of the normal thyroid hormone glandular secretion mechanism. J Theor Biol (1969) 22(3):412-7. doi:10.1016/00225193(69)90013-7

14. DiStefano JJ III, Stear EB. On identification of hypothalamo-hypophysial control and feedback relationships with the thyroid gland. J Theor Biol (1968) 19(1):29-50. doi:10.1016/0022-5193(68)90003-9

15. Brabant G, Ranft U, Ocran K, Hesch RD, von zur Muhlen A. Thyrotropin an episodically secreted hormone. Acta Endocrinol (Copenh) (1986) 112(3): 315-22.

16. Brabant G, Ranft U, Ocran K, Hesch RD, von zur Muhlen A. Pulsatile pattern of thyrotropin-release in normal men. Clin Chim Acta (1986) 155(2):159-62. doi:10.1016/0009-8981(86)90277-9

17. Dietrich JW, Tesche A, Pickardt CR, Mitzdorf U. Thyrotropic feedback control: evidence for an additional ultrashort feedback loop from fractal analysis. Cybern Syst (2004) 35(4):315-31. doi:10.1080/01969720490443354

18. Hoermann R, Midgley JE, Larisch R, Dietrich JW. Homeostatic control of the thyroid-pituitary axis: perspectives for diagnosis and treatment. Front Endocrinol (2015) 6:177. doi:10.3389/fendo.2015.00177

19. Hoermann R, Midgley JE, Giacobino A, Eckl WA, Wahl HG, Dietrich JW, et al. Homeostatic equilibria between free thyroid hormones and pituitary thyrotropin are modulated by various influences including age, body mass index and treatment. Clin Endocrinol (Oxf) (2014) 81(6):907-15. doi:10.1111/ cen. 12527

20. Hoermann R, Midgley JE, Larisch R, Dietrich JW. Is pituitary TSH an adequate measure of thyroid hormone-controlled homoeostasis during thyroxine treatment? Eur J Endocrinol (2013) 168(2):271-80. doi:10.1530/EJE-12-0819
21. Midgley JE, Hoermann R, Larisch R, Dietrich JW. Physiological states and functional relation between thyrotropin and free thyroxine in thyroid health and disease: in vivo and in silico data suggest a hierarchical model. JClin Pathol (2013) 66(4):335-42. doi:10.1136/jclinpath-2012-201213

22. Midgley JE, Larisch R, Dietrich JW, Hoermann R. Variation in the biochemical response to L-thyroxine therapy and relationship with peripheral thyroid hormone conversion efficiency. Endocr Connect (2015) 4(4):196-205. doi:10.1530/EC-150056

23. Boelen A, Wiersinga WM, Fliers E. Fasting-induced changes in the hypothalamus-pituitary-thyroid axis. Thyroid (2008) 18(2):123-9. doi:10.1089/thy.2007.0253

24. Dietrich JW, Stachon A, Antic B, Klein HH, Hering S. The AQUA-FONTIS study: protocol of a multidisciplinary, cross-sectional and prospective longitudinal study for developing standardized diagnostics and classification of non-thyroidal illness syndrome. BMC Endocr Disord (2008) 8:13. doi:10.1186/1472-6823-8-13

25. Fliers E, Bianco AC, Langouche L, Boelen A. Thyroid function in critically ill patients. Lancet Diabetes Endocrinol (2015) 3(10):816-25. doi:10.1016/ S2213-8587(15)00225-9

26. Fliers E, Kalsbeek A, Boelen A. Beyond the fixed setpoint of the hypothalamuspituitary-thyroid axis. Eur J Endocrinol (2014) 171(5):R197-208. doi:10.1530/ EJE-14-0285

27. Hackney AC, Davis HC, Lane AR. Growth hormone-insulin-like growth factor axis, thyroid axis, prolactin, and exercise. Front Horm Res (2016) 47:1-11. doi:10.1159/000445147

28. Joffe RT, Levitt AJ. The Thyroid Axis and Psychiatric Illness. Washington, DC: American Psychiatric Press (1993). 339 p.

29. Morreale de Escobar G, Obregon MJ, Escobar del Rey F. Fetal and maternal thyroid hormones. Horm Res (1987) 26(1-4):12-27.

30. Reichlin S, Martin JB, Mitnick M, Boshans RL, Grimm Y, Bollinger J, et al. The hypothalamus in pituitary-thyroid regulation. Recent Prog Horm Res (1972) 28:229-86.

31. Sterling K, Lazarus JH. The thyroid and its control. Annu Rev Physiol (1977) 39:349-71. doi:10.1146/annurev.ph.39.030177.002025

32. Larsen PR. Thyroid-pituitary interaction: feedback regulation of thyrotropin secretion by thyroid hormones. N Engl J Med (1982) 306(1):23-32. doi:10.1056/NEJM198201073060107

33. Sam S, Frohman LA. Normal physiology of hypothalamic pituitary regulation. Endocrinol Metab Clin North Am (2008) 37(1):1-22, vii. doi:10.1016/j. ecl.2007.10.007

34. Andersen S, Pedersen KM, Bruun NH, Laurberg P. Narrow individual variations in serum $\mathrm{T}(4)$ and $\mathrm{T}(3)$ in normal subjects: a clue to the understanding of subclinical thyroid disease. J Clin Endocrinol Metab (2002) 87(3):1068-72. doi:10.1210/jcem.87.3.8165

35. Dietrich JW, Landgrafe G, Fotiadou EH. TSH and thyrotropic agonists: key actors in thyroid homeostasis. J Thyroid Res (2012) 2012:351864. doi:10.1155/ 2012/351864

36. Goede SL, Leow MK, Smit JW, Dietrich JW. A novel minimal mathematical model of the hypothalamus-pituitary-thyroid axis validated for individualized clinical applications. Math Biosci (2014) 249:1-7. doi:10.1016/j.mbs. 2014.01.001

37. Goede SL, Leow MK, Smit JW, Klein HH, Dietrich JW. Hypothalamuspituitary-thyroid feedback control: implications of mathematical modeling and consequences for thyrotropin (TSH) and free thyroxine (FT4) reference ranges. Bull Math Biol (2014) 76(6):1270-87. doi:10.1007/s11538-014-9955-5

38. Hoermann R, Larisch R, Dietrich JW, Midgley JE. Derivation of a multivariate reference range for pituitary thyrotropin and thyroid hormones: diagnostic efficiency compared with conventional single-reference method. Eur J Endocrinol (2016) 174(6):735-43. doi:10.1530/EJE-16-0031

39. De Groot LJ. Non-thyroidal illness syndrome is a manifestation of hypothalamic-pituitary dysfunction, and in view of current evidence, should be treated with appropriate replacement therapies. Crit Care Clin (2006) 22(1):57-86, vi. doi:10.1016/j.ccc.2005.10.001

40. Van den Berghe G. Dynamic neuroendocrine responses to critical illness. Front Neuroendocrinol (2002) 23(4):370-91. doi:10.1016/S00913022(02)00006-7

41. Wajner SM, Maia AL. New insights toward the acute non-thyroidal illness syndrome. Front Endocrinol (2012) 3:8. doi:10.3389/fendo.2012.00008 
42. Hoermann R, Cheung AS, Milne M, Grossmann M. Hypothalamic-pituitarythyroid axis set point alterations are associated with body composition in androgen deprived men. J Endocr Soc (2017). doi:10.1210/js.2017-00057

43. Boelen A, Kwakkel J, Thijssen-Timmer DC, Alkemade A, Fliers E, Wiersinga WM. Simultaneous changes in central and peripheral components of the hypothalamus-pituitary-thyroid axis in lipopolysaccharide-induced acute illness in mice. J Endocrinol (2004) 182(2):315-23. doi:10.1677/joe.0.1820315

44. Chopra IJ. Nonthyroidal illness syndrome or euthyroid sick syndrome? Endocr Pract (1996) 2(1):45-52. doi:10.4158/EP.2.1.45

45. Moka D. Laborchemisch pathologische Schilddrüsenparameter bei Patienten ohne Schilddrüsenerkrankung. Der Nuklearmediziner (2016) 39:98-103. doi:10.1055/s-0042-106925

46. Terjung RL, Tipton CM. Plasma thyroxine and thyroid-stimulating hormone levels during submaximal exercise in humans. Am J Physiol (1971) 220(6):1840-5.

47. Rothenbuchner G, Loos U, Kiessling WR, Birk J, Pfeiffer EF. The influence of total starvation on the pituitary-thyroid-axis in obese individuals. Acta Endocrinol Suppl (Copenh) (1973) 173:144.

48. Carter JN, Eastman CJ, Corcoran JM, Lazarus L. Effect of severe, chronic illness on thyroid function. Lancet (1974) 2(7887):971-4. doi:10.1016/ S0140-6736(74)92070-4

49. Portnay GI, O’Brian JT, Bush J, Vagenakis AG, Azizi F, Arky RA, et al. The effect of starvation on the concentration and binding of thyroxine and triiodothyronine in serum and on the response to TRH. JClin Endocrinol Metab (1974) 39(1):191-4. doi:10.1210/jcem-39-1-191

50. Balsam A, Leppo LE. Effect of physical training on the metabolism of thyroid hormones in man. J Appl Physiol (1975) 38(2):212-5.

51. Bermudez F, Surks MI, Oppenheimer JH. High incidence of decreased serum triiodothyronine concentration in patients with nonthyroidal disease. J Clin Endocrinol Metab (1975) 41(1):27-40. doi:10.1210/jcem-41-1-27

52. Carter JN, Corcoran JM, Eastman CJ, Lazarus L, O'Halloran M. Serum T3 and T4 levels in sick children. Pediatrics (1976) 58(5):776.

53. Koulouri O, Moran C, Halsall D, Chatterjee K, Gurnell M. Pitfalls in the measurement and interpretation of thyroid function tests. Best Pract Res (2013) 27(6):745-62. doi:10.1016/j.beem.2013.10.003

54. Tognini S, Marchini F, Dardano A, Polini A, Ferdeghini M, Castiglioni M, et al. Non-thyroidal illness syndrome and short-term survival in a hospitalised older population. Age Ageing (2010) 39(1):46-50. doi:10.1093/ageing/ afp 197

55. Boelen A, Kwakkel J, Fliers E. Beyond low plasma T3: local thyroid hormone metabolism during inflammation and infection. Endocr Rev (2011) 32(5):670-93. doi:10.1210/er.2011-0007

56. Van den Berghe G. Non-thyroidal illness in the ICU: a syndrome with different faces. Thyroid (2014) 24(10):1456-65. doi:10.1089/thy.2014.0201

57. Schifferdecker E, Hering S, Bohm BO, Forster H, Althoff PH, Schulz F, et al. Thyroid hormone binding inhibition in critically ill patients - who is the inhibitor? Exp Clin Endocrinol (1990) 95(2):267-70. doi:10.1055/s-0029-1210963

58. Schifferdecker E, Hering S, Forster H, Althoff PH, Asskali F, Schulz F, et al. Freie Fettsäuren im Serum bei krisenhaften Erkrankungen: Spielen sie eine Rolle bei der Proteinbindung von Schilddrüsenhormonen? [Free fatty acids in the serum in critical diseases: do they play a role in the protein binding of thyroid hormones?]. Klin Wochenschr (1988) 66(7):308-13. doi:10.1007/ BF01727518

59. Fliers E, Guldenaar SE, Wiersinga WM, Swaab DF. Decreased hypothalamic thyrotropin-releasing hormone gene expression in patients with nonthyroidal illness. JClin Endocrinol Metab (1997) 82(12):4032-6. doi:10.1210/ jcem.82.12.4404

60. Plikat K, Langgartner J, Buettner R, Bollheimer LC, Woenckhaus U, Scholmerich J, et al. Frequency and outcome of patients with nonthyroidal illness syndrome in a medical intensive care unit. Metabolism (2007) 56(2):239-44. doi:10.1016/j.metabol.2006.09.020

61. Dietrich JW, Muller P, Schiedat F, Schlomicher M, Strauch J, Chatzitomaris A, et al. Nonthyroidal illness syndrome in cardiac illness involves elevated concentrations of 3,5-diiodothyronine and correlates with atrial remodeling. Eur Thyroid J (2015) 4(2):129-37. doi:10.1159/000381543

62. Pinna G, Meinhold H, Hiedra L, Thoma R, Hoell T, Graf KJ, et al. Elevated 3,5-diiodothyronine concentrations in the sera of patients with nonthyroidal illnesses and brain tumors. J Clin Endocrinol Metab (1997) 82(5):1535-42. doi:10.1210/jcem.82.5.3939
63. Langouche L, Lehmphul I, Vander Perre S, Koehrle J, Van den Berghe G. Circulating 3-T1AM and 3,5-T2 in critically ill patients: a cross-sectional observational study. Thyroid (2016) 26(12):1674-80. doi:10.1089/ thy.2016.0214

64. Iervasi G, Pingitore A, Landi P, Raciti M, Ripoli A, Scarlattini M, et al. Low-T3 syndrome: a strong prognostic predictor of death in patients with heart disease. Circulation (2003) 107(5):708-13. doi:10.1161/01. CIR.0000048124.64204.3F

65. Scoscia E, Baglioni S, Eslami A, Iervasi G, Monti S, Todisco T. Low triiodothyronine (T3) state: a predictor of outcome in respiratory failure? Results of a clinical pilot study. Eur J Endocrinol (2004) 151(5):557-60. doi:10.1530/ eje. 0.1510557

66. Wang B, Liu S, Li L, Yao Q, Song R, Shao X, et al. Non-thyroidal illness syndrome in patients with cardiovascular diseases: a systematic review and meta-analysis. Int J Cardiol (2017) 226:1-10. doi:10.1016/j. ijcard.2016.10.039

67. Brent GA, Hershman JM. Thyroxine therapy in patients with severe nonthyroidal illnesses and low serum thyroxine concentration. JClin Endocrinol Metab (1986) 63(1):1-8. doi:10.1210/jcem-63-1-1

68. Caplan RH. Comment on dangerous dogmas in medicine: the nonthyroidal illness syndrome. J Clin Endocrinol Metab (1999) 84(6):2261-2; author reply 2-3. doi:10.1210/jcem.84.6.5809-6

69. Carter JN, Eastman CJ, Corcoran JM, Lazarus L. Effects of triiodothyronine administration in patients with chronic renal failure. Aust N Z J Med (1977) 7(6):612-6. doi:10.1111/j.1445-5994.1977.tb02317.x

70. De Groot LJ. Dangerous dogmas in medicine: the nonthyroidal illness syndrome. JClin Endocrinol Metab (1999) 84(1):151-64. doi:10.1210/ jcem.84.1.5364

71. Cho EA, Yoon JH, Kim HK, Kang HC. A case of masked toxic adenoma in a patient with non-thyroidal illness. BMC Endocr Disord (2014) 14:1. doi:10.1186/1472-6823-14-1

72. Dietrich JW. Thyreotoxische Krise [Thyroid storm]. Med Klin Intensivmed Notfmed (2012) 107(6):448-53. doi:10.1007/s00063-012-0113-2

73. Pantalone KM, Nasr C. Approach to a low TSH level: patience is a virtue. Cleve Clin J Med (2010) 77(11):803-11. doi:10.3949/ccjm.77a.10056

74. Irvine CHG. Effect of exercise on thyroxine degradation in athletes and non-athletes. JClin Endocrinol Metab (1968) 28:942-8. doi:10.1210/ jcem-28-7-942

75. Irvine $\mathrm{CH}$. Thyroxine secretion rate in the horse in various physiological states. J Endocrinol (1967) 39(3):313-20. doi:10.1677/joe.0.0390313

76. Harland WA, Orr JS. A model of thyroxine metabolism based on the effects of environmental temperature. J Physiol (1969) 200(2):297-310. doi:10.1113/ jphysiol.1969.sp008694

77. Carter JN, Eastmen CJ, Corcoran JM, Lazarus L. Inhibition of conversion of thyroxine to triiodothyronine in patients with severe chronic illness. Clin Endocrinol (Oxf) (1976) 5(6):587-94. doi:10.1111/j.1365-2265.1976.tb03861.x

78. Augee ML, Raison JK, Hulbert AJ. Seasonal changes in membrane lipid transitions and thyroid function in the hedgehog. Am J Physiol (1979) 236(6):E589-93.

79. Stryjek-Kaminska D, Loos U, Maier V, Ditschuneit HH, Pfeiffer EF. Seasonal variations of glucose and triiodothyronine concentrations in serum of carp (Cyprinus carpio L). Horm Metab Res (1988) 20(12):727-9. doi:10.1055/ s-2007-1010932

80. Davis PJ, Goglia F, Leonard JL. Nongenomic actions of thyroid hormone. Nat Rev Endocrinol (2016) 12(2):111-21. doi:10.1038/nrendo.2015.205

81. Dietrich JW. In: Schardt F, editor. Der Hypophysen-Schilddrüsen-Regelkreis. Entwicklung und klinische Anwendung eines nichtlinearen Modells. Berlin: Logos-Verlag (2002). $188 \mathrm{p}$.

82. Prummel MF, Brokken LJ, Wiersinga WM. Ultra short-loop feedback control of thyrotropin secretion. Thyroid (2004) 14(10):825-9. doi:10.1089/ thy.2004.14.825

83. Lechan RM, Fekete C. Feedback regulation of thyrotropin-releasing hormone (TRH): mechanisms for the non-thyroidal illness syndrome. J Endocrinol Invest (2004) 27(6 Suppl):105-19.

84. Lechan RM, Fekete C. Central mechanisms for thyroid hormone regulation. Am J Psychiatry (2006) 163(9):1492. doi:10.1176/ajp.2006.163.9.1492

85. Erickson VJ, Cavalieri RR, Rosenberg LL. Thyroxine-5'-deiodinase of rat thyroid, but not that of liver, is dependent on thyrotropin. Endocrinology (1982) 111(2):434-40. doi:10.1210/endo-111-2-434 
86. Larsen PR, Berry MJ. Nutritional and hormonal regulation of thyroid hormone deiodinases. Аnnu Rev Nutr (1995) 15:323-52. doi:10.1146/annurev. nu.15.070195.001543

87. Maia AL, Goemann IM, Meyer EL, Wajner SM. Deiodinases: the balance of thyroid hormone: type 1 iodothyronine deiodinase in human physiology and disease. J Endocrinol (2011) 209(3):283-97. doi:10.1530/JOE-10-0481

88. Murakami M, Araki O, Hosoi Y, Kamiya Y, Morimura T, Ogiwara T, et al. Expression and regulation of type II iodothyronine deiodinase in human thyroid gland. Endocrinology (2001) 142(7):2961-7. doi:10.1210/ endo.142.7.8280

89. Schweizer U, Weitzel JM, Schomburg L. Think globally: act locally. New insights into the local regulation of thyroid hormone availability challenge long accepted dogmas. Mol Cell Endocrinol (2008) 289(1-2):1-9. doi:10.1016/j.mce.2008.04.007

90. Köhrle J. Thyrotropin (TSH) action on thyroid hormone deiodination and secretion: one aspect of thyrotropin regulation of thyroid cell biology. Horm Metab Res Suppl (1990) 23:18-28.

91. Dietrich JW, Midgley JE, Larisch R, Hoermann R. Of rats and men: thyroid homeostasis in rodents and human beings. Lancet Diabetes Endocrinol (2015) 3(12):932-3. doi:10.1016/S2213-8587(15)00421-0

92. Hoermann R, Midgley JE, Larisch R, Dietrich JW. Integration of peripheral and glandular regulation of triiodothyronine production by thyrotropin in untreated and thyroxine-treated subjects. Horm Metab Res (2015) 47(9):674-80. doi:10.1055/s-0034-1398616

93. Hoermann R, Midgley JE, Larisch R, Dietrich JW. Mini review: relational stability in the expression of normality, variation and control of thyroid function. Front Endocrinol (2016) 7:142. doi:10.3389/fendo.2016.00142

94. Hoermann R, Midgley JE, Larisch R, Dietrich JW. Relational stability of thyroid hormones in euthyroid subjects and patients with autoimmune thyroid disease. Eur Thyroid J (2016) 5(3):171-9. doi:10.1159/000447967

95. Joseph-Bravo P, Jaimes-Hoy L, Charli JL. Advances in TRH signaling. Rev Endocr Metab Disord (2016) 17(4):545-58. doi:10.1007/s11154016-9375-y

96. Arrojo E Drigo R, Fonseca TL, Werneck-de-Castro JP, Bianco AC. Role of the type 2 iodothyronine deiodinase (D2) in the control of thyroid hormone signaling. Biochim Biophys Acta (2013) 1830(7):3956-64. doi:10.1016/j. bbagen.2012.08.019

97. Deli L, Wittmann G, Kallo I, Lechan RM, Watanabe M, Liposits Z, et al. Type 1 cannabinoid receptor-containing axons innervate hypophysiotropic thyrotropin-releasing hormone-synthesizing neurons. Endocrinology (2009) 150(1):98-103. doi:10.1210/en.2008-0330

98. Fekete C, Lechan RM. Central regulation of hypothalamic-pituitary-thyroid axis under physiological and pathophysiological conditions. Endocr Rev (2014) 35(2):159-94. doi:10.1210/er.2013-1087

99. Joseph-Bravo P. Hypophysiotropic thyrotropin-releasing hormone neurons as transducers of energy homeostasis. Endocrinology (2004) 145(11):4813-5. doi:10.1210/en.2004-0979

100. Sterling P, Eyer J. Allostasis: a new paradigm to explain arousal pathology. In: Fisher S, Reason JT, editors. Handbook of Life Stress, Cognition, and Health. Chichester, NY: Wiley (1988). p. 629-49.

101. McEwen BS, Wingfield JC. The concept of allostasis in biology and biomedicine. Horm Behav (2003) 43(1):2-15. doi:10.1016/S0018-506X(02)00024-7

102. Chrousos GP. Stress and disorders of the stress system. Nat Rev Endocrinol (2009) 5(7):374-81. doi:10.1038/nrendo.2009.106

103. Koob GF, Le Moal M. Drug addiction, dysregulation of reward, and allostasis. Neuropsychopharmacology (2001) 24(2):97-129. doi:10.1016/ S0893-133X(00)00195-0

104. McEwen BS, Nasveld P, Palmer M, Anderson R. Allostatic Load - A Review of the Literature. Canberra: Department of Veterans' Affairs (2012). Contract No. P02297.

105. Goldstein DS. Computer models of stress, allostasis, and acute and chronic diseases. Ann N Y Acad Sci (2008) 1148:223-31. doi:10.1196/annals.1410.061

106. Sterling P. Principles of allostasis: optimal design, predictive regulation, pathophysiology and rational therapeutics. In: Schulkin J, editor. Allostasis, Homeostasis, and the Costs of Physiological Adaptation. Cambridge: Cambridge University Press (2004). p. 17-64.

107. Karatsoreos IN, McEwen BS. Psychobiological allostasis: resistance, resilience and vulnerability. Trends $\operatorname{Cog}$ Sci (2011) 15(12):576-84. doi:10.1016/j. tics.2011.10.005
108. Iwase K, Hummel BC, Walfish PG. Rat hepatic and renal 5'-deiodination of rT3 during fasting: supportive role of intermediate Mr cytosolic nonglutathione thiol cofactor and NADPH. Metabolism (1989) 38(3):230-7. doi:10.1016/0026-0495(89)90080-2

109. Jolin T, Morreale de Escobar G. Deiodination of L-thyroxine and its activity on the oxidation in vitro of reduced nicotinamide-adenine dinucleotide by peroxidase plus hydrogen peroxide. Bioechem J (1971) 125:869-78. doi:10.1042/bj1250869

110. Sato K, Mimura H, Wakai K, Tomori N, Tsushima T, Shizume K. Modulating effect of glutathione disulfide on thyroxine-5' -deiodination by rat hepatocytes in primary culture: effect of glucose. Endocrinology (1983) 113(3):878-86. doi:10.1210/endo-113-3-878

111. Fontenelle LC, Feitosa MM, Severo JS, Freitas TE, Morais JB, Torres-Leal FL, et al. Thyroid function in human obesity: underlying mechanisms. Horm Metab Res (2016) 48(12):787-94. doi:10.1055/s-0042-121421

112. Friedman MJ. Allostatic versus empirical perspectives on pharmacotherapy for PTSD. In: Wilson JP, Friedman MJ, Lindy JD, editors. Treating Psychological Trauma and PTSD. New York, London: The Guilford Press (2004). p. 94-124.

113. Mancini A, Di Segni C, Raimondo S, Olivieri G, Silvestrini A, Meucci E, et al. Thyroid hormones, oxidative stress, and inflammation. Mediators Inflamm (2016) 2016:6757154. doi:10.1155/2016/6757154

114. Libermann TA, Baltimore D. Activation of interleukin-6 gene expression through the NF-kappa B transcription factor. Mol Cell Biol (1990) 10(5):2327-34. doi:10.1128/MCB.10.5.2327

115. Wajner SM, Rohenkohl HC, Serrano T, Maia AL. Sodium selenite supplementation does not fully restore oxidative stress-induced deiodinase dysfunction: implications for the nonthyroidal illness syndrome. Redox Biol (2015) 6:436-45. doi:10.1016/j.redox.2015.09.002

116. Bianco AC, Kim BW. Deiodinases: implications of the local control of thyroid hormone action. J Clin Invest (2006) 116(10):2571-9. doi:10.1172/JCI29812

117. Lartey LJ, Werneck-de-Castro JP, O-Sullivan I, Unterman TG, Bianco AC. Coupling between nutrient availability and thyroid hormone activation. J Biol Chem (2015) 290(51):30551-61. doi:10.1074/jbc.M115.665505

118. Singh BK, Sinha RA, Zhou J, Tripathi M, Ohba K, Wang ME, et al. Hepatic FOXO1 target genes are co-regulated by thyroid Hormone via RICTOR protein deacetylation and MTORC2-AKT protein inhibition. J Biol Chem (2016) 291(1):198-214. doi:10.1074/jbc.M115.668673

119. Heemstra KA, Soeters MR, Fliers E, Serlie MJ, Burggraaf J, van Doorn MB, et al. Type 2 iodothyronine deiodinase in skeletal muscle: effects of hypothyroidism and fasting. JClin Endocrinol Metab (2009) 94(6):2144-50. doi:10.1210/jc.2008-2520

120. Elijah IE, Branski LK, Finnerty CC, Herndon DN. The GH/IGF-1 system in critical illness. Best Pract Res Clin Endocrinol Metab (2011) 25(5):759-67. doi:10.1016/j.beem.2011.06.002

121. Fekete C, Sarkar S, Christoffolete MA, Emerson CH, Bianco AC, Lechan RM. Bacterial lipopolysaccharide (LPS)-induced type 2 iodothyronine deiodinase (D2) activation in the mediobasal hypothalamus (MBH) is independent of the LPS-induced fall in serum thyroid hormone levels. Brain Res (2005) 1056(1):97-9. doi:10.1016/j.brainres.2005.07.021

122. Sanchez E, Singru PS, Fekete C, Lechan RM. Induction of type 2 iodothyronine deiodinase in the mediobasal hypothalamus by bacterial lipopolysaccharide: role of corticosterone. Endocrinology (2008) 149(5):2484-93. doi:10.1210/en.2007-1697

123. Carlin K, Carlin S. Possible etiology for euthyroid sick syndrome. Med Hypotheses (1993) 40(1):38-43. doi:10.1016/0306-9877(93)90194-U

124. Groeneweg S, Peeters RP, Visser TJ, Visser WE. Triiodothyroacetic acid in health and disease. J Endocrinol (2017). doi:10.1530/JOE-17-0113

125. Boelen A, Kwakkel J, Wiersinga WM, Fliers E. Chronic local inflammation in mice results in decreased TRH and type 3 deiodinase mRNA expression in the hypothalamic paraventricular nucleus independently of diminished food intake. J Endocrinol (2006) 191(3):707-14. doi:10.1677/ joe. 1.07056

126. Fekete C, Gereben B, Doleschall M, Harney JW, Dora JM, Bianco AC, et al. Lipopolysaccharide induces type 2 iodothyronine deiodinase in the mediobasal hypothalamus: implications for the nonthyroidal illness syndrome. Endocrinology (2004) 145(4):1649-55. doi:10.1210/en.2003-1439

127. Lechan RM, Fekete C. Role of thyroid hormone deiodination in the hypothalamus. Thyroid (2005) 15(8):883-97. doi:10.1089/thy.2005.15.883 
128. Dietrich JW. SimThyr. 4.0 ed. Fairfax, VA: sourceforge (1994-2016). RRID:SCR_014351.

129. Huang SA. Physiology and pathophysiology of type 3 deiodinase in humans. Thyroid (2005) 15(8):875-81. doi:10.1089/thy.2005.15.875

130. Casula S, Bianco AC. Thyroid hormone deiodinases and cancer. Front Endocrinol (2012) 3:74. doi:10.3389/fendo.2012.00074

131. Boelen A, van Beeren M, Vos X, Surovtseva O, Belegri E, Saaltink DJ, et al. Leptin administration restores the fasting-induced increase of hepatic type 3 deiodinase expression in mice. Thyroid (2012) 22(2):192-9. doi:10.1089/ thy.2011.0289

132. de Vries EM, van Beeren HC, Ackermans MT, Kalsbeek A, Fliers E, Boelen A. Differential effects of fasting vs food restriction on liver thyroid hormone metabolism in male rats. JEndocrinol (2014) 224(1):25-35. doi:10.1530/ JOE-14-0533

133. Peeters RP, Wouters PJ, Kaptein E, van Toor H, Visser TJ, Van den Berghe G. Reduced activation and increased inactivation of thyroid hormone in tissues of critically ill patients. JClin Endocrinol Metab (2003) 88(7):3202-11. doi:10.1210/jc.2002-022013

134. Harel G, Shamoun DS, Kane JP, Magner JA, Szabo M. Prolonged effects of tumor necrosis factor-alpha on anterior pituitary hormone release. Peptides (1995) 16(4):641-5. doi:10.1016/0196-9781(95)00019-G

135. Wassen FW, Moerings EP, Van Toor H, De Vrey EA, Hennemann G, Everts ME. Effects of interleukin-1 beta on thyrotropin secretion and thyroid hormone uptake in cultured rat anterior pituitary cells. Endocrinology (1996) 137(5):1591-8. doi:10.1210/endo.137.5.8612490

136. Rasmussen AK, Di Marco R, Diamant M, Feldt-Rasmussen U, Bendtzen K. Nitric oxide production is not involved in the effects of interleukin-1 beta on cAMP, thyroglobulin and interleukin-6 in TSH-stimulated human thyroid cells. Autoimmunity (1994) 19(4):239-45. doi:10.3109/08916939409071349

137. Yamashita S, Kimura H, Ashizawa K, Nagayama Y, Hirayu H, Izumi M, et al. Interleukin-1 inhibits thyrotrophin-induced human thyroglobulin gene expression. J Endocrinol (1989) 122(1):177-83. doi:10.1677/joe.0.1220177

138. Sutton AK, Pei H, Burnett KH, Myers MG Jr, Rhodes CJ, Olson DP. Control of food intake and energy expenditure by Nos1 neurons of the paraventricular hypothalamus. J Neurosci (2014) 34(46):15306-18. doi:10.1523/ JNEUROSCI.0226-14.2014

139. Swanson LW, Sawchenko PE. Paraventricular nucleus: a site for the integration of neuroendocrine and autonomic mechanisms. Neuroendocrinology (1980) 31(6):410-7. doi:10.1159/000123111

140. Lage R, Fernø J, Nogueiras R, Diéguez C, López M. Contribution of adaptive thermogenesis to the hypothalamic regulation of energy balance. Biochem $J$ (2016) 473:4063-82. doi:10.1042/BCJ20160012

141. Chiamolera MI, Wondisford FE. Minireview: thyrotropin-releasing hormone and the thyroid hormone feedback mechanism. Endocrinology (2009) 150(3):1091-6. doi:10.1210/en.2008-1795

142. Alkemade A, Friesema EC, Kalsbeek A, Swaab DF, Visser TJ, Fliers E. Expression of thyroid hormone transporters in the human hypothalamus. J Clin Endocrinol Metab (2011) 96(6):E967-71. doi:10.1210/jc.2010-2750

143. Alkemade A, Friesema EC, Unmehopa UA, Fabriek BO, Kuiper GG, Leonard JL, et al. Neuroanatomical pathways for thyroid hormone feedback in the human hypothalamus. J Clin Endocrinol Metab (2005) 90(7):4322-34. doi:10.1210/jc.2004-2567

144. Sanchez E, Vargas MA, Singru PS, Pascual I, Romero F, Fekete C, et al. Tanycyte pyroglutamyl peptidase II contributes to regulation of the hypothalamic-pituitary-thyroid axis through glial-axonal associations in the median eminence. Endocrinology (2009) 150(5):2283-91. doi:10.1210/en.2008-1643

145. Diano S, Leonard JL, Meli R, Esposito E, Schiavo L. Hypothalamic type II iodothyronine deiodinase: a light and electron microscopic study. Brain Res (2003) 976(1):130-4. doi:10.1016/S0006-8993(03)02692-1

146. Lechan RM, Fekete C. The TRH neuron: a hypothalamic integrator of energy metabolism. Prog Brain Res (2006) 153:209-35. doi:10.1016/ S0079-6123(06)53012-2

147. Arancibia S, Rage F, Astier H, Tapia-Arancibia L. Neuroendocrine and autonomous mechanisms underlying thermoregulation in cold environment. Neuroendocrinology (1996) 64(4):257-67. doi:10.1159/000127126

148. Arancibia S, Tapia-Arancibia L, Astier H, Assenmacher I. Physiological evidence for alpha 1 -adrenergic facilitatory control of the cold-induced TRH release in the rat, obtained by push-pull cannulation of the median eminence. Neurosci Lett (1989) 100(1-3):169-74. doi:10.1016/0304-3940(89)90679-4
149. Ishikawa K, Taniguchi Y, Inoue K, Kurosumi K, Suzuki M. Immunocytochemical delineation of thyrotrophic area: origin of thyrotropinreleasing hormone in the median eminence. Neuroendocrinology (1988) 47(5):384-8. doi: $10.1159 / 000124943$

150. Wittmann G, Liposits Z, Lechan RM, Fekete C. Medullary adrenergic neurons contribute to the cocaine- and amphetamine-regulated transcriptimmunoreactive innervation of thyrotropin-releasing hormone synthesizing neurons in the hypothalamic paraventricular nucleus. Brain Res (2004) 1006(1):1-7. doi:10.1016/j.brainres.2003.12.049

151. Legradi G, Emerson CH, Ahima RS, Flier JS, Lechan RM. Leptin prevents fasting-induced suppression of prothyrotropin-releasing hormone messenger ribonucleic acid in neurons of the hypothalamic paraventricular nucleus. Endocrinology (1997) 138(6):2569-76. doi:10.1210/ endo.138.6.5209

152. Mihaly E, Fekete C, Legradi G, Lechan RM. Hypothalamic dorsomedial nucleus neurons innervate thyrotropin-releasing hormone-synthesizing neurons in the paraventricular nucleus. Brain Res (2001) 891(1-2):20-31. doi:10.1016/S0006-8993(00)03094-8

153. Fekete C, Kelly J, Mihaly E, Sarkar S, Rand WM, Legradi G, et al. Neuropeptide $\mathrm{Y}$ has a central inhibitory action on the hypothalamicpituitary-thyroid axis. Endocrinology (2001) 142(6):2606-13. doi:10.1210/ endo.142.6.8207

154. Sarkar S, Lechan RM. Central administration of neuropeptide Y reduces alpha-melanocyte-stimulating hormone-induced cyclic adenosine 5'monophosphate response element binding protein (CREB) phosphorylation in pro-thyrotropin-releasing hormone neurons and increases CREB phosphorylation in corticotropin-releasing hormone neurons in the hypothalamic paraventricular nucleus. Endocrinology (2003) 144(1):281-91. doi:10.1210/en.2002-220675

155. Wittmann G, Liposits Z, Lechan RM, Fekete C. Medullary adrenergic neurons contribute to the neuropeptide Y-ergic innervation of hypophysiotropic thyrotropin-releasing hormone-synthesizing neurons in the rat. Neurosci Lett (2002) 324(1):69-73. doi:10.1016/S0304-3940(02)00165-9

156. Legradi G, Lechan RM. Agouti-related protein containing nerve terminals innervate thyrotropin-releasing hormone neurons in the hypothalamic paraventricular nucleus. Endocrinology (1999) 140(8):3643-52. doi:10.1210/ endo.140.8.6935

157. Joseph-Bravo P, Jaimes-Hoy L, Charli JL. Regulation of TRH neurons and energy homeostasis-related signals under stress. JEndocrinol (2015) 224(3):R139-59. doi:10.1530/JOE-14-0593

158. Vella KR, Ramadoss P, Lam FS, Harris JC, Ye FD, Same PD, et al. NPY and MC4R signaling regulate thyroid hormone levels during fasting through both central and peripheral pathways. Cell Metab (2011) 14(6):780-90. doi:10.1016/j.cmet.2011.10.009

159. Bartalena L, Robbins J. Variations in thyroid hormone transport proteins and their clinical implications. Thyroid (1992) 2(3):237-45. doi:10.1089/ thy.1992.2.237

160. Bartalena L, Farsetti A, Flink IL, Robbins J. Effects of interleukin-6 on the expression of thyroid hormone-binding protein genes in cultured human hepatoblastoma-derived (Hep G2) cells. Mol Endocrinol (1992) 6(6):935-42. doi:10.1210/me.6.6.935

161. Schussler GC. The thyroxine-binding proteins. Thyroid (2000) 10(2):141-9. doi:10.1089/thy.2000.10.141

162. Schoenemann PT, Yesair DW, Coffey JJ, Bullock FJ. Pharmacokinetic consequences of plasma protein binding of drugs. Ann N Y Acad Sci (1973) 226:162-71. doi:10.1111/j.1749-6632.1973.tb20479.x

163. Keller F, Maiga M, Neumayer HH, Lode H, Distler A. Pharmacokinetic effects of altered plasma protein binding of drugs in renal disease. Eur J Drug Metab Pharmacokinet (1984) 9(3):275-82. doi:10.1007/BF03189651

164. Mebis L, Paletta D, Debaveye Y, Ellger B, Langouche L, D'Hoore A, et al. Expression of thyroid hormone transporters during critical illness. Eur J Endocrinol (2009) 161(2):243-50. doi:10.1530/EJE-09-0290

165. Visser TJ, Kaptein E, Glatt H, Bartsch I, Hagen M, Coughtrie MW. Characterization of thyroid hormone sulfotransferases. Chem Biol Interact (1998) 109(1-3):279-91. doi:10.1016/S0009-2797(97)00139-7

166. Taurog A, Briggs FN, Chaikoff IL. I131-labeled 1-thyroxine. II. Nature of the excretion product in bile. J Biol Chem (1952) 194(2):655-68.

167. Moreno M, Kaptein E, Goglia F, Visser TJ. Rapid glucuronidation of tri- and tetraiodothyroacetic acid to ester glucuronides in human liver and to ether 
glucuronides in rat liver. Endocrinology (1994) 135(3):1004-9. doi:10.1210/ endo.135.3.8070342

168. Visser TJ. Role of sulfation in thyroid hormone metabolism. Chem Biol Interact (1994) 92(1-3):293-303. doi:10.1016/0009-2797(94)90071-X

169. van der Spek AH, Fliers E, Boelen A. The classic pathways of thyroid hormone metabolism. Mol Cell Endocrinol (2017). doi:10.1016/j.mce.2017.01.025

170. Moura Neto A, Zantut-Wittmann DE. Abnormalities of thyroid hormone metabolism during systemic illness: the low T3 syndrome in different clinical settings. Int J Endocrinol (2016) 2016:2157583. doi:10.1155/2016/2157583

171. Burger A, Nicod P, Suter P, Vallotton MB, Vagenakis P, Braverman L. Reduced active thyroid hormone levels in acute illness. Lancet (1976) 1(7961):653-5. doi:10.1016/S0140-6736(76)92774-4

172. Pittman CS, Shimizu T, Burger A, Chambers JB Jr. The nondeiodinative pathways of thyroxine metabolism: 3,5,3,5-tetraiodothyroacetic acid turnover in normal and fasting human subjects. J Clin Endocrinol Metab (1980) 50(4):712-6. doi:10.1210/jcem-50-4-712

173. Douyon L, Schteingart DE. Effect of obesity and starvation on thyroid hormone, growth hormone, and cortisol secretion. Endocrinol Metab Clin North Am (2002) 31(1):173-89. doi:10.1016/S0889-8529(01)00023-8

174. Roti E, Minelli R, Salvi M. Thyroid hormone metabolism in obesity. Int J Obes Relat Metab Disord (2000) 24(Suppl 2):S113-5. doi:10.1038/sj.ijo.0801293

175. Joffe RT, Blank DW, Post RM, Uhde TW. Decreased triiodothyronines in depression: a preliminary report. Biol Psychiatry (1985) 20(8):922-5. doi:10.1016/0006-3223(85)90218-5

176. Kamble MT, Nandedkar PD, Dharme PV, L LS, Bhosale PG. Thyroid function and mental disorders: an insight into the complex interaction. J Clin Diagn Res (2013) 7(1):11-4. doi:10.7860/JCDR/2012/4861.2656

177. Friedman MJ, Wang S, Jalowiec JE, McHugo GJ, McDonagh-Coyle A. Thyroid hormone alterations among women with posttraumatic stress disorder due to childhood sexual abuse. Biol Psychiatry (2005) 57(10):1186-92. doi:10.1016/j.biopsych.2005.01.019

178. Karlovic D, Marusic S, Martinac M. Increase of serum triiodothyronine concentration in soldiers with combat-related chronic post-traumatic stress disorder with or without alcohol dependence. Wien Klin Wochenschr (2004) 116(11-12):385-90. doi:10.1007/BF03040918

179. Mason J, Southwick S, Yehuda R, Wang S, Riney S, Bremner D, et al. Elevation of serum free triiodothyronine, total triiodothyronine, thyroxine-binding globulin, and total thyroxine levels in combat-related posttraumatic stress disorder. Arch Gen Psychiatry (1994) 51(8):629-41. doi:10.1001/ archpsyc.1994.03950080041006

180. Mason J, Weizman R, Laor N, Wang S, Schujovitsky A, AbramovitzSchneider P, et al. Serum triiodothyronine elevation in Israeli combat veterans with posttraumatic stress disorder: a cross-cultural study. Biol Psychiatry (1996) 39(10):835-8. doi:10.1016/0006-3223(95)00310-X

181. Wang S, Mason J. Elevations of serum T3 levels and their association with symptoms in World War II veterans with combat-related posttraumatic stress disorder: replication of findings in Vietnam combat veterans. Psychosom Med (1999) 61(2):131-8. doi:10.1097/00006842-199903000-00001

182. Wang S, Mason J, Charney D, Yehuda R, Riney S, Southwick S. Relationships between hormonal profile and novelty seeking in combat-related posttraumatic stress disorder. Biol Psychiatry (1997) 41(2):145-51. doi:10.1016/ S0006-3223(95)00648-6

183. Leslie RD, Isaacs AJ, Gomez J, Raggatt PR, Bayliss R. Hypothalamo-pituitarythyroid function in anorexia nervosa: influence of weight gain. $\mathrm{Br} \mathrm{Med} \mathrm{J}$ (1978) 2(6136):526-8. doi:10.1136/bmj.2.6136.526

184. Estour B, Germain N, Diconne E, Frere D, Cottet-Emard JM, Carrot G, et al. Hormonal profile heterogeneity and short-term physical risk in restrictive anorexia nervosa. J Clin Endocrinol Metab (2010) 95(5):2203-10. doi:10.1210/jc.2009-2608

185. Schorr M, Miller KK. The endocrine manifestations of anorexia nervosa: mechanisms and management. Nat Rev Endocrinol (2016) 13(3):174-86. doi:10.1038/nrendo.2016.175

186. Opstad K. Circadian rhythm of hormones is extinguished during prolonged physical stress, sleep and energy deficiency in young men. Eur J Endocrinol (1994) 131(1):56-66. doi:10.1530/eje.0.1310056

187. Opstad PK, Falch D, Oktedalen O, Fonnum F, Wergeland R. The thyroid function in young men during prolonged exercise and the effect of energy and sleep deprivation. Clin Endocrinol (Oxf) (1984) 20(6):657-69. doi:10.1111/ j.1365-2265.1984.tb00116.x
188. Goodman MN, Larsen PR, Kaplan MM, Aoki TT, Young VR, Ruderman NB. Starvation in the rat. II. Effect of age and obesity on protein sparing and fuel metabolism. Am J Physiol (1980) 239(4):E277-86.

189. Agnihothri RV, Courville AB, Linderman JD, Smith S, Brychta R, Remaley A, et al. Moderate weight loss is sufficient to affect thyroid hormone homeostasis and inhibit its peripheral conversion. Thyroid (2014) 24(1):19-26. doi:10.1089/thy.2013.0055

190. Gereben B, Zavacki AM, Ribich S, Kim BW, Huang SA, Simonides WS, et al. Cellular and molecular basis of deiodinase-regulated thyroid hormone signaling. Endocr Rev (2008) 29(7):898-938. doi:10.1210/er.2008-0019

191. Houten SM, Watanabe M, Auwerx J. Endocrine functions of bile acids. EMBO J (2006) 25(7):1419-25. doi:10.1038/sj.emboj.7601049

192. Watanabe M, Houten SM, Mataki C, Christoffolete MA, Kim BW, Sato $\mathrm{H}$, et al. Bile acids induce energy expenditure by promoting intracellular thyroid hormone activation. Nature (2006) 439(7075):484-9. doi:10.1038/ nature 04330

193. Fliers E, Unmehopa UA, Manniesing S, Vuijst CL, Wiersinga WM, Swaab DF. Decreased neuropeptide Y (NPY) expression in the infundibular nucleus of patients with nonthyroidal illness. Peptides (2001) 22(3):459-65. doi:10.1016/S0196-9781(01)00341-2

194. de Vries EM, Fliers E, Boelen A. The molecular basis of the non-thyroidal illness syndrome. J Endocrinol (2015) 225(3):R67-81. doi:10.1530/ JOE-15-0133

195. Pacifico L, Anania C, Ferraro F, Andreoli GM, Chiesa C. Thyroid function in childhood obesity and metabolic comorbidity. Clin Chim Acta (2012) 413(3-4):396-405. doi:10.1016/j.cca.2011.11.013

196. Reinehr T. Obesity and thyroid function. Mol Cell Endocrinol (2010) 316(2):165-71. doi:10.1016/j.mce.2009.06.005

197. van den Berg EH, van Tienhoven-Wind LJ, Amini M, Schreuder TC, Faber KN, Blokzijl H, et al. Higher free triiodothyronine is associated with non-alcoholic fatty liver disease in euthyroid subjects: the Lifelines Cohort Study. Metabolism (2017) 67:62-71. doi:10.1016/j.metabol.2016.11.002

198. Picard M, Juster RP, McEwen BS. Mitochondrial allostatic load puts the 'gluc' back in glucocorticoids. Nat Rev Endocrinol (2014) 10(5):303-10. doi:10.1038/nrendo.2014.22

199. Ambrosi B, Masserini B, Iorio L, Delnevo A, Malavazos AE, Morricone L, et al. Relationship of thyroid function with body mass index and insulinresistance in euthyroid obese subjects. J Endocrinol Invest (2010) 33(9):640-3. doi: $10.3275 / 6952$

200. United States Department of Health and Human Services, Centers for Disease Control and Prevention, National Center for Health S. National Health and Nutrition Examination Survey (NHANES), 2007-2008. Washington, DC: Inter-university Consortium for Political and Social Research (ICPSR) [distributor] (2012).

201. Giebelstein J, Poschmann G, Hojlund K, Schechinger W, Dietrich JW, Levin K, et al. The proteomic signature of insulin-resistant human skeletal muscle reveals increased glycolytic and decreased mitochondrial enzymes. Diabetologia (2012) 55(4):1114-27. doi:10.1007/s00125-012-2456-x

202. Bianco AC, Maia AL, da Silva WS, Christoffolete MA. Adaptive activation of thyroid hormone and energy expenditure. Biosci Rep (2005) 25(3-4):191208. doi:10.1007/s10540-005-2885-6

203. Bianco AC, Sheng XY, Silva JE. Triiodothyronine amplifies norepinephrine stimulation of uncoupling protein gene transcription by a mechanism not requiring protein synthesis. J Biol Chem (1988) 263(34):18168-75.

204. Bianco AC, Silva JE. Cold exposure rapidly induces virtual saturation of brown adipose tissue nuclear T3 receptors. Am J Physiol (1988) 255(4 Pt 1): E496-503.

205. Krotkiewski M. Thyroid hormones in the pathogenesis and treatment of obesity. Eur JPharmacol (2002) 440(2-3):85-98. doi:10.1016/ S0014-2999(02)01420-6

206. Marzetti E, D’Angelo E, Savera G, Leeuwenburgh C, Calvani R. Integrated control of brown adipose tissue. Heart Metab (2016) 69:9-14.

207. Golozoubova V, Hohtola E, Matthias A, Jacobsson A, Cannon B, Nedergaard J. Only UCP1 can mediate adaptive nonshivering thermogenesis in the cold. FASEB J (2001) 15(11):2048-50. doi:10.1096/f.00-0536fje

208. Nedergaard J, Golozoubova V, Matthias A, Asadi A, Jacobsson A, Cannon B. UCP1: the only protein able to mediate adaptive non-shivering thermogenesis and metabolic inefficiency. Biochim Biophys Acta (2001) 1504(1):82-106. doi:10.1016/S0005-2728(00)00247-4 
209. Broeders EP, Vijgen GH, Havekes B, Bouvy ND, Mottaghy FM, Kars M, et al. Thyroid hormone activates brown adipose tissue and increases non-shivering thermogenesis - a cohort study in a group of thyroid carcinoma patients. PLoS One (2016) 11(1):e0145049. doi:10.1371/journal.pone. 0145049

210. Rabelo R, Schifman A, Rubio A, Sheng X, Silva JE. Delineation of thyroid hormone-responsive sequences within a critical enhancer in the rat uncoupling protein gene. Endocrinology (1995) 136(3):1003-13. doi:10.1210/ endo.136.3.7867554

211. Rubio A, Raasmaja A, Maia AL, Kim KR, Silva JE. Effects of thyroid hormone on norepinephrine signaling in brown adipose tissue. I. Beta 1- and beta 2-adrenergic receptors and cyclic adenosine $3^{\prime}, 5^{\prime}$-monophosphate generation. Endocrinology (1995) 136(8):3267-76. doi:10.1210/endo.136.8.7628361

212. Ben Saad M, Bayle JD. Seasonal changes in plasma testosterone, thyroxine, and cortisol levels in wild rabbits (Oryctolagus cuniculus algirus) of Zembra island. Gen Comp Endocrinol (1985) 57(3):383-8. doi:10.1016/ 0016-6480(85)90218-7

213. Fregly MJ. Activity of the hypothalamic-pituitary-thyroid axis during exposure to cold. Pharmacol Ther (1989) 41(1-2):85-142. doi:10.1016/01637258(89)90103-4

214. Koono N. Reciprocal changes in serum concentrations of triiodothyronine and reverse triiodothyronine between summer and winter in normal adult men. Endocrinol Jpn (1980) 27(4):471-6. doi:10.1507/endocrj1954.27.471

215. Kim SS, Lew DH, Choi JY, Lee EJ, Kim MG, Kim KY, et al. The change of thyroid stimulating hormone values of healthy subjects according to temperature and aging. Kosin Med J (2014) 29:125-34. doi:10.7180/kmj.2014.29.2.125

216. Ririe DG, Butterworth JF, Hines M, Hammon JW Jr, Zaloga GP. Effects of cardiopulmonary bypass and deep hypothermic circulatory arrest on the thyroid axis during and after repair of congenital heart defects: preservation by deep hypothermia? Anesth Analg (1998) 87(3):543-8. doi:10.1097/ 00000539-199809000-00007

217. Gullo D, Latina A, Frasca F, Squatrito S, Belfiore A, Vigneri R. Seasonal variations in TSH serum levels in athyreotic patients under L-thyroxine replacement monotherapy. Clin Endocrinol (Oxf) (2017). doi:10.1111/cen.13351

218. Silva JE. Thyroid hormone control of thermogenesis and energy balance. Thyroid (1995) 5(6):481-92. doi:10.1089/thy.1995.5.481

219. Laurberg P, Andersen S, Karmisholt J. Cold adaptation and thyroid hormone metabolism. Horm Metab Res (2005) 37(9):545-9. doi:10.1055/s-2005-870420

220. Heinrich B. Heat exchange in relation to blood flow between thorax and abdomen in bumblebees. J Exp Biol (1976) 64(3):561-85.

221. Heinrich B. Keeping a cool head: honeybee thermoregulation. Science (1979) 205(4412):1269-71. doi:10.1126/science.205.4412.1269

222. Kim Y, Davari ED, Sevala V, Davey KG. Functional binding of a vertebrate hormone, L-3,5,3'-triiodothyronine (T3), on insect follicle cell membranes. Insect Biochem Mol Biol (1999) 29(10):943-50. doi:10.1016/ S0965-1748(99)00070-3

223. Flatt T, Moroz LL, Tatar M, Heyland A. Comparing thyroid and insect hormone signaling. Integr Comp Biol (2006) 46(6):777-94. doi:10.1093/icb/icl034

224. Davey KG. Do thyroid hormones function in insects? Insect Biochem Mol Biol (2000) 30(8-9):877-84. doi:10.1016/S0965-1748(00)00061-8

225. Tomasi TE, Hellgren EC, Tucker TJ. Thyroid hormone concentrations in black bears (Ursus americanus): hibernation and pregnancy effects. Gen Comp Endocrinol (1998) 109(2):192-9. doi:10.1006/gcen.1997.7018

226. Jallageas M, Assenmacher I. Annual plasma testosterone and thyroxine cycles in relation to hibernation in the edible dormouse Glis glis. Gen Comp Endocrinol (1983) 50(3):452-62. doi:10.1016/0016-6480(83)90266-6

227. Fowler PA. Seasonal endocrine cycles in the European hedgehog, Erinaceus europaeus. J Reprod Fertil (1988) 84(1):259-72. doi:10.1530/jrf.0. 0840259

228. Young RA, Danforth E Jr, Vagenakis AG, Krupp PP, Frink R, Sims EA. Seasonal variation and the influence of body temperature on plasma concentrations and binding of thyroxine and triiodothyronine in the woodchuck. Endocrinology (1979) 104(4):996-9. doi:10.1210/endo-104-4-996

229. Maurel D, Boissin J. Plasma thyroxine and testosterone levels in the red fox (Vulpes vulpes L.) during the annual cycle. Gen Comp Endocrinol (1981) 43(3):402-4. doi:10.1016/0016-6480(81)90301-4

230. Burrow GN, Fisher DA, Larsen PR. Maternal and fetal thyroid function. N Engl J Med (1994) 331(16):1072-8. doi:10.1056/NEJM199410203311608
231. Anselmo J, Cao D, Karrison T, Weiss RE, Refetoff S. Fetal loss associated with excess thyroid hormone exposure. JAMA (2004) 292(6):691-5. doi:10.1001/ jama.292.6.691

232. Thorpe-Beeston JG, Nicolaides KH, McGregor AM. Fetal thyroid function. Thyroid (1992) 2(3):207-17. doi:10.1089/thy.1992.2.207

233. Ahmed RG. Maternal-fetal thyroid interactions. In: Agrawal NK, editor. Thyroid Hormone. Rijeka: InTechOpen (2012). p. 125-56.

234. Esfandiari A, Courtin F, Lennon AM, Gavaret JM, Pierre M. Induction of type III deiodinase activity in astroglial cells by thyroid hormones. Endocrinology (1992) 131(4):1682-8. doi:10.1210/endo.131.4.1396314

235. Kaplan MM, Yaskoski KA. Phenolic and tyrosyl ring deiodination of iodothyronines in rat brain homogenates. J Clin Invest (1980) 66(3):551-62. doi:10.1172/JCI109887

236. Tu HM, Legradi G, Bartha T, Salvatore D, Lechan RM, Larsen PR. Regional expression of the type 3 iodothyronine deiodinase messenger ribonucleic acid in the rat central nervous system and its regulation by thyroid hormone. Endocrinology (1999) 140(2):784-90. doi:10.1210/endo.140.2.6486

237. Taylor RT, Badell ML. The endocrinology of pregnancy. 9th ed. In: Gardner DG, Shoback D, editors. Greenspan's Basic \& Clinical Endocrinology. New York: McGraw-Hill (2011). p. 553-71.

238. Korevaar TI, de Rijke YB, Chaker L, Medici M, Jaddoe VW, Steegers EA, et al. Stimulation of thyroid function by human chorionic gonadotropin during pregnancy: a risk factor for thyroid disease and a mechanism for known risk factors. Thyroid (2017) 27(3):440-50. doi:10.1089/thy.2016.0527

239. Hoermann R, Broecker M, Grossmann M, Mann K, Derwahl M. Interaction of human chorionic gonadotropin (hCG) and asialo-hCG with recombinant human thyrotropin receptor. J Clin Endocrinol Metab (1994) 78(4):933-8. doi:10.1210/jcem.78.4.8157724

240. Sotello D, Rivas AM, Test VJ, Lado-Abeal J. Choriocarcinoma presenting with thyrotoxicosis. Proc (Bayl Univ Med Cent) (2016) 29(1):42-3.

241. Arrabal-Polo MA, Jimenez-Pacheco A, Arrabal-Martin M, MorenoJimenez J, Gutierrez-Tejero F, Galisteo-Moya R, et al. Hyperthyroidism as a clinical manifestation of a embryonal carcinoma of the testis. Acta Clin Belg (2012) 67(3):214-6. doi:10.2143/ACB.67.3.2062658

242. de Almeida CE, Curi EF, de Almeida CR, Vieira DF. Thyrotoxic crisis associated with gestational trophoblastic disease. Rev Bras Anestesiol (2011) 61(5):604-9, 331-3. doi:10.1016/S0034-7094(11)70071-X

243. Walkington L, Webster J, Hancock BW, Everard J, Coleman RE Hyperthyroidism and human chorionic gonadotrophin production in gestational trophoblastic disease. Br J Cancer (2011) 104(11):1665-9. doi:10.1038/ bjc. 2011.139

244. Kohler S, Tschopp O, Jacky E, Schmid C. Paraneoplastic hyperthyroidism. BMJ Case Rep (2011) 2011. doi:10.1136/bcr.04.2011.4163

245. Ndungu JR, Amayo A, Qureshi ZP, Kigondu CS. Gestational thyrotoxicosis associated with emesis in early pregnancy. East Afr Med J (2009) 86(2):55-8. doi:10.4314/eamj.v86i2.46933

246. Oosting SF, de Haas EC, Links TP, de Bruin D, Sluiter WJ, de Jong IJ, et al. Prevalence of paraneoplastic hyperthyroidism in patients with metastatic non-seminomatous germ-cell tumors. Ann Oncol (2010) 21(1):104-8. doi:10.1093/annonc/mdp265

247. Chiniwala NU, Woolf PD, Bruno CP, Kaur S, Spector H, Yacono K. Thyroid storm caused by a partial hydatidiform mole. Thyroid (2008) 18(4):479-81. doi:10.1089/thy.2007.0212

248. Lazarus J, Brown RS, Daumerie C, Hubalewska-Dydejczyk A, Negro R, Vaidya B. 2014 European thyroid association guidelines for the management of subclinical hypothyroidism in pregnancy and in children. Eur Thyroid J (2014) 3(2):76-94. doi:10.1159/000362597

249. Stagnaro-Green A, Abalovich M, Alexander E, Azizi F, Mestman J, Negro R, et al. Guidelines of the American Thyroid Association for the diagnosis and management of thyroid disease during pregnancy and postpartum. Thyroid (2011) 21(10):1081-125. doi:10.1089/thy.2011.0087

250. Garber JR, Cobin RH, Gharib H, Hennessey JV, Klein I, Mechanick JI, et al. Clinical practice guidelines for hypothyroidism in adults: cosponsored by the American Association of Clinical Endocrinologists and the American Thyroid Association. Thyroid (2012) 22(12):1200-35. doi:10.1089/ thy.2012.0205

251. De Groot L, Abalovich M, Alexander EK, Amino N, Barbour L, Cobin RH, et al. Management of thyroid dysfunction during pregnancy and postpartum: 
an Endocrine Society clinical practice guideline. J Clin Endocrinol Metab (2012) 97(8):2543-65. doi:10.1210/jc.2011-2803

252. Kumru P, Erdogdu E, Arisoy R, Demirci O, Ozkoral A, Ardic C, et al. Effect of thyroid dysfunction and autoimmunity on pregnancy outcomes in low risk population. Arch Gynecol Obstet (2015) 291(5):1047-54. doi:10.1007/ s00404-014-3533-9

253. Liu H, Shan Z, Li C, Mao J, Xie X, Wang W, et al. Maternal subclinical hypothyroidism, thyroid autoimmunity, and the risk of miscarriage: a prospective cohort study. Thyroid (2014) 24(11):1642-9. doi:10.1089/thy.2014.0029

254. Chen LM, Du WJ, Dai J, Zhang Q, Si GX, Yang H, et al. Effects of subclinical hypothyroidism on maternal and perinatal outcomes during pregnancy: a single-center cohort study of a Chinese population. PLoS One (2014) 9(10):e109364. doi:10.1371/journal.pone.0109364

255. Taylor PN, Minassian C, Rehman A, Iqbal A, Draman MS, Hamilton W, et al. TSH levels and risk of miscarriage in women on long-term levothyroxine: a community-based study. J Clin Endocrinol Metab (2014) 99(10):3895-902. doi:10.1210/jc.2014-1954

256. Korevaar TI, Schalekamp-Timmermans S, de Rijke YB, Visser WE, Visser W, de Muinck Keizer-Schrama SM, et al. Hypothyroxinemia and TPO-antibody positivity are risk factors for premature delivery: the generation $\mathrm{R}$ study. J Clin Endocrinol Metab (2013) 98(11):4382-90. doi:10.1210/jc.2013-2855

257. Su PY, Huang K, Hao JH, Xu YQ, Yan SQ, Li T, et al. Maternal thyroid function in the first twenty weeks of pregnancy and subsequent fetal and infant development: a prospective population-based cohort study in China. J Clin Endocrinol Metab (2011) 96(10):3234-41. doi:10.1210/jc.2011-0274

258. Negro R, Schwartz A, Gismondi R, Tinelli A, Mangieri T, StagnaroGreen A. Increased pregnancy loss rate in thyroid antibody negative women with TSH levels between 2.5 and 5.0 in the first trimester of pregnancy. J Clin Endocrinol Metab (2010) 95(9):E44-8. doi:10.1210/jc.2010-0340

259. Sahu MT, Das V, Mittal S, Agarwal A, Sahu M. Overt and subclinical thyroid dysfunction among Indian pregnant women and its effect on maternal and fetal outcome. Arch Gynecol Obstet (2010) 281(2):215-20. doi:10.1007/ s00404-009-1105-1

260. Benhadi N, Wiersinga WM, Reitsma JB, Vrijkotte TG, Bonsel GJ. Higher maternal TSH levels in pregnancy are associated with increased risk for miscarriage, fetal or neonatal death. Eur J Endocrinol (2009) 160(6):985-91. doi:10.1530/EJE-08-0953

261. Casey BM, Dashe JS, Spong CY, McIntire DD, Leveno KJ, Cunningham GF. Perinatal significance of isolated maternal hypothyroxinemia identified in the first half of pregnancy. Obstet Gynecol (2007) 109(5):1129-35. doi:10.1097/01.AOG.0000262054.03531.24

262. Casey BM, Thom EA, Peaceman AM, Varner MW, Sorokin Y, Hirtz DG, et al. Treatment of subclinical hypothyroidism or hypothyroxinemia in pregnancy. N Engl J Med (2017) 376(9):815-25. doi:10.1056/NEJMoa1606205

263. Lazarus JH, Bestwick JP, Channon S, Paradice R, Maina A, Rees R, et al. Antenatal thyroid screening and childhood cognitive function. N Engl J Med (2012) 366(6):493-501. doi:10.1056/NEJMoa1106104

264. Alexander EK, Pearce EN, Brent GA, Brown RS, Chen H, Dosiou C, et al. 2017 Guidelines of the American Thyroid Association for the diagnosis and management of thyroid disease during pregnancy and the postpartum. Thyroid (2017) 27(3):315-89. doi:10.1089/thy.2016.0457

265. Korevaar TI, Medici M, de Rijke YB, Visser W, de Muinck KeizerSchrama SM, Jaddoe VW, et al. Ethnic differences in maternal thyroid parameters during pregnancy: the Generation R study. JClin Endocrinol Metab (2013) 98(9):3678-86. doi:10.1210/jc.2013-2005

266. Korevaar TI, Muetzel R, Medici M, Chaker L, Jaddoe VW, de Rijke YB, et al. Association of maternal thyroid function during early pregnancy with offspring IQ and brain morphology in childhood: a population-based prospective cohort study. Lancet (2016) 4(1):35-43. doi:10.1016/S2213-8587(15)00327-7

267. Medici M, Korevaar TI, Visser WE, Visser TJ, Peeters RP. Thyroid function in pregnancy: what is normal? Clin Chem (2015) 61(5):704-13. doi:10.1373/ clinchem.2014.236646

268. Medici M, Korevaar TI, Schalekamp-Timmermans S, Gaillard R, de Rijke YB, Visser WE, et al. Maternal early-pregnancy thyroid function is associated with subsequent hypertensive disorders of pregnancy: the generation R study. J Clin Endocrinol Metab (2014) 99(12):E2591-8. doi:10.1210/jc.2014-1505

269. Suzuki K, Nakaji S, Yamada M, Totsuka M, Sato K, Sugawara K. Systemic inflammatory response to exhaustive exercise. Cytokine kinetics. Exerc Immunol Rev (2002) 8:6-48.
270. Marriott BM, Carlson SJ. Nutritional Needs in Cold and in High-Altitude Environments - Applications for Military Personnel in Field Operations. Washington, DC: National Academy Press (1996). 584 p.

271. Cinar V. The effects of magnesium supplementation on thyroid hormones of sedentars and Tae-Kwon-Do sportsperson at resting and exhaustion. Neuro Endocrinol Lett (2007) 28(5):708-12.

272. Kilic M. Effect of fatiguing bicycle exercise on thyroid hormone and testosterone levels in sedentary males supplemented with oral zinc. Neuro Endocrinol Lett (2007) 28(5):681-5.

273. Kilic M, Baltaci AK, Gunay M, Gokbel H, Okudan N, Cicioglu I. The effect of exhaustion exercise on thyroid hormones and testosterone levels of elite athletes receiving oral zinc. Neuro Endocrinol Lett (2006) 27(1-2):247-52.

274. Ciloglu F, Peker I, Pehlivan A, Karacabey K, Ilhan N, Saygin O, et al. Exercise intensity and its effects on thyroid hormones. Neuro Endocrinol Lett (2005) 26(6):830-4.

275. Hackney AC, Dobridge JD. Thyroid hormones and the interrelationship of cortisol and prolactin: influence of prolonged, exhaustive exercise. Endokrynol Pol (2009) 60(4):252-7.

276. Moore AW, Timmermann S, Brownlee KK, Rubin DA, Hackney AC. Strenuous, fatiguing exercise: relationship of cortisol to circulating thyroid hormones. Int J Endocrinol Metab (2005) 3(1):18-24.

277. Aakvaag A, Sand T, Opstad PK, Fonnum F. Hormonal changes in serum in young men during prolonged physical strain. Eur J Appl Physiol Occup Physiol (1978) 39(4):283-91. doi:10.1007/BF00421452

278. Baylor LS, Hackney AC. Resting thyroid and leptin hormone changes in women following intense, prolonged exercise training. Eur J Appl Physiol (2003) 88(4-5):480-4. doi:10.1007/s00421-002-0737-7

279. Pakarinen A, Alen M, Hakkinen K, Komi P. Serum thyroid hormones, thyrotropin and thyroxine binding globulin during prolonged strength training. Eur J Appl Physiol Occup Physiol (1988) 57(4):394-8. doi:10.1007/ BF00417982

280. Pakarinen A, Hakkinen K, Alen M. Serum thyroid hormones, thyrotropin and thyroxine binding globulin in elite athletes during very intense strength training of one week. J Sports Med Phys Fitness (1991) 31(2):142-6.

281. Rosolowska-Huszcz D. The effect of exercise training intensity on thyroid activity at rest. J Physiol Pharmacol (1998) 49(3):457-66.

282. Hackney AC, Viru A. Research methodology: endocrinologic measurements in exercise science and sports medicine. J Athl Train (2008) 43(6):631-9. doi:10.4085/1062-6050-43.6.631

283. Boyden TW, Pamenter RW, Rotkis TC, Stanforth P, Wilmore JH. Thyroidal changes associated with endurance training in women. Med Sci Sports Exerc (1984) 16(3):243-6. doi:10.1249/00005768-198406000-00008

284. Lado-Abeal J, Romero A, Castro-Piedras I, Rodriguez-Perez A, AlvarezEscudero J. Thyroid hormone receptors are down-regulated in skeletal muscle of patients with non-thyroidal illness syndrome secondary to non-septic shock. Eur J Endocrinol (2010) 163(5):765-73. doi:10.1530/ EJE-10-0376

285. Kotake Y, Matsumoto M, Takeda J. Thiopental intensifies the euthyroid sick syndrome after cardiopulmonary resuscitation. J Anesth (2000) 14(1):38-41. doi: $10.1007 / s 005400050008$

286. Iltumur K, Olmez G, Ariturk Z, Taskesen T, Toprak N. Clinical investigation: thyroid function test abnormalities in cardiac arrest associated with acute coronary syndrome. Crit Care (2005) 9(4):R416-24. doi:10.1186/cc3479

287. Liu J, Wu X, Lu F, Zhao L, Shi L, Xu F. Low T3 syndrome is a strong predictor of poor outcomes in patients with community-acquired pneumonia. Sci Rep (2016) 6:22271. doi:10.1038/srep22271

288. Silva MH, Araujo MC, Diniz EM, Ceccon ME, Carvalho WB. Thyroid abnormalities in term infants with fungal sepsis. Rev Assoc Med Bras (1992) (2016) 62(6):561-7. doi:10.1590/1806-9282.62.06.561

289. Karadag F, Ozcan H, Karul AB, Yilmaz M, Cildag O. Correlates of nonthyroidal illness syndrome in chronic obstructive pulmonary disease. Respir Med (2007) 101(7):1439-46. doi:10.1016/j.rmed.2007.01.016

290. Cengiz SE, Cetinkaya E, Altin S, Gunluoglu Z, Demir A, Gunluoglu G, et al. Nutritional and prognostic significance of sick euthyroid syndrome in nonsmall cell lung cancer patients. Intern Med (2008) 47(4):211-6. doi:10.2169/ internalmedicine.47.0423

291. Wyne KL. The role of thyroid hormone therapy in acutely ill cardiac patients. Crit Care (2005) 9(4):333-4. doi:10.1186/cc3738 
292. Yazici S, Kiris T, Ceylan US, Terzi S, Erdem A, Atasoy I, et al. Relation of low T3 to one-year mortality in non-ST-elevation acute coronary syndrome patients. J Clin Lab Anal (2017) 31(2):e22036. doi:10.1002/jcla.22036

293. Abo-Zenah HA, Shoeb SA, Sabry AA, Ismail HA. Relating circulating thyroid hormone concentrations to serum interleukins- 6 and - 10 in association with non-thyroidal illnesses including chronic renal insufficiency. BMC Endocr Disord (2008) 8:1. doi:10.1186/1472-6823-8-1

294. Liu H, Yan W, Xu G. Thyroid hormone replacement for nephrotic syndrome patients with euthyroid sick syndrome: a meta-analysis. Ren Fail (2014) 36(9):1360-5. doi:10.3109/0886022X.2014.949559

295. Meuwese CL, Carrero JJ. Chronic kidney disease and hypothalamic-pituitary axis dysfunction: the chicken or the egg? Arch Med Res (2013) 44(8):591-600. doi:10.1016/j.arcmed.2013.10.009

296. Meuwese CL, Carrero JJ, Cabezas-Rodriguez I, Heimburger O, Barany P, Lindholm B, et al. Nonthyroidal illness: a risk factor for coronary calcification and arterial stiffness in patients undergoing peritoneal dialysis? J Intern Med (2013) 274(6):584-93. doi:10.1111/joim.12107

297. Meuwese CL, Dekkers OM, Stenvinkel P, Dekker FW, Carrero JJ. Nonthyroidal illness and the cardiorenal syndrome. Nat Rev Nephrol (2013) 9(10):599-609. doi:10.1038/nrneph.2013.170

298. Zoccali C, Mallamaci F. Low triiodothyronine: a pathway to coronary calcification in patients maintained on peritoneal dialysis. J Intern Med (2013) 274(6):581-3. doi:10.1111/joim.12125

299. Fan S, Ni X, Wang J, Zhang Y, Tao S, Chen M, et al. Low triiodothyronine syndrome in patients with radiation enteritis: risk factors and clinical outcomes an observational study. Medicine (Baltimore) (2016) 95(6):e2640. doi:10.1097/MD.0000000000002640

300. Han G, Ren J, Liu S, Gu G, Ren H, Yan D, et al. Nonthyroidal illness syndrome in enterocutaneous fistulas. Am J Surg (2013) 206(3):386-92. doi:10.1016/j. amjsurg.2012.12.011

301. Liu S, Ren J, Zhao Y, Han G, Hong Z, Yan D, et al. Nonthyroidal illness syndrome: is it far away from Crohn's disease? J Clin Gastroenterol (2013) 47(2):153-9. doi:10.1097/MCG.0b013e318254ea8a

302. Al-Awadhi AM, Olusi S, Hasan EA, Abdullah A. Frequency of abnormal thyroid function tests in Kuwaiti Arabs with autoimmune diseases. Med Princ Pract (2008) 17(1):61-5. doi:10.1159/000109592

303. Kumar K, Kole AK, Karmakar PS, Ghosh A. The spectrum of thyroid disorders in systemic lupus erythematosus. Rheumatol Int (2012) 32(1):73-8. doi:10.1007/s00296-010-1556-5

304. Luongo C, Trivisano L, Alfano F, Salvatore D. Type 3 deiodinase and consumptive hypothyroidism: a common mechanism for a rare disease. Front Endocrinol (2013) 4:115. doi:10.3389/fendo.2013.00115

305. Garasto S, Montesanto A, Corsonello A, Lattanzio F, Fusco S, Passarino G, et al. Thyroid hormones in extreme longevity. Mech Ageing Dev (2017). doi:10.1016/j.mad.2017.03.002

306. Van den Berghe G. On the neuroendocrinopathy of critical illness. Perspectives for feeding and novel treatments. Am J Respir Crit Care Med (2016) 194(11):1337-48. doi:10.1164/rccm.201607-1516CI

307. Langouche L, Van den Berghe G. The dynamic neuroendocrine response to critical illness. In: Van den Berghe G, editor. Acute Endocrinology - From Cause to Consequence. New York: Humana Press (2008). p. 167-80.

308. Boonen E, Van den Berghe G. Endocrine responses to critical illness: novel insights and therapeutic implications. JClin Endocrinol Metab (2014) 99(5):1569-82. doi:10.1210/jc.2013-4115

309. Bello G, Pennisi MA, Montini L, Silva S, Maviglia R, Cavallaro F, et al. Nonthyroidal illness syndrome and prolonged mechanical ventilation in patients admitted to the ICU. Chest (2009) 135(6):1448-54. doi:10.1378/ chest.08-1816

310. Gao R, Liang JH, Wang L, Zhu HY, Wu W, Wu JZ, et al. Low T3 syndrome is a strong prognostic predictor in diffuse large B cell lymphoma. Br J Haematol (2017) 177(1):95-105. doi:10.1111/bjh.14528

311. Huang SA, Bianco AC. Reawakened interest in type III iodothyronine deiodinase in critical illness and injury. Nat Clin Pract Endocrinol Metab (2008) 4(3):148-55. doi:10.1038/ncpendmet0727

312. Hull G. Caleb Hillier Parry 1755-1822: a notable provincial physician. J R Soc Med (1998) 91(6):335-8. doi:10.1177/014107689809100618

313. Parry CH. Collections from the Unpublished Medical Writings of C. H. Parry. London: Underwoods (1825).
314. Hage MP, Azar ST. The link between thyroid function and depression. J Thyroid Res (2012) 2012:590648. doi:10.1155/2012/590648

315. Mason JW. A review of psychoendocrine research on the pituitary-thyroid system. Psychosom Med (1968) 30(5 Suppl):666-81. doi:10.1097/00006842196809000-00020

316. Vita R, Lapa D, Trimarchi F, Benvenga S. Stress triggers the onset and the recurrences of hyperthyroidism in patients with Graves' disease. Endocrine (2015) 48(1):254-63. doi:10.1007/s12020-014-0289-8

317. Chopra IJ, Solomon DH, Huang TS. Serum thyrotropin in hospitalized psychiatric patients: evidence for hyperthyrotropinemia as measured by an ultrasensitive thyrotropin assay. Metabolism (1990) 39(5):538-43. doi:10.1016/0026-0495(90)90014-4

318. Cohen KL, Swigar ME. Thyroid function screening in psychiatric patients. JAMA (1979) 242(3):254-7. doi:10.1001/jama.242.3.254

319. Levy RP, Jensen JB, Laus VG, Agle DP, Engel IM. Serum thyroid hormone abnormalities in psychiatric disease. Metabolism (1981) 30(11):1060-4. doi:10.1016/0026-0495(81)90048-2

320. Morley JE, Shafer RB. Thyroid function screening in new psychiatric admissions. Arch Intern Med (1982) 142(3):591-3. doi:10.1001/archinte.142.3.591

321. Spratt DI, Pont A, Miller MB, McDougall IR, Bayer MF, McLaughlin WT. Hyperthyroxinemia in patients with acute psychiatric disorders. Am J Med (1982) 73(1):41-8. doi:10.1016/0002-9343(82)90922-6

322. Styra R, Joffe R, Singer W. Hyperthyroxinemia in major affective disorders. Acta Psychiatr Scand (1991) 83(1):61-3. doi:10.1111/j.1600-0447.1991. tb05512.x

323. Joffe RT, Levitt AJ. The thyroid and depression. In: Joffe RT, Levitt AJ, editors. The Thyroid Axis and Psychiatric Illness. Washington, DC: American Psychiatric Press (1993). p. 195-253.

324. Dewhurst KE, Kabir DJ, Exley D, Harris GW, Mandelbrote BM. Blood-levels of thyrotrophic hormone, protein-bound iodine, and cortisol in schizophrenia and affective states. Lancet (1968) 2(7579):1160-2. doi:10.1016/ S0140-6736(68)91639-5

325. Hatotani N, Nomura J, Yamaguchi T, Kitayama I. Clinical and experimental studies on the pathogenesis of depression. Psychoneuroendocrinology (1977) 2(2):115-30. doi:10.1016/0306-4530(77)90017-8

326. Kolakowska T, Swigar ME. Thyroid function in depression and alcohol abuse: a retrospective study. Arch Gen Psychiatry (1977) 34(8):984-8. doi:10.1001/ archpsyc.1977.01770200122018

327. Takahashi S, Kondo H, Yoshimura M, Ochi Y. Thyrotropin responses to TRH in depressive illness: relation to clinical subtypes and prolonged duration of depressive episode. Folia Psychiatr Neurol Jpn (1974) 28(4):355-65.

328. Targum SD, Sullivan AC, Byrnes SM. Compensatory pituitary-thyroid mechanisms in major depressive disorder. Psychiatry Res (1982) 6(1):85-96. doi:10.1016/0165-1781(82)90041-5

329. Whybrow PC, Coppen A, Prange AJ Jr, Noguera R, Bailey JE. Thyroid function and the response to liothyronine in depression. Arch Gen Psychiatry (1972) 26(3):242-5. doi:10.1001/archpsyc.1972.01750210050010

330. Baumgartner A, Graf KJ, Kurten I, Meinhold H. The hypothalamicpituitary-thyroid axis in psychiatric patients and healthy subjects: parts 1-4. Psychiatry Res (1988) 24(3):271-332. doi:10.1016/0165-1781(88)90109-6

331. Brady KT, Anton RF. The thyroid axis and desipramine treatment in depression. Biol Psychiatry (1989) 25(6):703-9. doi:10.1016/0006-3223(89)90241-2

332. Joffe RT, Singer W. The effect of tricyclic antidepressants on basal thyroid hormone levels in depressed patients. Pharmacopsychiatry (1990) 23(2):67-9. doi:10.1055/s-2007-1014485

333. Kirkegaard C, Bjorum N, Cohn D, Faber J, Lauridsen UB, Nekup J. Studies on the influence of biogenic amines and psychoactive drugs on the prognostic value of the TRH stimulation test in endogenous depression. Psychoneuroendocrinology (1977) 2(2):131-6. doi:10.1016/03064530(77)90018-X

334. Kirkegaard C, Faber J. Altered serum levels of thyroxine, triiodothyronines and diiodothyronines in endogenous depression. Acta Endocrinol (Copenh) (1981) 96(2):199-207.

335. Kirkegaard C, Faber J. Influence of free thyroid hormone levels on the TSH response to $\mathrm{TRH}$ in endogenous depression. Psychoneuroendocrinology (1986) 11(4):491-7. doi:10.1016/0306-4530(86)90009-0

336. Kirkegaard C, Norlem N, Lauridsen UB, Bjorum N. Prognostic value of thyrotropin-releasing hormone stimulation test in endogenous depression. 
Acta Psychiatr Scand (1975) 52(3):170-7. doi:10.1111/j.1600-0447.1975. tb00034.x

337. Kirkegaard C, Norlem N, Lauridsen UB, Bjorum N, Christiansen C. Protirelin stimulation test and thyroid function during treatment of depression. Arch Gen Psychiatry (1975) 32(9):1115-8. doi:10.1001/archpsyc. 1975.01760270047004

338. Mason JW, Kennedy JL, Kosten TR, Giller EL Jr. Serum thyroxine levels in schizophrenic and affective disorder diagnostic subgroups. J Nerv Ment Dis (1989) 177(6):351-8. doi:10.1097/00005053-198906000-00006

339. Unden F, Ljunggren JG, Kjellman BF, Beck-Friis J, Wetterberg L. Twenty-fourhour serum levels of T4 and T3 in relation to decreased TSH serum levels and decreased TSH response to TRH in affective disorders. Acta Psychiatr Scand (1986) 73(4):358-65. doi:10.1111/j.1600-0447.1986.tb02696.x

340. Golstein J, Van Cauter E, Linkowski P, Vanhaelst L, Mendlewicz J. Thyrotropin nyctohemeral pattern in primary depression: differences between unipolar and bipolar women. Life Sci (1980) 27(18):1695-703. doi:10.1016/ 0024-3205(80)90645-1

341. Kjellman BF, Beck-Friis J, Ljunggren JG, Wetterberg L. Twenty-four-hour serum levels of TSH in affective disorders. Acta Psychiatr Scand (1984) 69(6):491-502. doi:10.1111/j.1600-0447.1984.tb02524.x

342. Weeke A, Weeke J. Disturbed circadian variation of serum thyrotropin in patients with endogenous depression. Acta Psychiatr Scand (1978) 57(4):281-9. doi:10.1111/j.1600-0447.1978.tb06896.x

343. Yamaguchi T, Hatotani N, Nomura J, Ushijima Y. Function of hypothalamo-pituitary thyroid axis in depressed patients. Folia Psychiatr Neurol Jpn (1977) 31(2):173-81.

344. Krishna VN, Thunga R, Unnikrishnan B, Kanchan T, Bukelo MJ, Mehta RK, et al. Association between bipolar affective disorder and thyroid dysfunction. Asian J Psychiatr (2013) 6(1):42-5. doi:10.1016/j.ajp.2012.08.003

345. Linnoila M, Cowdry R, Lamberg BA, Makinen T, Rubinow D. CSF triiodothyronine (rT3) levels in patients with affective disorders. Biol Psychiatry (1983) 18(12):1489-92.

346. Linnoila M, Lamberg BA, Potter WZ, Gold PW, Goodwin FK. High reverse T3 levels in manic an unipolar depressed women. Psychiatry Res (1982) 6(3):271-6. doi:10.1016/0165-1781(82)90016-6

347. Mason J, Weizman R, Laor N, Wang S, Schujovitsky A, AbramovitzSchneider $\mathrm{P}$, et al. Serum triiodothyronine elevation with posttraumatic stress disorder: a cross-cultural study. Biol Psychiatry (1996) 39(10):835-8. doi:10.1016/0006-3223(95)00310-X

348. Sinai C, Hirvikoski T, Nordstrom AL, Nordstrom P, Nilsonne A, Wilczek A, et al. Hypothalamic pituitary thyroid axis and exposure to interpersonal violence in childhood among women with borderline personality disorder. Eur J Psychotraumatol (2014) 5(1). doi:10.3402/ejpt.v5.23911

349. Wang S, Mason J, Southwick S, Johnson D, Lubin H, Charney D. Relationships between thyroid hormones and symptoms in combat-related posttraumatic stress disorder. Psychosom Med (1995) 57(4):398-402. doi:10.1097/00006842-199507000-00012

350. Reist C, Kauffmann CD, Chicz-Demet A, Chen CC, Demet EM. REM latency, dexamethasone suppression test, and thyroid releasing hormone stimulation test in posttraumatic stress disorder. Prog Neuropsychopharmacol Biol Psychiatry (1995) 19(3):433-43. doi:10.1016/0278-5846(95)00024-P

351. Santos NC, Costa P, Ruano D, Macedo A, Soares MJ, Valente J, et al. Revisiting thyroid hormones in schizophrenia. J Thyroid Res (2012) 2012:569147. doi:10.1155/2012/569147

352. Joffe RT, Levitt AJ. The thyroid and schizophrenia. In: Joffe RT, Levitt AJ, editors. The Thyroid Axis and Psychiatric Illness. Washington, DC: American Psychiatric Press (1993). p. 317-25.

353. Banki CM, Bissette G, Arato M, Nemeroff CB. Elevation of immunoreactive CSF TRH in depressed patients. Am J Psychiatry (1988) 145(12):1526-31. doi:10.1176/ajp.145.12.1526

354. Kirkegaard C, Faber J, Hummer L, Rogowski P. Increased levels of TRH in cerebrospinal fluid from patients with endogenous depression. Psychoneuroendocrinology (1979) 4(3):227-35. doi:10.1016/0306-4530(79)90006-4

355. Choi J, Kim JE, Kim TK, Park JY, Lee JE, Kim H, et al. TRH and TRH receptor system in the basolateral amygdala mediate stress-induced depression-like behaviors. Neuropharmacology (2015) 97:346-56. doi:10.1016/ j.neuropharm.2015.03.030

356. de Gortari P, Uribe RM, Garcia-Vazquez A, Aguilar-Valles A, Martinez A, Valdes A, et al. Amygdala kindling differentially regulates the expression of the elements involved in TRH transmission. Neurochem Int (2006) 48(1):31-42. doi:10.1016/j.neuint.2005.08.003

357. Aguilar-Valles A, Sanchez E, de Gortari P, Garcia-Vazquez AI, RamirezAmaya V, Bermudez-Rattoni F, et al. The expression of TRH, its receptors and degrading enzyme is differentially modulated in the rat limbic system during training in the Morris water maze. Neurochem Int (2007) 50(2):404-17. doi:10.1016/j.neuint.2006.09.009

358. Wittmann G, Lechan RM, Liposits Z, Fekete C. Glutamatergic innervation of corticotropin-releasing hormone- and thyrotropin-releasing hormonesynthesizing neurons in the hypothalamic paraventricular nucleus of the rat. Brain Res (2005) 1039(1-2):53-62. doi:10.1016/j.brainres.2005. 01.090

359. Gutierrez-Mariscal M, Sanchez E, Garcia-Vazquez A, Rebolledo-Solleiro D, Charli JL, Joseph-Bravo P. Acute response of hypophysiotropic thyrotropin releasing hormone neurons and thyrotropin release to behavioral paradigms producing varying intensities of stress and physical activity. Regul Pept (2012) 179(1-3):61-70. doi:10.1016/j.regpep.2012.08.010

360. Gutierrez-Mariscal M, de Gortari P, Lopez-Rubalcava C, Martinez A, JosephBravo P. Analysis of the anxiolytic-like effect of TRH and the response of amygdalar TRHergic neurons in anxiety. Psychoneuroendocrinology (2008) 33(2):198-213. doi:10.1016/j.psyneuen.2007.11.002

361. Gutierrez-Mariscal M, Sanchez E, Rebolledo-Solleiro D, Garcia-Vazquez AI, Cote-Velez A, Acasuso-Rivero C, et al. The acute response of the amygdalar TRH system to psychogenic stressors varies dependent on the paradigm and circadian condition. Brain Res (2012) 1452:73-84. doi:10.1016/j. brainres.2012.02.071

362. Shakhar K, Shakhar G. Why do we feel sick when infected - can altruism play a role? PLoS Biol (2015) 13(10):e1002276. doi:10.1371/journal.pbio.1002276

363. Economidou F, Douka E, Tzanela M, Nanas S, Kotanidou A. Thyroid function during critical illness. Hormones (Athens) (2011) 10(2):117-24. doi:10.14310/horm.2002.1301

364. Rosene ML, Wittmann G, Arrojo e Drigo R, Singru PS, Lechan RM, Bianco AC. Inhibition of the type 2 iodothyronine deiodinase underlies the elevated plasma TSH associated with amiodarone treatment. Endocrinology (2010) 151(12):5961-70. doi:10.1210/en.2010-0553

365. Sogol PB, Hershman JM, Reed AW, Dillmann WH. The effects of amiodarone on serum thyroid hormones and hepatic thyroxine 5'-monodeiodination in rats. Endocrinology (1983) 113(4):1464-9. doi:10.1210/endo-113-4-1464

366. Laurberg P. The effect of some iodine-containing radiocontrast agents on iodothyronine secretion from the perfused canine thyroid. Endocrinology (1982) 111(6):1904-8. doi:10.1210/endo-111-6-1904

367. Laurberg $\mathrm{P}$, Boye N. Inhibitory effect of various radiographic contrast agents on secretion of thyroxine by the dog thyroid and on peripheral and thyroidal deiodination of thyroxine to tri-iodothyronine. J Endocrinol (1987) 112(3):387-90. doi:10.1677/joe.0.1120387

368. St Germain DL. Dual mechanisms of regulation of type I iodothyronine 5 '-deiodinase in the rat kidney, liver, and thyroid gland. Implications for the treatment of hyperthyroidism with radiographic contrast agents. J Clin Invest (1988) 81(5):1476-84. doi:10.1172/JCI113479

369. Adli H, Bazin R, Perret GY. Interaction of amiodarone and triiodothyronine on the expression of beta-adrenoceptors in brown adipose tissue of rat. Br J Pharmacol (1999) 126(6):1455-61. doi:10.1038/sj.bjp.0702456

370. Perret G, Yin YL, Nicolas P, Pussard E, Vassy R, Uzzan B, et al. Amiodarone decreases cardiac beta-adrenoceptors through an antagonistic effect on 3,5,3' triiodothyronine. J Cardiovasc Pharmacol (1992) 19(4):473-8. doi:10.1097/00005344-199204000-00001

371. Dietrich JW. TSH - Physiologie, Funktionsstörungen und Einflussfaktoren auf die Referenzwerte. EHK (2014) 63(02):93-9. doi:10.1055/s-0033-1357626

372. Dietrich JW, Brisseau K, Boehm BO. [Absorption, transport and bio-availability of iodothyronines]. Dtsch Med Wochenschr (2008) 133(31-32):1644-8. doi:10.1055/s-0028-1082780

373. Bello G, Ceaichisciuc I, Silva S, Antonelli M. The role of thyroid dysfunction in the critically ill: a review of the literature. Minerva Anestesiol (2010) 76(11):919-28.

374. Perret G, Yin YL, Nicolas P, Vassy R, Uzzan B, Louchahi M. In vivo effects of macrolides on thyroid hormone serum levels and on hepatic type 1 5 '-deiodinase in rat. A comparative study with amiodarone, phenobarbital and propranolol. Fundam Clin Pharmacol (1991) 5(7):583-93. doi:10.1111/ j.1472-8206.1991.tb00747.x 
375. Abdulrahman RM, Verloop H, Hoftijzer H, Verburg E, Hovens GC, Corssmit EP, et al. Sorafenib-induced hypothyroidism is associated with increased type 3 deiodination. J Clin Endocrinol Metab (2010) 95(8):3758-62. doi:10.1210/jc.2009-2507

376. Midgley JE. Direct and indirect free thyroxine assay methods: theory and practice. Clin Chem (2001) 47(8):1353-63.

377. Thienpont LM, Van Uytfanghe K, Beastall G, Faix JD, Ieiri T, Miller WG, et al. Report of the IFCC Working Group for Standardization of Thyroid Function Tests; part 2: free thyroxine and free triiodothyronine. Clin Chem (2010) 56(6):912-20. doi:10.1373/clinchem.2009.140178

378. Crofton KM. Thyroid disrupting chemicals: mechanisms and mixtures. Int J Androl (2008) 31(2):209-23. doi:10.1111/j.1365-2605.2007.00857.x

379. Leijs MM, ten Tusscher GW, Olie K, van Teunenbroek T, van Aalderen WM, de Voogt P, et al. Thyroid hormone metabolism and environmental chemical exposure. Environ Health (2012) 11(Suppl 1):S10. doi:10.1186/1476069X-11-S1-S10

380. Pearce EN, Braverman LE. Environmental pollutants and the thyroid. Best Pract Res (2009) 23(6):801-13. doi:10.1016/j.beem.2009.06.003

381. Leung AM, Pearce EN, Braverman LE. Environmental perchlorate exposure: potential adverse thyroid effects. Curr Opin Endocrinol Diabetes Obes (2014) 21(5):372-6. doi:10.1097/MED.0000000000000090

382. Wolff J. Perchlorate and the thyroid gland. Pharmacol Rev (1998) 50(1):89-105.

383. Crofton KM, Zoeller RT. Mode of action: neurotoxicity induced by thyroid hormone disruption during development - hearing loss resulting from exposure to PHAHs. Crit Rev Toxicol (2005) 35(8-9):757-69. doi:10.1080/ 10408440591007304

384. Wu Y, Beland FA, Fang JL. Effect of triclosan, triclocarban, 2,2'4,4'tetrabromodiphenyl ether, and bisphenol A on the iodide uptake, thyroid peroxidase activity, and expression of genes involved in thyroid hormone synthesis. Toxicol In Vitro (2016) 32:310-9. doi:10.1016/j.tiv.2016.01.014

385. Beck V, Roelens SA, Darras VM. Exposure to PCB 77 induces tissuedependent changes in iodothyronine deiodinase activity patterns in the embryonic chicken. Gen Comp Endocrinol (2006) 148(3):327-35. doi:10.1016/j.ygcen.2006.04.003

386. Fisher JW, Campbell J, Muralidhara S, Bruckner JV, Ferguson D, Mumtaz M, et al. Effect of PCB 126 on hepatic metabolism of thyroxine and perturbations in the hypothalamic-pituitary-thyroid axis in the rat. Toxicol Sci (2006) 90(1):87-95. doi:10.1093/toxsci/kfj069

387. Soechitram SD, Berghuis SA, Visser TJ, Sauer PJ. Polychlorinated biphenyl exposure and deiodinase activity in young infants. Sci Total Environ (2016) 574:1117-24. doi:10.1016/j.scitotenv.2016.09.098

388. Cunha Lima ST, Merrigan TL, Rodrigues ED. Synthetic and plant derived thyroid hormone analogs. In: Ward L, editor. Thyroid and Parathyroid Diseases - New Insights into Some Old and Some New Issues. Rijeka: InTech (2012). p. 221-36.

389. Crofton KM, Craft ES, Hedge JM, Gennings C, Simmons JE, Carchman RA, et al. Thyroid-hormone-disrupting chemicals: evidence for dose-dependent additivity or synergism. Environ Health Perspect (2005) 113(11):1549-54. doi:10.1289/ehp. 8195

390. Flippin JL, Hedge JM, DeVito MJ, Leblanc GA, Crofton KM. Predictive modeling of a mixture of thyroid hormone disrupting chemicals that affect production and clearance of thyroxine. Int J Toxicol (2009) 28(5):368-81. doi:10.1177/1091581809341883

391. McLanahan ED, Campbell JL Jr, Ferguson DC, Harmon B, Hedge JM, Crofton KM, et al. Low-dose effects of ammonium perchlorate on the hypothalamic-pituitary-thyroid axis of adult male rats pretreated with PCB126. Toxicol Sci (2007) 97(2):308-17. doi:10.1093/toxsci/kfm063

392. Strollo F. Hormonal changes in humans during spaceflight. Adv Space Biol Med (1999) 7:99-129. doi:10.1016/S1569-2574(08)60008-8

393. Gunga H-C, Kirsch KA, Molz B, Heyduck B, Röcker L. Effects of microgravity on erythropoietin, thyroid-stimulating hormone and plasma proteins in four astronauts. In: Sahm PR, Keller MH, Schiewe B, editors. Proceedings of the Norderney Symposium on Scientific Results of the German Spacelab Mission D-2. Norderney: WPF D2 RWTH c/o DLR Köln (1994). p. 738-42.

394. Kaplanskii AS, Grindeland RE, Il'ina-Kakueva EI, Durnova GN, Grossman ED. [Role of the hypophysis, hormonal growth inducers and physical exercises in the regulation of function of thyrocytes, C-cells and parathyrocytes in rats during simulated weightlessness]. Aviakosm Ekolog Med (1995) 29(4):47-52.

395. Merrill AH Jr, Wang E, Mullins RE, Grindeland RE, Popova IA. Analyses of plasma for metabolic and hormonal changes in rats flown aboard COSMOS 2044. J Appl Physiol (1985) (1992) 73(2 Suppl):132S-5S.

396. Plakhuta-Plakutina GI, Kabitskii EN, Dmitrieva NP, Amirkhanian EA. [Studies of the morphology of the thyroid gland and thyroid hormone levels in the blood of rats in experiments on "Kosmos-1667" and "Kosmos-1887"]. Kosm Biol Aviakosm Med (1990) 24(4):25-7.

397. Knopp J, Macho L, Tigranian RA, Kalita NF, Strbak V. [Thyroid hormones in rats after a flight on the Kosmos-936 biosatellite]. Kosm Biol Aviakosm Med (1983) 17(4):83-4.

398. McMonigal KA, Braverman LE, Dunn JT, Stanbury JB, Wear ML, Hamm PB, et al. Thyroid function changes related to use of iodinated water in the U.S. Space Program. Aviat Space Environ Med (2000) 71(11):1120-5.

399. Smith SM, Zwart SR, McMonigal KA, Huntoon CL. Thyroid status of Space Shuttle crewmembers: effects of iodine removal. Aviat Space Environ Med (2011) 82(1):49-51. doi:10.3357/ASEM.2926.2011

400. Ehrenkranz J, Bach PR, Snow GL, Schneider A, Lee JL, Ilstrup S, et al. Circadian and circannual rhythms in thyroid hormones: determining the TSH and free T4 reference intervals based upon time of day, age, and sex. Thyroid (2015) 25(8):954-61. doi:10.1089/thy.2014.0589

401. Fantz CR, Dagogo-Jack S, Ladenson JH, Gronowski AM. Thyroid function during pregnancy. Clin Chem (1999) 45(12):2250-8.

402. Midgley JE, Hoermann R. Measurement of total rather than free thyroxine in pregnancy: the diagnostic implications. Thyroid (2013) 23(3):259-61. doi:10.1089/thy.2012.0469

403. Anckaert E, Poppe K, Van Uytfanghe K, Schiettecatte J, Foulon W, Thienpont LM. FT4 immunoassays may display a pattern during pregnancy similar to the equilibrium dialysis ID-LC/tandem MS candidate reference measurement procedure in spite of susceptibility towards binding protein alterations. Clin Chim Acta (2010) 411(17-18):1348-53. doi:10.1016/j. cca.2010.05.032

404. Kahric-Janicic N, Soldin SJ, Soldin OP, West T, Gu J, Jonklaas J. Tandem mass spectrometry improves the accuracy of free thyroxine measurements during pregnancy. Thyroid (2007) 17(4):303-11. doi:10.1089/thy.2006.0303

405. Korevaar TI, Chaker L, Medici M, de Rijke YB, Jaddoe VW, Steegers EA, et al. Maternal total T4 during the first half of pregnancy: physiologic aspects and the risk of adverse outcomes in comparison with free T4. Clin Endocrinol (Oxf) (2016) 85(5):757-63. doi:10.1111/cen.13106

406. Soldin OP. Thyroid function testing in pregnancy and thyroid disease: trimester-specific reference intervals. Ther Drug Monit (2006) 28(1):8-11. doi:10.1097/01.ftd.0000194498.32398.7b

407. Dietrich JW, Landgrafe-Mende G, Wiora E, Chatzitomaris A, Klein HH, Midgley JE, et al. Calculated parameters of thyroid homeostasis: emerging tools for differential diagnosis and clinical research. Front Endocrinol (2016) 7:57. doi:10.3389/fendo.2016.00057

408. Langenstein C, Schork D, Badenhoop K, Herrmann E. Relapse prediction in Graves disease: towards mathematical modeling of clinical, immune and genetic markers. Rev Endocr Metab Disord (2016) 17(4):571-81. doi:10.1007/ s11154-016-9386-8

409. Pandiyan B, Merrill SJ, Benvenga S. A patient-specific model of the negative-feedback control of the hypothalamus-pituitary-thyroid (HPT) axis in autoimmune (Hashimoto's) thyroiditis. Math Med Biol (2014) 31(3):226-58. doi:10.1093/imammb/dqt005

410. Wang X, Liu H, Chen J, Huang Y, Li L, Rampersad S, et al. Metabolic characteristics in obese patients complicated by mild thyroid hormone deficiency. Horm Metab Res (2016) 48(5):331-7. doi:10.1055/s-0042-105150

411. Rosolowska-Huszcz D, Kozlowska L, Rydzewski A. Influence of low protein diet on nonthyroidal illness syndrome in chronic renal failure. Endocrine (2005) 27(3):283-8. doi:10.1385/ENDO:27:3:283

412. Jostel A, Ryder WD, Shalet SM. The use of thyroid function tests in the diagnosis of hypopituitarism: definition and evaluation of the TSH Index. Clin Endocrinol (2009) 71(4):529-34. doi:10.1111/j.1365-2265.2009. 03534.x

413. Wang F, Pan W, Wang H, Wang S, Pan S, Ge J. Relationship between thyroid function and ICU mortality: a prospective observation study. Crit Care (2012) 16(1):R11. doi:10.1186/cc11151 
414. Angelousi AG, Karageorgopoulos DE, Kapaskelis AM, Falagas ME. Association between thyroid function tests at baseline and the outcome of patients with sepsis or septic shock: a systematic review. Eur J Endocrinol (2011) 164(2):147-55. doi:10.1530/EJE-10-0695

415. Zargar AH, Ganie MA, Masoodi SR, Laway BA, Bashir MI, Wani AI, et al. Prevalence and pattern of sick euthyroid syndrome in acute and chronic non-thyroidal illness - its relationship with severity and outcome of the disorder. J Assoc Physicians India (2004) 52:27-31.

416. Polini A, Iglesias P, Dardano A, Tognini S, Castiglioni M, Diez JJ, et al. Sindrome del malato eutiroideo e iperglicemia a digiuno nel paziente geriatrico: fattori di rischio indipendenti di mortalità intraospedaliera. Studio prospettico, multicentrico [Euthyroid sick syndrome and fasting hyperglycaemia in the elderly: independent risk factors of in-hospital mortality. A prospective multicentric study]. G Gerontol (2012) 60(2): 61-9.

417. Klemperer JD, Klein IL, Ojamaa K, Helm RE, Gomez M, Isom OW, et al. Triiodothyronine therapy lowers the incidence of atrial fibrillation after cardiac operations. Ann Thorac Surg (1996) 61(5):1323-7; discussion 8-9. doi:10.1016/0003-4975(96)00102-6

418. Ranasinghe AM, Quinn DW, Pagano D, Edwards N, Faroqui M, Graham TR, et al. Glucose-insulin-potassium and tri-iodothyronine individually improve hemodynamic performance and are associated with reduced troponin I release after on-pump coronary artery bypass grafting. Circulation (2006) 114(1 Suppl):I245-50. doi:10.1161/CIRCULATIONAHA. 105.000786

419. Schonberger W, Grimm W, Emmrich P, Gempp W. Reduction of mortality rate in premature infants by substitution of thyroid hormones. Eur J Pediatr (1981) 135(3):245-53. doi:10.1007/BF00442098

420. Ronald A, Dunning J. Does perioperative thyroxine have a role during adult cardiac surgery? Interact Cardiovasc Thorac Surg (2006) 5(2):166-78. doi:10.1510/icvts.2006.128363

421. Utiger RD. Altered thyroid function in nonthyroidal illness and surgery. To treat or not to treat? N Engl J Med (1995) 333(23):1562-3. doi:10.1056/ NEJM199512073332310
422. Li R, Ren J, Wu Q, Wang G, Wu X, Chen J, et al. Role of enteral nutrition in nonthyroidal illness syndrome: a retrospective observational study. BMC Endocr Disord (2015) 15:69. doi:10.1186/s12902-015-0061-y

423. Petrone A, Mormile F, Bruni G, Quartieri M, Bonsignore MR, Marrone O. Abnormal thyroid hormones and non-thyroidal illness syndrome in obstructive sleep apnea, and effects of CPAP treatment. Sleep Med (2016) 23:21-5. doi:10.1016/j.sleep.2016.07.002

424. Depuydt PO, Kress JP, Salluh JI. The ten "diseases" that are not true diseases. Intensive Care Med (2016) 42(3):411-4. doi:10.1007/s00134-015-3945-4

425. Chiong YV, Bammerlin E, Mariash CN. Development of an objective tool for the diagnosis of myxedema coma. Transl Res (2015) 166(3):233-43. doi:10.1016/j.trsl.2015.01.003

426. Dietrich JW. Thyreotoxische Krise und Myxödemkoma. Der Nuklearmediziner (2016) 39:124-31. doi:10.1055/s-0042-105786

427. Popoveniuc G, Chandra T, Sud A, Sharma M, Blackman MR, Burman KD, et al. A diagnostic scoring system for myxedema coma. Endocr Pract (2014) 20(8):808-17. doi:10.4158/EP13460.OR

Conflict of Interest Statement: JD received funding and personal fees by SanofiHenning, Hexal AG, Bristol-Myers Squibb, and Pfizer and is co-owner of the intellectual property rights for the patent "System and Method for Deriving Parameters for Homeostatic Feedback Control of an Individual" (Singapore Institute for Clinical Sciences, Biomedical Sciences Institutes, Application Number 201208940-5, WIPO number WO/2014/088516). All other authors declare that there is no conflict of interest that could be perceived as prejudicing the impartiality of the research reported.

Copyright (C) 2017 Chatzitomaris, Hoermann, Midgley, Hering, Urban, Dietrich, Abood, Klein and Dietrich. This is an open-access article distributed under the terms of the Creative Commons Attribution License (CC BY). The use, distribution or reproduction in other forums is permitted, provided the original author(s) or licensor are credited and that the original publication in this journal is cited, in accordance with accepted academic practice. No use, distribution or reproduction is permitted which does not comply with these terms. 